NBER WORKING PAPER SERIES

THE RIGHT AMOUNT OF TRUST

Jeffrey Butler

Paola Giuliano

Luigi Guiso

Working Paper 15344

http://www.nber.org/papers/w15344

\author{
NATIONAL BUREAU OF ECONOMIC RESEARCH \\ 1050 Massachusetts Avenue \\ Cambridge, MA 02138 \\ September 2009
}

We thank Yann Algan, Oriana Bandiera, Sascha Becker, Larry Blume, Francesco Caselli, Bhajan Grewal, Erzo Luttmer, Bo Rothstein, Bernard Salanié, Guido Tabellini, Romain Wacziarg and Georg Weizsäcker, as well as participants at various conferences and seminars. We are grateful to the International Atlantic Economic Society for inviting Luigi Guiso to deliver the Robert A. Mundell distinguished address at the 67th meeting. Luigi Guiso and Paola Giuliano thank the EUI and the UCLA-CIBER grant, respectively, for financial support. The views expressed herein are those of the author(s) and do not necessarily reflect the views of the National Bureau of Economic Research.

NBER working papers are circulated for discussion and comment purposes. They have not been peerreviewed or been subject to the review by the NBER Board of Directors that accompanies official NBER publications.

(C) 2009 by Jeffrey Butler, Paola Giuliano, and Luigi Guiso. All rights reserved. Short sections of text, not to exceed two paragraphs, may be quoted without explicit permission provided that full credit, including $(\mathcal{C}$ notice, is given to the source. 
The Right Amount of Trust

Jeffrey Butler, Paola Giuliano, and Luigi Guiso

NBER Working Paper No. 15344

September 2009, Revised June 2014

JEL No. A1,A12,D01,O15,Z1

\begin{abstract}
$\underline{\text { ABSTRACT }}$
We investigate the relationship between individual trust and individual economic performance. We find that individual income is hump-shaped in a measure of intensity of trust beliefs. Our interpretation is that highly trusting individuals tend to assume too much social risk and to be cheated more often, ultimately performing less well than those with a belief close to the mean trustworthiness of the population. On the other hand, individuals with overly pessimistic beliefs avoid being cheated, but give up profitable opportunities, therefore underperforming. The cost of either too much or too little trust is comparable to the income lost by forgoing college. We develop a framework to take into account heterogeneity in the trustworthiness of the pool of people with whom individuals interact as well as the presence of heterogenous costs of trust mistakes. Both sources of heterogeneity drive the relationship between trust and income which is hump-shaped for all individuals. This framework allows us to show that income-maximizing trust typically exceeds the trust level of the average person as well as to estimate the distribution of income lost to trust mistakes. We find that although a majority of individuals has well calibrated beliefs, a non-trivial proportion of the population $(10 \%)$ has trust beliefs sufficiently poorly calibrated to lower income by more than $13 \%$. Our findings hold in large-scale international survey data as well as inside a country with high quality institutions and are also supported by experimental findings.
\end{abstract}

Jeffrey Butler

Einaudi Institute for Economics and Finance

Via Sallustiana 62 - 00187

Rome, Italy

jeff.butler@eief.it

Paola Giuliano

Anderson School of Management

UCLA

110 Westwood Plaza

C517 Entrepreneurs Hall

Los Angeles, CA 90095-1481

and IZA

and also NBER

paola.giuliano@anderson.ucla.edu
Luigi Guiso

Axa Professor of Household Finance

Einaudi Institute for Economics and Finance

Via Sallustiana 62 - 00187

Rome, Italy

luigi.guiso@eief.it 


\section{Introduction}

More than 35 years ago Kenneth Arrow (1972), recognizing the pervasiveness of mutual trust in commercial and non-commercial transactions, went so far as to state that "it can be plausibly argued that much of the economic backwardness in the world can be explained by the lack of mutual confidence" (p. 357). Since then, Arrow's conjecture has received considerable empirical support. A vast literature investigates the link between aggregate trust and aggregate economic performance and finds a positive and monotonic relationship. ${ }^{1}$ However, there is no research available on the relationship between individuals' levels of trust — beliefs held about others' trustworthiness - and individuals' economic outcomes. The latter relationship is the focus of this paper.

Trust beliefs are quite heterogeneous across individuals. Figure 1 shows the distribution of trust for each of the countries surveyed in the European Social Survey (ESS). Here, trust is the belief about how much a generic person should be trusted, measured on a scale between 0 and 10: zero means no trust at all, while 10 means others can be fully trusted. ${ }^{2}$ If this question accurately measures individuals' beliefs about the average trustworthiness of each country - a single number — respondents cannot all be simultaneously right. ${ }^{3}$ Some must have overly pessimistic beliefs, while others must have beliefs that are too optimistic. Individuals with beliefs in the tails of the trust distribution must either underestimate or overestimate the trustworthiness of others and this should be reflected in their economic performances: those who trust too little will give up trade and profit opportunities too often, depressing their economic performance; conversely, individuals who trust too much will over-invest in others and get cheated more frequently, hampering their economic outcomes.

\footnotetext{
${ }^{1}$ Trust has been shown to be strongly correlated with GDP per capita and GDP growth (Knack and Zak (2001); Knack and Keefer (1996); Guiso et al (2004); Tabellini (2008b); Algan and Cahuc (2010)); with the organization of firms across countries (Bloom et al., (2009) and their ability to grow large (La Porta et. al. (1997)); with the size of a country's stock market (Guiso et. al. (2008a)); with regulation (Aghion, Algan, Cahuc and Shleifer, (2010) and with cross-country trade patterns (Guiso et al., 2009)).

${ }^{2}$ See Section 3 for the exact wording of the question in the European Social Survey.

${ }^{3}$ An alternative story is that answers reflect the trustworthiness of only those people with whom respondents interact. Since these sub-populations are likely heterogeneous, all respondents can be simultaneously correct. We take this concern seriously and, after developing a theoretical model, at the end of Section 2 argue that this would work against our main finding.
} 
Hence, at the individual level, the relationship between trust and economic performance is hump-shaped. There exists an intermediate level of trust - the "right amount of trust" that maximizes individual income. This level of income, and trust, will be attained by individuals whose beliefs are in line with the average trustworthiness of the population they interact with.

We test the relationship between trust and income using data from the European Social Survey. Since the survey measures the intensity of individuals' trust beliefs on a scale from zero to 10, we can explore the relationship between individual trust and individual economic performance, particularly at the tails of the distribution of trust beliefs. When we regress individuals' income on a set of dummies for the 11 different levels of trust we find a marked hump-shaped relationship: people with low levels of trust have significantly lower income than those with intermediate levels of trust. Income tends to reach a peak at a level of trust around 7. Beyond a trust level of 7 income declines. The decline is initially small, however income falls precipitously moving from the trust level of 9 to the highest trust level. This is consistent with the idea that some people make trust mistakes. The magnitude of the income cost of these mistakes is also economically relevant. On average, the income of individuals with the lowest level of trust is 14 percent lower than that of individuals with a level of trust corresponding to peak income. This difference is of the same order of magnitude as the income premium in our data associated with obtaining a college degree. Those who express the highest level of trust (10) make an income that is 7.3 percent lower than the income at the peak. Accordingly, the cost of deviating from the right amount of trust can be substantial.

There are four issues with the pooled OLS analysis done with the European Social Survey. The first is that the identification of the hump-shaped relationship between income and trust mainly comes from the drop in income for individuals whose level of trust is equal to 10. This raises the concern that the results could be driven by a small fraction of the population with specific characteristics. We show this is not the case in three ways. First of all, we document that individuals reporting a trust level of ten do not differ significantly 
in terms of observables from the median person in their country. Secondly, we restrict attention to countries in the ESS with a relatively low average level of trust, where the identification does not come from individuals reporting 10 anymore, and show that income is still hump-shaped in trust in these countries. Thirdly, we gather additional data on Sweden, a country in which there is a substantial fraction of observations in the upper tail of the trust distribution, and show that the hump-shaped relationship still holds there.

The second issue with the pooled regressions with the ESS is that there might be different groups (possibly different by country), all of which have a different trust-income relationship, perhaps not necessarily inverted-U shaped. The inverted-U shaped relationship could then simply be the result of composition effects, obtained by pooling different groups from different countries. The Swedish dataset allows us to address this concern by splitting the sample according to a large number of observable characteristics. We find that the relationship between trust and income is hump-shaped in a wide variety of sub-groups.

The third concern is the possibility of reverse causality: it may be income causing trust rather than the other way around. Although we believe reverse causality could explain the rising portion of the relationship but not the declining part, we tackle the issue formally with an instrumental variable approach, developed using the observation that trust beliefs are highly persistent across generations. The instrument will also address the possibility that omitted variables could at the same time have an effect on both income and trust.

The last concern is that when pooling all the countries in the ESS, we impose a single income-trust relation and thus the same income maximizing trust for all individuals in the sample. But the right amount of trust could be individual specific: if individuals in our sample interact with pools of people which differ in their trustworthiness, the level of trust that maximizes income will also differ across individuals. Additionally, the cost of trust mistakes can also vary among individuals: for instance, a trust mistake made by an entrepreneur may have different income consequences than a trust mistake made by a public employee. We formally model heterogeneity by allowing for: a) observed systematic cross-country differences in the average trustworthiness of the pool of people in a country; 
b) unobserved heterogeneity in the trustworthiness of the pool a person faces; c) unobserved heterogeneity in the cost of making trust mistakes.

Modeling heterogeneity explicitly in the ESS considerably enriches our results by allowing us to calculate the cross-sectional distribution of the right amount of trust, the magnitude of trust mistakes at the individual level - i.e., the difference between the right amount of trust and individual trust - as well as individuals' income losses induced by trust mistakes. It also allows us to test for the presence of two different sources of heterogeneity - the pool people interact with and individuals' sensitivity to trust mistakes. We cannot reject that both sources are present. Still, we do establish that the income-trust relationship is hump-shaped for all individuals in the sample. Modeling heterogeneity also allows us to calculate whether a person benefits or not (in terms of income) from having a level of trust that differs from his or her country's average trust level. We find that typically the income-maximizing trust exceeds the trust level of the average person. For example, for a country where the average person has a trust level of 5 , we estimate that the level of trust that maximizes income is 6.7 . When we compute the cross-sectional distribution of trust mistakes and the associated costs we find that although a majority of individuals has well calibrated beliefs, for 10 percent of the sample trust mistakes entail income losses exceeding $13 \%$ of the income they would earn in the absence of such mistakes.

Beyond documenting the trust-income relationship, the European Social Survey allows us to study one of the mechanisms through which trust beliefs affect economic performance: exposure to the risk of being cheated. The survey asks individuals whether, over the past five years, they have been "cheated" over four different domains: dealing with a bank, buying goods second hand, buying food, and dealing with a plumber, builder, mechanic or repairman. All else equal, exceedingly trusting individuals should be cheated more often. Obscuring this relationship in the data, however, is the fact that individuals who are cheated learn and revise their trust beliefs downward. In this way, learning generates a negative correlation between trust and the experience of being cheated. We isolate the causal effect of trust on the probability of being cheated with an instrumental variable approach and 
find that those who trust more are indeed more likely to be cheated across all the domains for which we have data.

The remainder of the paper is organized as follows. In Section 2 we present a simple framework that predicts a hump-shaped relationship between individual trust and performance. In Section 3 we describe the survey data and present basic descriptive results from our estimation of the trust-performance relationship coming from the ESS complemented with evidence from a large survey for Sweden. Section 4 formally deals with the key issue of heterogeneity, whereas in Section 5 we estimate the effect of trust on the frequency with which one is cheated. Section 6 concludes.

\section{Individual trust and economic performance: a simple model}

In this section we present a simple framework to motivate the empirical relationship between income and trust found in the data. Consider an investor with an endowment $E$ which can be invested, totally or partially, in a venture managed by a partner. The endowment and the partnership should be interpreted broadly. The endowment could represent capital contributed to a project run by an entrepreneur or money invested in a fund managed by a professional which affects income from capital. Alternatively, $E$ could be the time and effort (human capital) that a worker allows his or her boss to manage in hopes of advancing more quickly along the career path which affects labor income. Or, in a more familiar setting, $E$ could represent ideas that a researcher shares with coauthors on a joint project.

An amount $S \leq E$ invested creates surplus according to the production function $f(S)>$ $S$, of which the partner agrees to return a fraction $0<\gamma<1$ to the investor. Partners can be one of two types: honest or cheater. A fraction $1-\pi$ of partners are cheaters, while the rest of the economy's partners are honest. Each investor is randomly matched with a partner, as in Dixit (2003). An honest partner returns the promised share of the surplus, $\gamma f(S)$, while a cheater absconds with the whole surplus. ${ }^{4}$ Investors are heterogenous in

\footnotetext{
${ }^{4}$ We assume that $f(S)$ is increasing and concave $\left(f^{\prime}>0\right.$ and $\left.f^{\prime \prime}<0\right)$, and that $\gamma f(S)>S$ so that investment has a positive return if the partner does not cheat. We also assume that $\pi \gamma f^{\prime}(0)>1$ : at zero
} 
their trust beliefs. Assume there is a continuum of investors each characterized by a level of trust, $\tau$, distributed on the unit interval $[0,1]$. Given these (possibly incorrect) beliefs, an investor solves the problem:

$$
\begin{aligned}
& \operatorname{Max}_{S}: Y(S)=E-S+\tau \gamma f(S) \\
& \text { s.t. }: S \leq E
\end{aligned}
$$

Let $S_{\tau}^{*}$ denote the optimal amount invested when beliefs about others' trustworthiness are equal to $\tau$ and let $Y\left(S_{\tau}^{*}\right)=E-S_{\tau}^{*}+\pi \gamma f\left(S_{\tau}^{*}\right)$ be the investor's average income.

Income realizations depend on the actual fraction of trustworthy partners. In particular it is easy to show that an investor's average income, $Y\left(S_{\tau}^{*}\right)$, is a hump-shaped function of the investor's trust beliefs ${ }^{5}$. This function attains its maximum when the investor's beliefs about the share of trustworthy partners, $\tau$, equals the true share $\pi$. We will often refer to the level of trust beliefs that maximizes income as the "right amount of trust." This implies that both investors with very low and very high levels of trust do worse than those with a trust level close to the average trustworthiness of the population. In the first case, by underinvesting, investors with very low trust lose little if cheated; but by retaining too much of their endowment, they give up profit opportunities - and the latter effect far exceeds the former. On the other hand, investors in the second group invest a lot in the productive venture, which can potentially raise their income. But since they grant partners more trust than they deserve, they lose a lot when cheated and the latter effect dominates the former. Hence, the relationship between individual economic performance and trust beliefs is hump-shaped. Furthermore, if individuals face pools of partners which differ in their trustworthiness, then observed individual performance, $Y\left(S_{\tau}^{*}\right)$, will, ceteris paribus, peak at

investment the expected marginal return from investing exceeds the return from keeping the endowment idle. Together these assumptions imply a unique, internal, optimal investment amount.

${ }^{5}$ When an individual's trust beliefs are $\tau$, his average realized income is $Y\left(S_{\tau}^{*}\right)=E-S_{\tau}^{*}+\pi \gamma f\left(S_{\tau}^{*}\right)$ where $S_{\tau}^{*}$ is such that $\tau \gamma f^{\prime}\left(S_{\tau}^{*}\right) \equiv 1$ from the first order condition of the individual's maximization problem. This also implies $\frac{\partial S_{\tau}^{*}}{\partial \tau}=-\frac{f^{\prime}\left(S_{\tau}^{*}\right)}{\tau f^{\prime \prime}\left(S_{\tau}^{*}\right)}>0$. Differentiating $Y\left(S_{\tau}^{*}\right)$ with respect to the level of trust, $\tau$, yields $\frac{\partial Y\left(S_{\tau}^{*}\right)}{\partial \tau}=\left[\frac{\pi}{\tau}-1\right] \frac{\partial S_{\tau}^{*}}{\partial \tau}$. It follows that $\frac{\partial Y\left(S_{\tau}^{*}\right)}{\partial \tau}=0$ when $\tau=\pi$ and $\frac{\partial Y\left(S_{\tau}^{*}\right)}{\partial \tau} \gtrless 0$ when $\tau \gtrless \pi$, implying $Y\left(S_{\tau}^{*}\right)$ is hump shaped in $\tau$ and achieves a maximum when $\tau=\pi$. 
a higher level of trust for individuals facing more trustworthy pools. So, for instance, one would expect income to peak at a higher level of trust in more highly trustworthy countries. This is a relevant prediction that we can and do test empirically.

In this simple model the channel through which trust beliefs and individual performance are related is systematic errors in beliefs. In our empirical analysis below, we will provide evidence suggesting that these systematic errors in beliefs are driven by ingrained heterogeneous priors given the trustworthiness, possibly itself heterogeneous, of the pool of people with whom individuals interact. Obviously, there could be other channels. For instance, highly trusting people may become targets of swindlers who can exploit naive expectations of good faith. Alternatively, highly trusting people may be more exposed to confidence games even when their own attitude to trust is not explicitly targeted. Bernard Madoff's story can be interpreted as one where highly trusting individuals were more likely to fall prey to Madoff's game even if they were not individually targeted. These two mechanisms can explain why those who trust too much may under-perform. However, they cannot explain why those who trust too little do poorly. Culturally-induced heterogeneity in beliefs or heterogeneity in values, together with the tendency of individuals to form beliefs extrapolating from their own types, i.e. a form of false consensus, can explain both. ${ }^{6}$

Before ending this section, it is worth noting that if the heterogeneity in trust that we observe in the data reflects correctly anticipated heterogeneity in the trustworthiness of the partners each individual interacts with instead of reflecting, at least to some extent, trust mistakes, then the individual trust-income relationship should be monotonically increasing in trust. Individuals matched with less trustworthy partners correctly foresee this, express lower trust, trade less, create lower surplus and make less income than individuals matched with more trustworthy groups. ${ }^{7}$ If both trust mistakes and anticipated heterogeneity in

\footnotetext{
${ }^{6}$ For the relevance of false consensus in the determination of heterogeneity in trust beliefs, see Butler, Giuliano and Guiso (2013).

${ }^{7}$ Suppose individuals correctly forsee the trustworthiness of the group they are matched with and groups differ in trustworthiness. From $Y\left(S_{\tau=\pi}^{*}\right)=E-S_{\tau=\pi}^{*}+\pi \gamma f\left(S_{\tau=\pi}^{*}\right)$ differentiating with respect to $\pi$ we have $\frac{\partial Y}{\partial \tau}=\gamma f\left(S_{\tau=\pi}^{*}\right)>0$, since $-\frac{\partial S_{\tau=\pi}^{*}}{\partial \tau}+\pi \gamma \frac{\partial f\left(S_{\tau=\pi}^{*}\right)}{\partial S_{\tau=\pi}^{*}} \frac{\partial S_{\tau=\pi}^{*}}{\partial \tau}=0$ from the first order condition. Thus income is monotonically increasing in trust.
} 
the trustworthiness of partners are both present in the data, then ignoring the latter when estimating the trust-income relationship tends to bias the results against finding a humpshaped relationship. This should be kept in mind when interpreting the results in Section 3.2 .

\section{$3 \quad$ Data and Empirical Analysis}

\subsection{Data}

\subsubsection{The European Social Survey}

To study the relationship between individual performance and trust beliefs we rely as a main data source on five waves of the European Social Survey (ESS). The ESS is a biennial crosssectional survey administered in a large sample of mostly European nations, containing information on individuals' social values, cultural norms and behavioral patterns. The survey has been conducted five times: in 2002/2003, 2004/2005, 2006/2007, 2008/2009, 2010/2011. We pool data from the five waves, using information on 32 different countries. ${ }^{8}$ When studying the relationship between trust and cheating (Section 5), we use only the second wave because it is the only one containing the measures of cheating. For each wave, within each country, a representative sample of around 2,000 individuals is surveyed. ${ }^{9}$ Pooling data across countries and waves yields 228,609 observations. From the original sample of 228,609 we lose 65,973 observations because of missing data for income or the trust variable $(28.9 \%$ of the whole sample, so that the restricted sample would be 162,636$)$; an additional 60,338 observations (37.1\% of the whole sample) are lost due to missing values in the explanatory variables. Our final reference sample for the baseline specification consists of 102,298 observations. The non-response rate in the income variable is unevenly distributed across countries. As long as the country non-response is related to some country

\footnotetext{
${ }^{8}$ The list of countries together with further details about the sample, the overall survey design and our variables of interest is provided in the on-line appendix (henceforth, OA).

${ }^{9}$ Some countries are not present in all the waves. In our regressions, sample size differs by country depending on country population and ranges from 579 in Iceland (which was surveyed only once) to 14,487 for Germany (by pooling together all of the waves).
} 
characteristics, the country fixed effects should correct for the bias in non-response. We do, however, treat the problem of selection on observables in non-reporting income more rigorously by estimating a Heckman selection model (see the empirical analysis for details).

Measuring trust The ESS elicits trust beliefs by asking the classical question "Generally speaking, would you say that most people can be trusted, or that you can't be too careful in dealing with people?" While in most comparable surveys (the World Values Survey, the US General Social Survey, etc.) the trust question is binary, in the ESS respondents are asked to express the intensity of their trust beliefs on a scale from 0 to 10 , where 0 means no trust at all and 10 means that most people can be fully trusted. It is this feature of the ESS that allows us to investigate whether the relationship between individuals' trust beliefs and economic performance is hump-shaped. The overall distribution of the trust measure is reported in Table A2 of the online appendix.

Measuring performance The ESS is rich in many dimensions, but as with most surveys focusing on values it has little information on individuals' economic outcomes or other economic variables. The best available performance indicator is a measure of total net household income, which is the measure we use. Respondents are asked to report which income bracket, identified with a letter, best approximates their household's total net income. They are asked to consider income from all sources, including labor income and income from capital and investments. This is an important feature because, as we have argued, trust can affect all sources of income. ${ }^{10}$ In order to facilitate answers, the question is framed in a way that accounts for country-specific conventions in the frequency of income payments. Respondents can provide the income figure using the frequency they know best: weekly, monthly or annual. Each letter identifies an income bracket in euros defined so as to be

\footnotetext{
${ }^{10}$ While trust may affect all types of income, certain types, such as income from capital, may perhaps be more exposed to opportunistic behavior than other types (e.g., labor income) and thus more sensitive to incorrect trust beliefs. Unfortunately, we cannot test this possibility as the ESS does not provide information on income components.
} 
consistent across different frequencies. ${ }^{11}$ We convert all responses to their annual equivalent. The resulting brackets range from less than 1800 euros per year to above 120,000 (the largest net income allowed). In our analysis we identify each bracket with its mid-point. The last bracket for the top income is coded in a country specific way. ${ }^{12}$ Table A1, panel A, shows summary statistics for (log) income in the sample.

\subsubsection{The SOM survey}

To study the relationship between individual performance and trust beliefs we also use information drawn from the SOM survey, a nationwide survey carried out in Sweden from the SOM Institute, a research center studying Society, Opinion and Media at Gothenborg University. The survey collects information on politics, society, the use of media, public service, the environment, risks, new media technology and leisure-time activities. Starting from 1996, individuals were also asked (like in the ESS, on a scale from 0 to 10) the extent to which they believe that in general other people can be trusted. We use all the years from 1996 to 2009. The number of observations varies by wave, ranging from 1,779 in 1996 to 4,926 in 2009. Pooling data across waves yields 47,111 observations. From the original sample of 47,111 we lose 6,291 observations because of missing data for one or more explanatory variables (the restricted sample would be 40,820); an additional 1,829 observations (roughly $4 \%$ of the whole sample) are lost due to missing values in income. Our final reference sample consists of 38,991 observations.

Measuring trust The SOM survey elicits trust beliefs by asking the following question: "In your opinion, to what extent can one trust people in general?" Responses can take

\footnotetext{
${ }^{11}$ For instance, the first income category identifies income below 40 euros per week or below 150 euros per month or below 1800 euros per year. These figures are roughly equivalent if a month is made of four paid working weeks and a year of 12 paid working months. See the OA for more details.

${ }^{12}$ The average income for people whose income is higher than 120,000 euros has been calculated using a variety of surveys. For most of the countries in our sample, we use the European Union Statistics on Income and Living Conditions (EU-SILC); data for Switzerland and Turkey (the only two countries not covered by EU-SILC) have been obtained from the Luxembourg Income Study and the Income and Living Condition Use Survey, respectively. We also run as a robustness check interval regressions and the results are essentially the same.
} 
values from 0 ("Cannot trust people in general") to 10 ("Can trust people in general.") One interesting feature of the Swedish dataset is the high number of individuals answering 9 or 10: 3,070 and 2,703, respectively (see Table A3 of the OA). This makes it unlikely that the hump-shaped income-trust relationship, if present, is identified only from a small number of people with peculiar unobserved characteristics.

Measuring performance We measure performance using the log of household income before taxes (the definition includes pensions and study allowances). The variable is defined in brackets. As for the ESS, we assign the mid-point to each income bracket and adjust for inflation. ${ }^{13}$ Table A1, panel B, shows summary statistics for (log) income in the sample.

\subsection{Empirical analysis}

Figure 1 shows the distribution of trust beliefs by country. The figure indicates systematic differences in the shape of the trust distribution across countries. In one group - the high trust North European countries such as Norway, Denmark, Finland, Sweden, Iceland and the Netherlands - the distribution has a fat right tail and the modal level of trust is quite high and at around 7. A second group, which includes several Mediterranean and Eastern European countries, features a fat left tail, denoting low average trust. In a third group consisting of several European countries (e.g., Austria, Germany, France and the UK) the distribution is approximately symmetric around modal values of $5 .^{14}$ Figure 1 also shows that there is a considerable number of observations at the two tails of the distribution which also varies substantially among countries: in high trust countries like Denmark, the fraction of people reporting 9 or 10 is equal to 12.0 and 6.7 per-cent of the overall sample respectively, whereas the fraction of people reporting 0 or 1 is equal to 1.0 and 0.9 percent, respectively. At the other extreme are countries like Turkey, where the fraction of people reporting 9 or 10 is equal to 3.3 percent of the sample, whereas the fraction of people reporting 0 or 1 is

\footnotetext{
${ }^{13}$ There are 10 income brackets for the period between 1996 and 1998, 8 income brackets for the period between 1999 and 2007, and 9 income brackets for the 2008-2009 period. Details are provided in the OA. We also run interval regressions with the SOM survey and the results are unchanged.

${ }^{14}$ The (whole) sample mean trust level is around 5, with a standard deviation of 2.5 (see Table A1).
} 
equal to 48.4 percent overall.

We start to study the relationship between individual economic performance and individual trust by estimating the following model in the pooled sample of the countries in the ESS:

$$
y_{i c}=\Sigma_{j} \alpha_{j} \text { Trust }_{j i c}+\beta X_{i c}+\delta C+\epsilon_{i c}
$$

Here $y_{i c}$ is the income (in $\operatorname{logs}$ ) of individual $i$ in country $c$ and $X_{i c}$ is a vector of individual controls that can affect economic performance. We capture the effect of trust with a set of $10{\text { dummies } \text { Trust }_{1}, \text { Trust }_{2}, \ldots . \text { Trust }}_{10}$, the excluded group being individuals reporting the lowest possible trust level of 0 . This specification allows wide flexibility in estimating the relationship between income and trust imposing no parametric assumptions. Finally, to control for systematic differences in average income across countries we insert a vector of country fixed effects $C$. Among other things, these fixed effects capture differences in individual performance due to systematic differences in the average level of trustworthiness across countries. ${ }^{15}$ The vector $X_{i c}$ includes years of education as well as years of education of the father as proxies for acquired and inherited human capital, respectively. It also contains a linear and quadratic term in age to capture life cycle effects in income, dummies for gender, marital and employment status, immigration status, as well as dummies for city size with rural areas as the excluded category. ${ }^{16}$ To account for the possibility that the trust question is not measuring risk aversion, altruism or trustworthiness, ${ }^{17}$ we also include proxies for these three variables in our specification. ${ }^{18}$

\footnotetext{
${ }^{15}$ In the appendix we also report estimates of (1) that include regional fixed effects. These estimates (see Table A6 of the OA) give the same results as the specification with only country fixed effects. We do not include them in the main specification because of the large number of missing observations on the region. We always include region fixed effects when we use data from Sweden.

${ }^{16}$ This set of controls could be correlated with trust (Alesina and La Ferrara, 2002) and affect income independently.

${ }^{17}$ These variables are described in the OA, p. 4 and p. 6 .

${ }^{18}$ There is a still-unsettled debate over whether questions such as those asked by the ESS or the World Values Survey (WVS) reflect expected trustworthiness only, or a mix of beliefs and individual preferences (see Miller and Mitamura, 2003). Fehr (2009) points out that the answers to trust questions like those asked in the ESS likely reflect not only individuals' beliefs about others' trustworthiness, but also individuals' preferences toward risk, and in particular towards social risk. Cox (2004) has argued that trust may reflect pure altruistic preferences in addition to beliefs about others' trustworthiness, so that for given beliefs, more altruistic individuals would exhibit more trust. Finally, Glaeser et al. (2000) argue that the typical trust
} 
The baseline specification indicates that the income-trust relationship is increasing for low levels of trust, before leveling off and peaking at a trust level of 7 . Beyond a trust level of 7 income declines. The decline is initially small, however income falls precipitously moving from the trust level of 9 to the highest trust level. Table 1 shows the resulting estimates and Figure 2 plots the corresponding coefficients of column $1 .^{19}$ Using these estimates, those with a very low level of trust (trust=1) earn an income that is 14 percent lower than that of individuals with a level of trust corresponding to peak income. This difference is of the same order of magnitude as the income premium in our data associated with obtaining a college degree. Those who express the highest level of trust (10) make an income that is 7.3 percent lower than the income at the peak. Both of these differences are statistically significant, as the t-tests at the bottom of the table show. Thus, departing from the right amount of trust, either because one trusts too much or because one trusts too little can be individually very costly.

In columns 2-5 we report robustness to some concerns with the baseline specification. Column 2 accounts for selection in reporting income with the use of a Heckman selection model. ${ }^{20}$ Accounting for selection the peak of income is at a trust level of 8 and the cost of departing from the income maximizing trust is even higher. But the qualitative result is unchanged. Column 3 tests whether the hump-shaped effect of trust on income is robust to the inclusion of a larger set of controls. In particular, we include a full set of age dummies to better capture the non-linearity in the age-income relationship, a full set of education dummies and their interactions with each country to account for country-specific

survey question measures trustworthiness rather than trust beliefs. For a different view on this point see Sapienza et al. (2007).

${ }^{19}$ The controls have effects consistent with our priors: income increases with own and father's education; it is higher for male and married people, lower for the unemployed, for those out of the labor force and for immigrants. The coefficients for the full set of controls are reported in the OA, Table A4. Risk tolerance and trustworthiness are positively related to income, whereas altruism does not have a significant effect.

${ }^{20}$ The exclusion restriction in the selection equation is the absolute difference between the month in which the individual is interviewed and the month in which taxes are filed in a given country. We expect that this variable affects the probability of reporting income because individuals are more likely to remember income when taxes are due. Hence, the probability of reporting should decrease with the distance between the interview and tax filing. However, this distance is unlikely to systematically affect the level of reported income. The complete estimates of the Heckman model are reported in Table A5 of the OA. 
human capital effects, measures of mother's and partner's education (in addition to own and father's education) as well as the number of people living at home. The inclusion of this richer set of controls (although it substantially reduces the sample size) does not alter the results. Column 4 addresses another concern: generalized trust in people could be correlated with, and therefore pick up the effect of, trust in institutions. To allow for this possibility we include ten dummies measuring the level of trust individuals have in the legal system (also available in the survey on a scale from 0 to 10). ${ }^{21}$ The "trust in the legal system" variable does not affect the hump in the generalized trust regression. Using other measures of trust such as trust in parliament, trust in the police, trust in politicians, trust in political parties and trust in the United Nations produces similar results (Table A7 of OA). Finally, the trust measure may be capturing a general tendency of individuals with moderate attitudes (e.g., moderate risk aversion or moderate generosity) to succeed economically. For instance, it may be that people who are too generous or too stingy make less income than moderately generous people, and moderation itself is an individual characteristic also reflected in moderate levels of trust. To account for this possibility we allow other types of traits to affect income non-monotonically. Column 5 reports the results with the non-linear inclusion of risk aversion, in the appendix we test the robustness to other traits including altruism, political preferences and religiosity. ${ }^{22}$ The hump-shaped relationship between income and trust beliefs is not affected.

One additional concern with the hump-shaped relationship is that it may be the result of systematic variation in the dispersion of trust beliefs with income. Suppose that individuals can collect costly information about the probability that their counterparts are trustworthy. Wealthier people can afford to pay for more informative signals about their trading partners and therefore have more precise assessments of their trustworthiness. If true, this implies that wealthy people have similar trust beliefs concentrated around the population's true trustworthiness; the middle class would have beliefs that are correct on average but some-

\footnotetext{
${ }^{21}$ The question reads as follows: "Please tell me on a score of 0-10 how much do you personally trust the legal system. 0 means you do not trust an institution at all, and 10 means you have complete trust".

${ }^{22}$ For the exact wording of the questions see the OA. Results are reported in Table A8.
} 
what less precise; while the poor would also have beliefs that are correct on average but even more diffuse. In this way, heterogeneity in belief precision could mechanically imply a hump-shaped relationship between trust and economic performance. This difference in incentives to collect information has, however, another implication: dispersion in trust beliefs should be inversely related to income. To check whether this mechanism is driving our results, we computed for each country the relationship between the standard deviation of trust beliefs and income. The predicted negative relationship is not in the data (Figure A1 in the OA). What our model instead implies, since exposure to social risk increases with how much one trusts, is a positive relationship between the variance of income and trust. We investigate this prediction using our survey data by calculating the standard deviation of income for each level of trust and for each country in the ESS. The results confirm the presence of a positive association between trust and the variance of income. ${ }^{23}$

The strategy followed so far provides a first good description of the data and it is useful to rule out a number of potential confounds. But it has an important drawback: apart from the shifts in the constant captured by country fixed effects, the specification restricts the trust-income relationship to be the same - and thus generates the same right level of trust - across individuals. If individuals in our sample interact with pools of people which differ in their trustworthiness and if the costs to trust mistakes are individual specific, the level of trust that maximizes income will also differ. We account explicitly for the presence of these heterogeneous effects in Section 4.

\subsubsection{Further probing of the hump-shaped relationship between trust and in- come}

In this section we provide additional results to confirm the existence of a hump-shaped relationship between trust and income. One concern with the pooled OLS regressions in Table 1 is that the hump-shaped relationship is identified entirely from individuals who

\footnotetext{
${ }^{23}$ We run two different regressions: one where the data are collapsed at the trust-country-wave level and country and wave fixed effects are included; and another where the data are collapsed at the trust-country level and only country fixed effects are included (see Table A9 in the OA).
} 
respond 10 to the trust question, who may be few in number and possibly have peculiar (unobserved) characteristics that could be responsible for the results. We address this issue in three ways.

First, we compare observables in our sample between people reporting a trust level of 10 and people whose level of trust is equal to the median of the population in each country. We find few systematic differences in observables. Compared to individuals reporting the median level of trust, individuals reporting trust equal to 10 have similar levels of education, both own and parental. These highly trusting individuals furthermore are not less likely to be migrants, are not less likely to be married, nor are they less likely to live in urban or rural areas. They are also not systematically different in terms of risk aversion or trustworthiness. We find small differences in gender, more women report 10, and unemployment status. Since unemployment is lower for people reporting 10, however, this latter difference is unlikely to drive the decline in income observed at 10 . The only significant difference we find is in terms of age, for which we fully control with the inclusion of age dummies in our specification. ${ }^{24}$

Second, we run separate regressions for low, average and high trust countries. Once we split the sample in groups of countries with similar distribution of trust beliefs, the identification in low trust countries does not come anymore from people answering 10, as Figure 3 shows. ${ }^{25}$ In these countries, income peaks at a lower level of trust and starts falling already at trust 8 and 9 . It is interesting to note that the peak moves from 7 to 8 and 9 depending on the average level of trust in the population (using a quadratic specification, the peak is obtained at 6,8 and 8.25 respectively). This is what the model in Section (2) predicts, under the mild assumption that the average trust in a country is correlated with the average trustworthiness of its population.

Third, we report results using the Swedish dataset. This country is particularly relevant for our purposes because of the large fraction of people in the upper tail of the trust

\footnotetext{
${ }^{24}$ Results are reported in Table A10 of the OA.

${ }^{25}$ The figure reports the coefficients of a regression for each group of countries with all the individual controls of column 1, Table1. In Table A11 of the OA we report the regression results for the three groups and the quadratic specification.
} 
distribution which makes it less likely that such individuals have peculiar characteristics. Furthermore, it allows us to document that exceeding in personal trust can be harmful even when high quality institutions are in place and when most of the population has a high level of trust. ${ }^{26}$

Results from the Swedish sample are shown in Table $2 .{ }^{27}$ These estimates also point to a hump-shaped relationship between income and trust: as shown at the bottom of the table we can reject the hypothesis that income at trust=10 is not lower than at the incomemaximizing level of trust. Those with a trust level of 10 have an income about 7.7 percentage points lower than the peak of income, which occurs at trust level of 9. The second column uses a quadratic specification. With this specification, the income-maximizing level of trust is also equal to 9 .

The data on Sweden are also useful to rule out the possibility that results are driven by composition effects. One worry with the ESS is that there might be different groups, possibly different by country, all of which have a different trust-income relationship (e.g. some positively others negatively sloped), and that the hump-shaped relationship we document comes primarily from composition effects when different groups from different countries are pooled in the same regression. The relatively small number of observations for each country in the ESS does not allow us to split the sample by sub-groups. With the Swedish dataset, however, we can split the sample according to a large number of observables and check whether the shape of the trust-income relationship differs qualitatively across sub-groups. Appendix Table A13 shows separate regressions for the following groups: young and old; married and unmarried; living in rural versus urban areas, or in different regions of Sweden. We also show differences by level of education and by types of occupation (entrepreneurs versus workers, white collar or farmers). We also split the sample by gender, by different levels of risk aversion and by whether respondents are Swedish citizens. Finally, we split the sample according to whether an individual grew up in Sweden or not. Reassuringly, we

\footnotetext{
${ }^{26}$ See Figure A2 in the OA for the distribution of trust across different regions of Sweden.

${ }^{27}$ The controls are the same individual-level variables as in Table 1 . The full specification is reported in Table A12 of the OA.
} 
find a hump-shaped trust-income relationship in all of these different sub-groups.

\subsubsection{Reverse causality, persistence of trust beliefs and IV estimates}

When looking at the correlation between individual income and trust one may argue that it may be income causing patterns in trust rather than the other way around, as we are arguing. For instance, high income people may be more prone to trust others if they tend to accumulate more social relations, as in Glaeser (2000), and social relations enhance trust. Insofar as this reverse causality argument is true, the rising portion of the documented trust-performance relationship may reflect it; however it cannot explain the declining part of the relationship. Similarly, if, for whatever reason, high income causes lower trust, then reverse causality could explain the falling part of the relationship but not its rising portion. Hence reverse causality, even if present, is unlikely to be the full driver of the relationship. Nevertheless, we tackle directly the issue of reverse causality using an instrumental variable approach.

To define our instrument we use the fact that trust beliefs tend to be highly persistent across generations. ${ }^{28}$ To develop our instrument, we follow Algan and Cahuc (2010). The authors develop a method to uncover the causal effect of trust on economic growth by focusing on the inherited component of trust. In particular, the authors propose a strategy where current generation average trust is instrumented with a measure of inherited trust,

\footnotetext{
${ }^{28}$ Two plausible explanations have been provided in literature to justify this persistence. According to one view, individuals' beliefs are initially acquired through cultural transmission and then slowly updated through experience from one generation to the next (see Guiso, Sapienza and Zingales, 2008b). Dohmen et. al (2012) provide evidence consistent with this view. Heterogeneity is the result of family specific shocks. Within a generation, correlation between current beliefs and received priors is diluted as people age and learn. Yet this dilution need not to be complete and a high degree of persistence remains. One mechanism generating this persistence could be confirmation bias (a tendency to seek and find evidence that confirms existing beliefs and ignores disconfirmatory evidence), which tends to operate unconsciously (Westen, et. al., 2006). Alternatively, cultural beliefs may persist because, once hardwired, they are painful to eradicate and this pain makes one reluctant to update them even in spite of disconfirmatory information (Blanco, 2008). The second plausible explanation is that parents instill values rather than beliefs and beliefs reflect values because of false consensus. In particular, parents may teach values of trustworthiness: acting justly even at the expense of material gains. Cultural transmission of values of cooperation and trustworthiness is the focus of Bisin and Verdier (2000), Bisin, Topa, and Verdier (2004) and Tabellini (2008a) who show how norms of behavior are optimally passed down from parents to children and persist from generation to generation. Heterogeneity in parents' preferences and experiences may then result in heterogeneity in instilled trustworthiness and in trust beliefs via false consensus (cf. Butler et al, 2013).
} 
calculated using data from second generation immigrants. The idea is as follows: if trust beliefs are transmitted from parents to children, one can instrument the beliefs of individuals of the current generation with those of their ancestors. The beliefs of the ancestors can be calculated by looking at second generation immigrants in a given or different countries.

Algan and Cahuc (2010) instrument the average level of trust of the current generation in a given country with the average level of trust among second generation immigrants in the US from that country. We adapt this idea to our case by making two fundamental changes. First we work with the individual level of trust and instrument the trust of an individual in a given country. Second, instead of using only the mean as an instrument, we use the information on the overall distribution by mapping the individual level of trust to the corresponding moment of the distribution of trust among second generation immigrants from the same country and living in any of the countries present in the ESS. For example, if for a Spaniard based in Spain trust is equal to 1 and this corresponds to the 10th percentile of the current trust distribution in Spain we look for the value of trust corresponding to that specific percentile among second generation immigrants from Spain (the value of trust corresponding to the 10th percentile could be equal to 2 in the distribution of second generation immigrants from that specific country) living in any of the other ESS countries.

Assuming intergenerational transmission of beliefs, a moment in the distribution of immigrants has predictive power over the same moment in the home distribution; because it is uncorrelated with income at home, it is uncorrelated with income shocks to individual $i$ and is thus a valid instrument. The instrument could of course be correlated with other transmitted values that are relevant for income (e.g., education) which we do control for in our regressions.

To support the instrument, in the OA we report the distribution of trust among second generation immigrants by country of origin (Figure A3) which can be compared with the distribution of current population trust in the country of origin in Figure 1. We also compute the correlation between several moments of the trust distribution in the countries of origin (mean, median, standard deviation and skewness) and second generation immigrants 
(Figure A4). Both the direct comparison of the distributions in Figures 1 and A3 as well as inspection of the correlations in Figure A4 show evidence of a remarkable persistence in the distribution of trust beliefs.

To obtain IV estimates we rely on a quadratic specification so as to reduce the number of instruments needed. In Table 3, for comparison we first run an OLS regression (column 1) of income on a linear and a quadratic term in individual trust, as well as on all the other controls used in our baseline specification. This parametric specification allows a direct test of the hump-shaped relationship. Consistent with the previous evidence, the linear term is positive and significant, while the quadratic term is negative and significant. With these estimated parameters, the maximum level of income is attained when trust is equal to 8.66, confirming the hump-shaped relationship. ${ }^{29}$ Next we run our instrumental variables regression, where individual trust is instrumented with the corresponding moment in the distribution of trust beliefs among second generation immigrants, using it linearly and squared to match the linear and quadratic terms in current individual trust. ${ }^{30}$ The first stage is shown at the bottom of the panel and reveals the considerable predictive power of the instruments. With the IV strategy the income maximizing level of trust is 8.5. This suggests that reverse causality, or other sources of endogeneity that are addressed by the instrument, do not seem to be biasing much the income-trust relationship.

One potential concern with our instrument is that the distribution of trust from the country of origin reflects some characteristics of the original population that could be correlated with trust. For example migrants reporting 1 could do so as a result of a lower level of education, or higher risk aversion. For that reason we construct for each level of trust of the migrant population the average level for all the observables included in our regressions. When we include these controls the results are basically unchanged: the right amount of

\footnotetext{
${ }^{29}$ We include in the regression a dummy for a level of trust equal to five. People tend to cluster around this value in survey questions and we do observe a blip in our data. Results do not change if we omit this dummy.

${ }^{30}$ For brevity we do not report all individual controls, which have magnitude and sign similar to the OLS regressions in Table 1.
} 
trust is equal to $8.25 . .^{31}$

\section{Dealing with heterogeneity}

As already remarked in Section 3, the most serious limitation of the analysis with the pooled data is that it implicitly assumes that individuals in our sample face pools of people that are equally trustworthy and that the cost of trust mistakes is similar across individuals. These assumptions imply that the right amount of trust is the same for all individuals, independently, for instance, of the country where they live. We already noticed that heterogeneity could be an important element for the interpretation of our results: when splitting the sample of countries in low, average and high trust level countries we find that the right amount of trust varies depending on the average level in the population. This result was of course only suggestive, as one could split the sample in various ways depending on the underlying assumptions on the pool of people with whom individuals interact.

In this section we tackle this problem more formally. We indeed relax the assumption that the right amount of trust is the same for all individuals, by modeling heterogeneity explicitly. This will allow us to show that the hump-shaped relation between individual income and trust extends to all individuals though its shape differs systematically (as predicted by our model) across individuals of different countries and, to a lesser extent, individuals of the same country.

\subsection{Modelling heterogeneity}

To model heterogeneity we write the income (in $\operatorname{logs}$ ) of individual $i$ living in country $c$, as:

$$
y_{i c}=y_{\max }\left(X_{i c}\right)-a_{i}\left(\pi_{i c}-\tau_{i c}\right)^{2}+\varsigma_{i}
$$

where:

\footnotetext{
${ }^{31}$ The linear and quadratic level of trust are equal to 0.0328965 and -0.00115368 , with standard errors of 0.0037 and 0.000 , respectively.
} 
- $y_{\max }\left(X_{i c}\right)$ is the individual maximum attainable income when trust beliefs are correct. The maximum attainable income depends on a vector of variables $\left(X_{i c}\right)$ capturing both features of the country and characteristics of the individual;

- $L_{i c}=a_{i}\left(\pi_{i c}-\tau_{i c}\right)^{2}$ is a loss incurred by an individual upon failing to correctly anticipate the true trustworthiness of the pool of people with which he or she interacts. The loss $L_{i c}$ depends on the trustworthiness of the pool of people individual $i$ interacts with $\left(\pi_{i c}\right)$, his/her individual level of trust $\left(\tau_{i c}\right)$ and his/her sensitivity to trust mistakes $\left(a_{i}\right)$.

- $\varsigma_{i}$ is a random component orthogonal to the explanatory variables.

Our strategy allows for heterogeneity in both the trustworthiness of the pool of people individuals interact with $\left(\pi_{i c}\right)$ as well as the sensitivity to trust mistakes $\left(a_{i}\right)$.

We model $\pi_{i c}$ as having two components. The first component is an observed heterogeneity component common to all individuals in the same country, $\pi_{c}$. We assume this component is linearly related to the average trust in the country, $x_{c}$, so that $\pi_{c}=m+b x_{c}$ where $m$ and $b$ are parameters. The second is an unobserved individual-specific component, $\eta_{i}$, corresponding to the trustworthiness of the pool of people with whom $i$ interacts. This latter component is identically and independently distributed across individuals, has zero mean and is independent of $\epsilon_{i}$ - the heterogeneity in the income sensitivity to trust mistakes (see below) - but potentially correlated with individual trust, $\tau_{i c}$, though not with the other explanatory variables in (2). Hence $\pi_{i c}=m+b x_{c}+\eta_{i}$.

We model $a_{i}$ as $a_{i}=a+\epsilon_{i}$ where $\epsilon_{i}$ is an individual specific component of the sensitivity to making trust mistakes, distributed with zero mean and potentially correlated with $\tau_{i c}$ but not with the other explanatory variables in 2. In particular we assume $E\left(\epsilon_{i}\right)=E\left(\epsilon_{i} \epsilon_{j}\right)=0$ for $i \neq j, E\left(\epsilon_{i} \varsigma_{i}\right)=0, E\left(\epsilon_{i} X_{i c}\right)=0$. With this specification we avoid taking a stance on what drives this heterogeneity.

\subsubsection{Estimating the income trust relation in presence of heterogeneity}

After replacing $a_{i}$ and $\pi_{i c}$ in (2), the equation we want to estimate becomes: $:^{32}$

\footnotetext{
${ }^{32}$ See Appendix 1 for details on how to obtain equation (3).
} 


$$
y_{i c}=\kappa+\beta_{1} \tau_{i c}-\beta_{2} \tau_{i c}^{2}+\beta_{3} x_{c} \tau_{i c}+v_{i}
$$

where $\kappa=y_{\max }\left(X_{i c}\right)-a m^{2}-a b^{2} x_{c}^{2}-2 a b m x_{c}, \beta_{1}=2 a m ; \beta_{2}=a ; \beta_{3}=2 a b$; and the error term is $v_{i}=\varsigma_{i}-\left(a+\varepsilon_{i}\right) \eta_{i}^{2}-2 \eta_{i}\left(a+\varepsilon_{i}\right)\left(\pi_{c}-\tau_{i c}\right)-\varepsilon_{i}\left(\pi_{c}-\tau_{i c}\right)^{2}$.

Consistent estimates of the parameters of equation (3) would allow us to obtain an estimate of the average income sensitivity to trust mistakes $\left(a=\beta_{2}\right)$ and back out the parameters $b\left(=\beta_{3} / 2 \beta_{2}\right)$ and $m\left(=\beta_{1} / 2 \beta_{2}\right)$ that tie the average trustworthiness of a country population to its average trust beliefs. OLS estimation of equation (3) would deliver consistent estimates ${ }^{33}$ only if individual trust $\tau_{i c}$ were exogenous and there were no feedback from income to trust. If, however, individuals optimally select their current trust - e.g. because there is some learning and learning depends on income shocks - then OLS estimates are inconsistent ${ }^{34}$ as in standard selection models (Garen, 1984). To obtain consistent estimates of the parameters in (3) we follow Garen's (1984) selection correction model.

The methodology is a two equation system, where the main equation is the income equation given in equation (3) together with a trust selection equation:

$$
\begin{aligned}
& y_{i c}=\kappa+\beta_{1} \tau_{i c}-\beta_{2} \tau_{i c}^{2}+\beta_{3} x_{c} \tau_{i c}+v_{i} \\
& \tau_{i c}=\gamma \pi_{c}+(1-\gamma) \tau_{p i c}+\xi_{i}
\end{aligned}
$$

We model the trust selection equation as a linear combination of three elements:

- the average trustworthiness of the country pool, $\pi_{c}$, which is in turn given by $m+b x_{c}$

\footnotetext{
${ }^{33}$ Estimates could be possibly inefficient as the error term is heteroskedastic (Hildreth and Houck, 1968).

${ }^{34} \mathrm{~A}$ model that generates selection is one, for instance, where individuals choose their current trust beliefs so as to minimize a quadratic cost function $C\left(\tau_{i}\right)$ that depends on the deviation of income from its maximum attainable value and a cost of adjusting the beliefs from their prior $\tau_{p i}: C\left(\tau_{i}\right)=f\left(y_{\max }-y_{i}\right)+d\left(\tau_{i}-\tau_{p i}\right)^{2}$. The cost of deviating from this prior can be thought of as a psychological cost of giving up the inherited component of trust ingrained during childhood. The minimization of the above cost function (using (2) to replace $\left.y_{\max }-y_{i}\right)$ with respect to $\tau_{i}$ yields $\tau_{i}=\frac{f a_{i}}{f a_{i}+d} \pi_{i c}+\frac{d}{f a_{i}+d} \tau_{i p}$. Replacing $a_{i}=a+\varepsilon_{i}$ and taking a first order approximation of the two parameters around $a_{i}=a$ we obtain $\tau_{i}=\gamma \pi_{c}+(1-\gamma) \tau_{i p}+\xi_{i}$ where $\xi_{i}=\gamma \eta_{i}+\delta \eta_{i} \varepsilon_{i}+\delta\left(\pi_{c}-\tau_{i p}\right) \varepsilon_{i}$, and $\gamma=f a /(f a+d)$. Thus, because $\tau_{i}$ is correlated with $\varepsilon_{i}$ and $\eta_{i}$ it will be correlated with the error term $v_{i}$ in (3), implying that OLS estimates are inconsistent .
} 
(see above)

- the individual prior, $\tau_{p i c}$ and

- a specific error component $\xi_{i}$ containing the unobserved heterogeneity terms.

The individual prior is our exclusion restriction, which we discuss at length later. Intuitively, it affects an individual's current level of trust but does not enter directly into the income equation once current trust is controlled for.

This specification yields a triangular system of equations with random parameters. If the errors terms $\xi_{i}$ were uncorrelated with $v_{i}$, the system could be estimated consistently with 2SLS using as an instrument $\tau_{p i c}$ (Kelejian, 1974). If instead the error $v_{i}$ and $\xi_{i}$ were correlated (for example as a result of some selection mechanism like the one described in footnote 34), the 2SLS will not be consistent. Garen's (1984) methodology allows us to produce consistent estimates. The methodology works in two steps:

i) in the first, it uses the trust selection equation to obtain a consistent estimate of $\xi_{i}$, say $\widehat{\xi}_{i}$.

ii) in the second step, this consistent estimate is used to replace the error term $v_{i}$ in (4) with a function of $\widehat{\xi}_{i}$ (the derivation of $v_{i}$ is provided in the appendix) given by: $\beta_{4} \widehat{\xi}_{i}+$ $\beta_{5} \widehat{\xi}_{i}\left(\pi_{c}-\tau_{i c}\right)+\beta_{6} \widehat{\xi}_{i}\left(\pi_{c}-\tau_{i c}\right)^{2}+\widehat{\psi}_{i}$, where $\widehat{\psi}_{i}$ is a pure error term possibly heteroskedastic. It is the analogous of the two step Heckman selection model for the case where the selection variable is continuous rather than dichotomous.

The equation to be estimated is: ${ }^{35}$

$$
y_{i c}=\kappa+\beta_{1} \tau_{i c}-\beta_{2} \tau_{i c}^{2}+\beta_{3} x_{c} \tau_{i c}+\beta_{4} \widehat{\xi}_{i}+\beta_{5} \widehat{\xi}_{i}\left(\pi_{c}-\tau_{i}\right)+\beta_{6} \widehat{\xi}_{i}\left(\pi_{c}-\tau_{i}\right)^{2}+\widehat{\psi}_{i}
$$

which, after replacing $\pi_{c}=m+b x_{c}$, becomes:

\footnotetext{
${ }^{35}$ See Appendix 1 for the derivation of equation (6)
} 
$y_{i c}=\kappa+\beta_{1} \tau_{i c}-\beta_{2} \tau_{i c}^{2}+\beta_{3} x_{c} \tau_{i c}+\beta_{4}^{\prime} \widehat{\xi}_{i}+b \beta_{5}^{\prime} \widehat{\xi}_{i} x_{c}-\beta_{5}^{\prime} \widehat{\xi}_{i} \tau_{i c}+b^{2} \beta_{6} \widehat{\xi}_{i} x_{c}^{2}+\beta_{6} \widehat{\xi}_{i} \tau_{i c}^{2}-2 b \beta_{6} \widehat{\xi}_{i} x_{c} \tau_{i c}+\widehat{\psi}_{i}$

where $\beta_{4}^{\prime}=\beta_{4}+m \beta_{5}+m^{2} \beta_{6} ; \beta_{5}^{\prime}=\beta_{5}+2 m \beta_{6}$.

Overall equation (6) is useful because:

1. It allows us to calculate an individual-specific right amount of trust, which is given by: $\tau_{i c}^{*}=\frac{\beta_{1}+\beta_{3} x_{c}}{2\left(\beta_{2}-\beta_{6} \widehat{\xi}_{i}\right)}-\frac{\left(\beta_{5}^{\prime}+2 b \beta_{6} x_{c}\right) \widehat{\xi}_{i}}{2\left(\beta_{2}-\beta_{6} \widehat{\xi}_{i}\right)}$. Since the right amount of trust is a function of $x_{c}$ this naturally generates a different average right level of trust for each country. In addition by comparing $\tau_{i c}^{*}$ with $x_{c}$ we can establish whether the level of trust that maximizes income falls short or exceeds the level of trust of the average person in the country.

2. It allows us to test which of the two sources of heterogeneity matters. Recall that the heterogeneity in the trustworthiness of the pool faced by each individual depends on $\eta_{i}$, whereas heterogeneity in the income sensitivity to trust mistakes is expressed by $\varepsilon_{i}$. The estimated parameters $\beta_{5}^{\prime}$ and $\beta_{6}$ depend on $\eta_{i}$ and $\varepsilon_{i}$ and are thus informative of the sources of unobserved heterogeneity. It can be shown that: ${ }^{36}$

- if $\beta_{5}^{\prime} \neq 2(a+m) \beta_{6}$ and $\beta_{6} \neq 0$ then $\varepsilon_{i} \neq 0$ and $\eta_{i} \neq 0$ and thus both types of heterogeneity are present. Notice also that since $\beta_{1}=2 a m$ and $\beta_{2}=a$, the expression for $\beta_{5}^{\prime}$ can be rewritten as: $\beta_{5}^{\prime} \neq 2\left(\beta_{2}+\beta_{1} / 2 \beta_{2}\right) \beta_{6}$.

- if $\beta_{6} \neq 0$ and $\beta_{5}^{\prime}=2\left(\beta_{2}+\beta_{1} / 2 \beta_{2}\right) \beta_{6}$, then only heterogeneity in the trustworthiness of the pool is present.

- if $\beta_{5}^{\prime} \neq 2\left(\beta_{2}+\beta_{1} / 2 \beta_{2}\right) \beta_{6}$ and $\beta_{6}=0$, which implies that $\beta_{5}^{\prime} \neq 0$, then only heterogeneity in the income sensitivity to trust mistakes is present.

\footnotetext{
${ }^{36}$ See Appendix 1 for the exact derivation.
} 
3. It allows us to calculate the loss $L_{i c}$ of deviating from the right amount of trust for each individual in the sample.

\subsubsection{Evidence from the ESS sample}

Following Garen's methodology described above, we perform the two-step procedure using data from the ESS sample. As a first step we obtain a consistent estimate of $\xi_{i}$, by estimating with OLS the trust selection equation.

The trust selection equation In order to model the trust equation we need to find a proxy for the average trustworthiness of the country pool and a proxy for an individual trust prior. We can capture the average trustworthiness of the country pool with a set of country fixed effects. The difficult part of the selection equation is to find a proxy for the individual prior. For this to be a valid instrument it should affect the individual current level of trust but should not enter the income equation once current trust is controlled for. The instrument described in Section 3.2.2 (the corresponding moment of second generation immigrants' trust distribution) satisfies both conditions.

We use two different specifications of the trust selection equation: one when no individual controls are added in the first stage selection regression (this corresponds to the specification of column 3 of Table 3), and another where individual controls are included (column 4; for brevity these controls are not reported). ${ }^{37}$ The results of the trust selection equation are reported in panel B of Table 3. Immigrants' trust has a strong predictive power in the selection equation for current individual trust, both when none of the individual-level variables used in the income regressions are added and also when all are added. This provides reassurance that the exclusion restriction for the selection equation induces relevant variation in current trust, helping identification.

\footnotetext{
${ }^{37}$ Which specification is appropriate depends on the model that generates the selection equation. For instance, in the example of footnote 34 all individual controls that affect the maximum attainable level of income do not affect individual trust. But other models may have different implications.
} 
The trust-income relationship As a second step, we estimate the trust-income relationship given in (6). To capture systematic differences in the maximum attainable income we include country fixed effects and the set of controls of the pooled OLS regressions of the determinants of income. To account for heteroskedasticity we compute robust standard errors. The results for the income equation are reported in the upper panel of Table 3 (columns 3 and 4).

Looking at the third column in the top panel, ${ }^{38}$ both the linear and quadratic terms in individual trust are highly statistically significant, the first $\left(\beta_{1}\right)$ with a positive coefficient and the second $\left(\beta_{2}\right)$ negative, implying that the trust-income relationship is hump-shaped. Furthermore, the interaction between individual trust and the average trust in the country is positive and significant so that the income maximizing level of trust increases systematically with the average trust of the country. At the bottom of Table 3 we report the incomemaximizing level of trust computed for a country with a mean trust level of 5 (the average trust in the pooled data) and for an individual with $\widehat{\xi}_{i}=0$ and find that it is equal to 6.6. In general, for an individual with $\widehat{\xi}_{i}=0$ the parameter estimates imply that $\tau_{i c}^{*}=\frac{\beta_{1}+\beta_{3} x_{c}}{2 \beta_{2}}=2.6+0.8 x_{c}$. Thus $\tau_{i c}^{*}$ always exceeds the trust of the average person in the country. Put differently, the average person trusts less than the level that would maximize his/her income.

Finding the right amount of trust Consider the case of a generic individual with $\widehat{\xi}_{i} \neq 0$. The shape of the trust-income relationship and the level of trust that maximizes income involve also the interaction terms with the individual component $\widehat{\xi}_{i}$. Concerning the hump, the second derivative of income with respect to individual trust is $-2 \times(0.005+0.001$ $\left.\widehat{\xi}_{i}\right)$ and is negative (implying a hump-shaped relationship) whenever $\widehat{\xi}_{i}>-5$. Empirically, this is always the case in our sample since the lowest $\widehat{\xi_{i c}}$ is equal to -4.41 (for the estimates in column $2 ;-4.28$ for those in column 3 ). Thus, the trust-income relationship is humpshaped for all individuals in our sample.

\footnotetext{
${ }^{38}$ The results are essentially the same if we use estimates of column 4 .
} 
What are the sources of heterogeneity? Using the estimates in Table 3 , column 3 (results are similar using those in column 4 ), since $\beta_{6} \neq 0$ we cannot reject that there is heterogeneity in the trustworthiness of the pool faced by each individual. In addition $2\left(\beta_{2}+\frac{\beta_{1}}{2 \beta_{2}}\right) \beta_{6}=-0.0052$ using the point estimates of these parameters $\left(\beta_{1}=0.026, \beta_{2}=\right.$ $\left.0.005, \beta_{6}=-0.001\right)$. Since the estimated $\beta_{5}^{\prime}$ is -0.004 with a standard error of 0.002 we reject the null that $\beta_{5}^{\prime}=2\left(\beta_{2}+\frac{\beta_{1}}{2 \beta_{2}}\right) \beta_{6}=-0.0052$ at the $5 \%$ confidence level and thus reject that there is no heterogeneity in income sensitivity to trust mistakes. Therefore both sources of heterogeneity drive the relationship between trust and income.

Cross-sectional distributions of the right amount of trust, trust mistakes and income losses from making trust mistakes We can use the results of Table 3 to calculate the cross-sectional distributions of the right amount of trust, trust mistakes and income losses induced by trust mistakes (Figure 4, Panels A-C). For a country with average trust level of 5 , in the cross-section the income-maximizing level of trust ranges from $\tau_{i c}^{*}=7$ when $\widehat{\xi}_{i}$ equals its 5 th percentile to $\tau_{i c}^{*}=6.28$ for $\widehat{\xi}_{i}$ equal to its 95 th percentile. Results are essentially the same when in the selection equation we insert all individual controls that appear in the income equation (last column of Table 3). In the overall sample the mean value of $\tau_{i c}^{*}$ is 6.54 with a standard deviation of 0.81 . Figure 4 panel A shows the sample distribution of $\tau_{i c}^{*}$. It reflects both variation in the average trust across countries as well as heterogeneity in the pool of people faced by each individual. As can be seen, $90 \%$ of the observations are bounded between 5.5 and 8. Furthermore, we have checked that most of the variation in the cross sectional distribution of $\tau_{i c}^{*}$ is due to variation in average trust across countries rather than in the pool of people individuals face. In fact, restricting the sample to countries with average trust between 5 and $6,90 \%$ of the values of $\tau_{i c}^{*}$ are in the interval 6.4-7.5 suggesting that most individuals tend to interact with a pool of people that is representative of their country's population in this respect.

Figure 4, panel B shows the cross sectional distribution of trust mistakes computed as the difference between the income-maximizing trust level and actual trust, $\tau_{i c}^{*}-\tau_{i c}$. 
Because on average $\tau_{i c}^{*}$ exceeds the trust of the average person in the country, mistakes are not symmetric around zero but tend to be positive. The mean mistake is 1.65 (median 1.55) with considerable variation as documented by a high standard deviation (2.4). Though a majority of individuals has well calibrated beliefs ( $55 \%$ have an absolute mistake not greater than 1.68), a full $10 \%$ of the people in the sample make trust mistakes exceeding 4.98. These are typically individuals with very low levels of trust interacting with relatively trustworthy groups.

Figure 4, panel $\mathrm{C}$ shows the cross sectional distribution of the income loss implied by estimated trust mistakes computed using the estimated average cost of a mistake $a=0.005$. Consistent with the fact that most people have trust beliefs close to the trustworthiness of their pool, the distribution is highly skewed to the right. For around half of the sample the income cost of trust mistakes is less than $1.6 \%$ of what they would earn if they had correct beliefs, and for $3 / 4$ of the sample it is less than $6.4 \%$. However for about $10 \%$ of the sample the cost exceeds $13 \%$ of potential income and for half of these individuals the cost is larger than $17 \%$.

Finally, Figure 4 panel D shows the relationship between income loss and the level of individual trust implied by our estimates country by country. Because the trust-income relationship is hump-shaped in all countries the income loss is u-shaped in trust with a minimum at the right amount of trust. The point to take away from this figure is that in all countries in our sample it is generally true that trusting very little - that is exposing oneself to the risk of giving up profit opportunities - is more costly than trusting a lot and facing a higher risk of being cheated. The first type of loss is particularly large in highly trustworthy countries such as Denmark and Norway, while in less trustworthy countries (e.g. Greece and Turkey) the cost of the two types of mistakes is of comparable size. We conclude that accounting for systematic differences in trustworthiness across countries, unobserved heterogeneity in the trustworthiness of the pool each individual faces within a country, as well as for unobserved heterogeneity in the sensitivity to trust mistakes, still results in a humped-shaped relationship between income and trust beliefs. Thus, it is unlikely that 
the latter simply reflects composition effects. If anything, accounting for heterogeneity magnifies the hump as the income maximizing level of trust is estimated below that implied by the pooled OLS regressions.

\section{$5 \quad$ Trust and cheating}

Two sources of suboptimal behavior contribute to the hump-shaped relationship between income and trust. On the one hand, too little trust worsens performance through overlycautious decision making that leads to missed profit opportunities. On the other hand, too much trust undermines performance by increasing the chances of being cheated and, conditional on being cheated, exposing individuals to larger losses. The first channel implies that the chances of missing profitable opportunities are smaller for those who trust more; the second channel implies that the chances of being cheated are increasing in trust. Providing evidence on the first channel is problematic because missed opportunities are typically unobservable. However, we can test the second channel since the European Social Survey provides information on how often individuals have been cheated in various domains.

\subsection{Measuring cheating experience}

The second wave of the ESS reports information on how often respondents have been cheated within the five years prior to the interview along four dimensions: being cheated by a bank/insurance company; a plumber, builder, car mechanic or other repair person; a seller of second hand goods; or a grocer or food seller. Specifically, the ESS asks participants:

"How often, if ever, have each of these things happened to you in the last five years?"

1. A bank or insurance company failed to offer you the best deal you were entitled to.

2. You were sold something second-hand that quickly proved to be faulty.

3. You were sold food that was packed to conceal the worse bits. 
4. A plumber, builder, car mechanic or other repair person overcharged you or did unnecessary work.

Respondents could answer in one of 5 ways - never, once, twice, 3 or 4 times or, finally, 5 times or more - which we code with the numbers 0 to 4 . Figure 5 shows histograms of the answers to each of the four cheating dimensions for the pooled data. Not surprisingly, in all cases there is a spike at "Never," so that the vast majority of respondents report not having been cheated. However, a non-negligible proportion of people-ranging from $22 \%$ in the case of the purchase of second-hand goods to over $40 \%$ for food purchases - report having been cheated at least once. Furthermore, quite a few people report being cheated more than once, but the frequency with which people report being cheated decays rapidly in all domains except food, where close to $10 \%$ of respondents report being cheated 5 times or more.

In addition to analyzing the frequency with which individuals are cheated in each of the four domains, we also construct two summary indicators: the number of times an individual has been cheated over the four domains collectively, and a variable extracting the first principal component of the four cheating indicators. Summary statistics are reported in Table A1.

\subsection{Empirical specification}

To test whether the chances of being cheated increase with trust we estimate the following model:

$$
Z_{i c}^{d}=\alpha \text { Trust }_{i c}+\beta X_{i c}+\gamma C+\xi_{i c}
$$

where $Z_{i c}^{d}$ is an indicator of how often individual $i$ has been cheated in country $C$ in the domain $d$ (cheated by a bank; or when buying food; or by a car repairer; or when buying goods second hand). The other variables have the same meaning as in equation (1) of Section 3 , but in this specification trust is a single variable (rather than a set of dummies) taking values from 0 to 10 . We use a single trust measure because we are going to instrument 
for trust. Furthermore, in principle the risk of being cheated should increase monotonically with trust. We control for income to capture differences in the number of transactions people engage in for a given level of trust. To address the concern that trust is simply a proxy for risk attitudes, we add the survey measure of risk tolerance as a control. All regressions include a full set of occupation dummies. In the OA we also report a specification in which we further control for industry dummies, establishment size and a dummy for whether the person is responsible for supervising other employees (Table A14).

Moreover, we insert into this regression a full set of country $(C)$ dummies to account for national differences in the fraction of cheaters, and to absorb any location-specific characteristics that may encourage or discourage cheating. ${ }^{39}$

Before considering the estimates of (7) we have to confront an identification issue. Since people learn from experience and revise their priors accordingly, those who have been cheated are more likely to revise their trust beliefs downwards. Because we observe the level of trust after they have been cheated, this tends to generate a negative correlation between cheating and trust. When we run OLS estimates of (7) for the various domains we indeed find that this negative correlation is predominant (OA, Table A15). A solution to this reverse causality problem would be to instrument current trust with the level of inherited trust, for example using second generation immigrants trust. This instrument however is likely to be invalid in this context. To see why, notice that a negative correlation between cheating and trust is not necessarily (or at least not only) the result of learning. For instance, those mistrusting could be more likely to report being cheated because they are more attentive and thus more likely to detect cheating. This reporting error in our measures of cheating biases towards finding a negative correlation. Alternatively, those mistrusting could also be more paranoid about the possibility of being cheated. They could, for example, consider as cheating any small disappointment in an exchange/relation with a counterpart, again biasing towards finding a negative correlation between cheating

\footnotetext{
${ }^{39}$ These fixed effects also take care of any variation across countries in what is considered to be cheating, and that may result in different frequencies of reported cheating across countries. Our results are robust to the inclusion of regional dummies.
} 
and trust. IV estimates can also account for these sources of bias arising from unobserved heterogeneity. However, if they are present, inherited trust is not a valid instrument in the cheating regression. In fact, though inherited trust could be a valid instrument to correct the reverse causality induced by learning, it would still be correlated with "unobserved attentiveness to cheating" or "unobserved cheating notions" breaking its validity.

To address this endogeneity issue we need a variable that systematically affects an individual's propensity to trust others, but is unlikely to respond to shocks to being cheated or be correlated with these sources of unobserved heterogeneity in the cheating regression. To obtain this exogenous source of variation we rely on the idea that individuals, when forming their trust beliefs, are affected by their own intrinsic trustworthiness because of "false consensus" - the tendency of individuals to extrapolate the behavior of others from their own type (Ross, Green and House, 1977). In our context own trustworthiness can be seen as a source of information any time an individual needs to form a trust belief. In the absence of a history of information about the reliability of a pool of people, those interacting with an unknown pool form a belief by asking themselves how they would behave in similar circumstances: since they would personally behave differently, they come up with different beliefs. ${ }^{40}$ Our index of trustworthiness is a measure of how much responsibility is delegated to individuals by their supervisors at work. Specifically, the ESS asks individuals to state, on a scale from zero to 10 , how much latitude their manager grants them along three different dimensions: a) freedom in organizing their daily work; b) power to influence policy decisions about the activities of the organization; and c) freedom to choose or change the pace of their work (see the OA for exact wording) ${ }^{41}$

We sum the answers from the three parts of the delegation question to construct a single

\footnotetext{
${ }^{40}$ False consensus has been shown to be a persistent phenomenon: neither providing additional information about the population of interest, nor warning individuals about false consensus, eliminates the effect (Krueger and Clement, 1994). Furthermore, it has been found that false consensus is not drowned out by monetary incentives for accurate predictions (e.g. Massey and Thaler, 2006). Butler et al. (2013) show that measures of trustworthiness obtained from behavior in a trust game predict trust beliefs in the same experiment and that, in addition, trustworthiness can be traced back to the values instilled by parents.

${ }^{41}$ It is worth remarking that while the "delegation" measure is likely to be a valid instrument in the cheating regression it is not in the income regression estimated in Section 3, as delegation may affect income directly. Inherited trust instead is a valid instrument in the income regression.
} 
measure of how much authority individuals' managers grant them on the job. Since more trustworthy individuals are more likely, ceteris paribus, to be delegated more power and freedom of choice, we use this variable as a proxy for individuals' intrinsic trustworthiness. If individuals indeed extrapolate from their own type when forming trust beliefs, this index should have predictive power on measured trust. To be a valid instrument we also require that workplace delegation has no direct effect on individuals' risk of being cheated in the domains we observe. We see no obvious reason why such delegation would directly affect the chances that a person is cheated by, e.g., a mechanic or a plumber. Similarly, we do not see why being more or less trustworthy should make one more or less attentive to cheating or paranoid about it, or how shocks to how frequently a person is cheated in his private life - which is private information and thus unobservable to the manager - could affect the amount of delegation a manager grants this person on the job. The only reason we see why there could be a correlation with the residuals in the cheating regression is because there could be an uncontrolled-for individual characteristic making it obvious to an outsider that the individual is susceptible to being cheated which would also reduce delegation to this individual. If this were the case, the IV estimates would be inconsistent. However, the inconsistency would take the form of a downwardly biased estimate of the true effect of trust on the frequency of being cheated. Since, as we will see, the IV estimates suggest a positive effect, this should be taken as a lower bound of the true effect of trust on the risk of being cheated. We do acknowledge that the validity of our instrument may not be robust to the presence of unobserved heterogeneity in skills. If delegation is correlated with a worker's skill, our instrument may be invalid as skilled workers might be better able to deal with untrustworthy individuals (which would lead to a negative bias in the IV estimates); but skilled workers might also be better able to recognize that they were indeed cheated (which would lead to a positive bias in the estimates). This concern should at least partly be dealt with by the fact that we control for education and income in the cheating regressions.

Table 4 (Panel A) shows the results of the IV estimates. The first four columns report results for each of the four domains. In all cases, the negative effect of trust beliefs in the 
OLS estimates is reversed by the IV estimates, and a positive effect of trust on the number of times an individual has been cheated results. Economically, the effect of trust on exposure to cheating is substantial. Increasing trust by one standard deviation raises the number of times one is cheated by a bank by 1.85 (1.22 times the sample mean); the frequency of being cheated when buying second hand goods by 0.57 ( $62 \%$ of the sample mean); the frequency of being cheated when buying food by 1.38 (68\% of the sample mean); and increases how frequently one is cheated by a plumber or repairer by 1.28 ( $79 \%$ of the sample mean). The remaining two columns show estimates using as the dependent variable the total number of times an individual was cheated in any domain (column 5) and the first principal component

of the measure of being cheated (column 6). In all cases the IV estimate shows a positive and highly significant effect of trust beliefs on being cheated.

Table 4 (Panel B) shows the first stage regression, focusing on the excluded instrument. Consistent with our identification strategy the instrument has a positive effect on the level of individual trust and is highly statistically significant (with the F-stat always above 10). The reduced form estimates of the effect of delegation (Table 4, Panel C) imply that the effect of delegation on the number of times one is cheated is close to that implied by the first and the second stage of the IV estimates, lending indirect support to the validity of this instrument.

Overall, these estimates imply a large effect of trust on exposure to cheating. This is consistent with the idea that mistrust shields individuals from the risk of being cheated, while too much trust amplifies this risk and hinders individual economic performance, lending support to one of the mechanisms through which heterogeneity in trust beliefs can produce a hump-shaped relationship between trust and income.

\section{Conclusions}

We document the existence of a hump-shaped relationship between individual trust and individual income. For an individual the cost of miscalibrated trust beliefs can be substantial 
and of the same order of magnitude as returns to education. Our results hold in large scale survey data and inside a country with high quality institutions. They hold when we use an instrumental variable strategy and formally account for heterogeneity. In the working paper version of this paper (Butler et al. (2009)), we also show that the relationship between trust and income is hump-shaped in a laboratory setting, where subjects play a trust game. In the laboratory income is the result of performance and cannot cause participants' beliefs. In addition, since in the laboratory individuals face the same pool of opponents and are randomly matched with one of them, the results cannot be due to pool heterogeneity and sorting but only to incorrect beliefs. In summary, the relationship between trust and income uncovered in this paper is quite general and holds in different settings.

Though both excessive trust and excessive mistrust are individually costly, the data suggest that the income cost of trusting too little far exceeds that of trusting too much, even in low trust countries. From a societal point of view, however, there is an important difference between the two excesses. While excessive mistrust and excessive trust are both individually costly, mistrust is also socially costly as it reduces surplus creation. On the contrary, excessive trust may create social surplus even if this surplus is allocated in a way that harms the overly trusting individuals. This difference reconciles our findings of a concave relationship between performance and trust at the individual level and the monotonically increasing relationship found in aggregate data. 


\section{References}

[1] Aghion, Philippe, Yann Algan, Pierre Cahuc and Andrei Shleifer (2010), "Regulation and Distrust", The Quarterly Journal of Economics, 125 (3): 1015-1049.

[2] Algan,Yann and Pierre Cahuc (2010) "Inherited Trust and Growth," American Economic Review, 100 (5): 2060-92.

[3] Alesina, Alberto and Eliana La Ferrara (2002), "Who Trusts Others?," Journal of Public Economics, 85(2), 207-234.

[4] Arrow, Kenneth (1972), "Gifts and Exchanges," Philosopy ESPublic Affairs, 1(4), 343362.

[5] Berg, J., Dickhaut, J. and K. McCabe (1995), "Trust, Reciprocity and Social History," Games and Economic Behavior, 10, 122-142.

[6] Bisin, Alberto, Giorgio Topa, and Thierry Verdier (2004). "Cooperation as a Transmitted Cultural Trait," Rationality and Society, 16 (4), 477-507.

[7] Bisin, Alberto, and Thierry Verdier (2000). "Beyond the Melting Pot: Cultural Transmission, Marriage, and the Evolution of Ethnic and Religious Traits," Quarterly Journal of Economics, 115 (3), 955-988.

[8] Blanco, Mariana (2008), "Within-Subject Experiments on Other-Regarding Preferences," Chapter 1, Phd thesis, Royal Holloway, University of London.

[9] Bloom, Nicholas, Raffaella Sadun and John Van Reenen (2009), "The Organization of Firms across Countries," CEPR DP 937.

[10] Butler, Jeffrey V., Paola Giuliano and Luigi Guiso (2009), "The Right Amount of Trust", NBER WP 15344.

[11] Butler, Jeffrey V., Paola Giuliano and Luigi Guiso (2013), "Trust, Values and False Consensus", UCLA mimeo. 
[12] Camerer, Colin F (2003). Behavioral Game Theory: experiments in strategic interaction. Princeton, NJ: Princeton University Press.

[13] Hildreth, Clifford and James P. Houck (1968), "Some Estimators for a Linear Model with Random Coefficients", Journal of the American Statistical Association, Vol. 63, No. 322 , pp. $584-595$

[14] Cox, James C. (2004), "How to Identify Trust and Reciprocity," Games and Economic Behavior, 46, 260-281

[15] Dixit, Avinash (2003), "Trade Expansion and Contract Enforcement," Journal of Political Economy, 111 (6), 1293-1317.

[16] Dohmen, Thomas, Armin Falk, David Huffman, and Uwe Sunde (2012). "The Intergenerational Transmission of Risk and Trust Attitudes," Review of Economic Studies, 79 (2): $645-677$.

[17] Fehr, Ernst (2009), "On the Economics and Biology of Trust," Journal of the European Economic Association, 7 (2-3): 235-266.

[18] Fernandez, Raquel and Alessandra Fogli (2009), "Culture: An Empirical Investigation of Beliefs, Work, and Fertility," American Economic Journal: Macroeconomics, 1(1), 146-177.

[19] Garen, John, "The Returns to Schooling: A Selectivity Bias Approach with a Continuous Choice Variable", Econometrica, Vol. 52, No. 5 (Sep., 1984), pp. 1199-1218

[20] Giuliano, Paola (2007), "Living Arrangements in Western Europe: Does Cultural Origin Matter?," Journal of the European Economic Association, 5 (5), 927-952.

[21] Glaeser, Edward, David Laibson, Josï¿œ A. Scheinkman and Christine L. Soutter (2000), "Measuring Trust," Quarterly Journal of Economics 115(3), 811-846. 
[22] Guiso, Luigi, Paola Sapienza and Luigi Zingales (2004), "The Role of Social Capital in Financial Development," The American Economic Review, 94, 526-556.

[23] Guiso, Luigi, Paola Sapienza and Luigi Zingales (2008a), "Trusting the Stock Market," Journal of Finance, 63 (6), 2557-2600.

[24] Guiso, Luigi, Paola Sapienza and Luigi Zingales (2008b), "Social Capital as Good Culture," Journal of the European Economic Association, 6(2-3), 295-320.

[25] Guiso, Luigi, Paola Sapienza and Luigi Zingales (2009), "Cultural Biases in Economic Exchange?," Quarterly Journal of Economics, 124 (3), 1095-1131.

[26] Kelejian, H. H. (1974), "Random Parameters in a Simultaneous Equation Framework: Identification and Estimation", Econometrica, Vol. 42, No. 3 (May, 1974), pp. 517-528

[27] Knack, Stephen and Keefer, Philip (1996) "Does Social Capital Have an Economic Payoff?A Cross-Country Investigation," The Quarterly Journal of Economics, 112 (4), 1251-1288.

[28] Knack, Stephen and Paul Zak (2001) "Trust and Growth," The Economic Journal, $111,295-321$.

[29] Krueger, Joachim and Russel W. Clement (1994), "The Truly False Consensus Effect: An Ineradicable and Egocentric Bias in Social Perception," Journal of Personality and Social Psychology of Addictive Behaviors, 67 (4):596-610.

[30] La Porta, Rafael, Florencio Lopez de Silanes, Andrea Shleifer and Robert Vishny (1997) "Trust in Large Organizations," The American Economic Review, 87 (2), 333-338.

[31] Luttmer, Erzo and Monica Singhal (2011), "Culture, Context, and the Taste for Redistribution", American Economic Journal: Economic Policy, 3(1), 157 - 179.

[32] Massey, Cade and Richard H. Thaler (2006), "The Loser's Curse: Overconfidence vs. Market Efficiency in the National Football League Draft," University of Chicago, mimeo. 
[33] Miller, A. S., and T. Mitamura (2003). "Are Surveys on Trust Trustworthy?," Social Psychology Quarterly, 66, 62-70.

[34] Ross, Lee, Greene, D., and House, P. (1977), "The False Consensus Phenomenon: An Attributional Bias in Self-Perception and Social Perception Processes," Journal of Experimental Social Psychology, 13(3), 279-301.

[35] Sapienza, Paola, Anna Toldra and Luigi Zingales (2007), "Understanding Trust," NBER WP 13387

[36] Tabellini, Guido (2008a). "The Scope of Cooperation: Values and Incentives," Quarterly Journal of Economics, 123 (3), 905-950.

[37] Tabellini, Guido (2008b), "Institutions and Culture," Journal of the European Economic Association, 6(2-3), 255-294.

[38] Westen, Drew, Pavel S. Blagov, Keith Harenski, Clint Kilts and Stephan Hamann (2006), "Neural Bases of Motivated Reasoning: An MRI Study of Emotional Constraints on Partisan Political Judgment in the 2004 U.S. Presidential Election,", Journal of Cognitive Neuroscience, 18(11), 1947-58. 
Figure 1

Trust beliefs: density functions by country

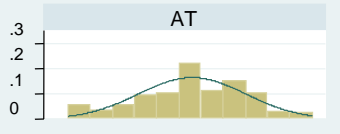

DE
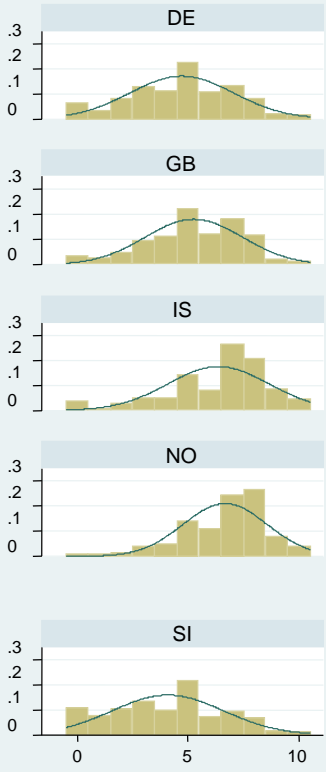

Most people can be trusted or you can't be too careful

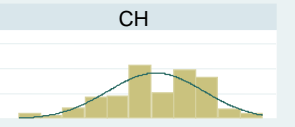

ES

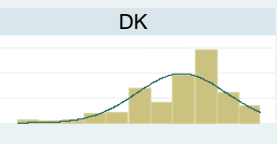

GR

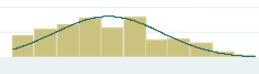

IT

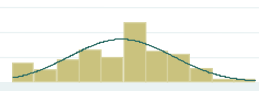

PL
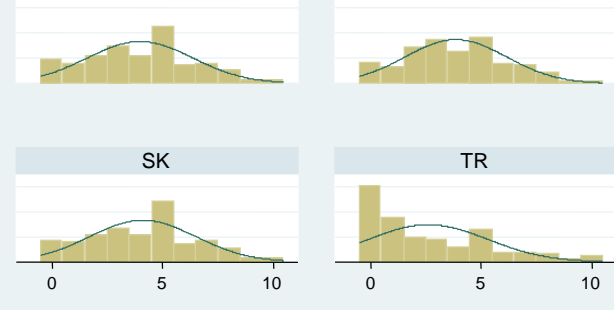

HU
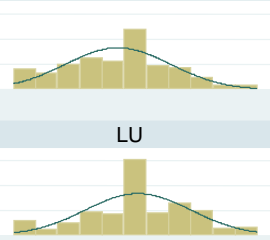

RO
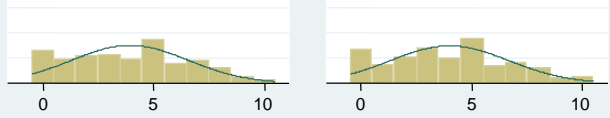

LV

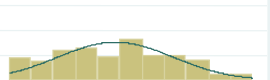

$\mathrm{RU}$
$\mathrm{CZ}$
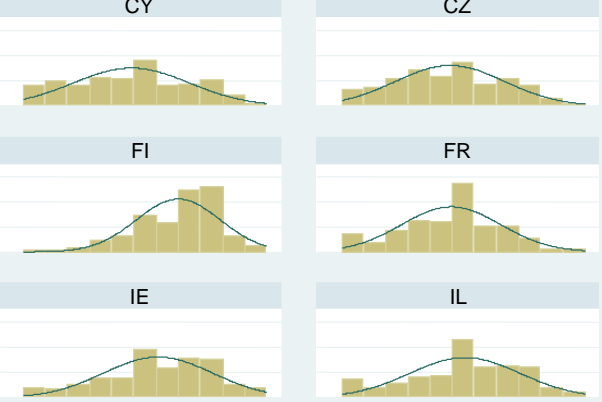

FR
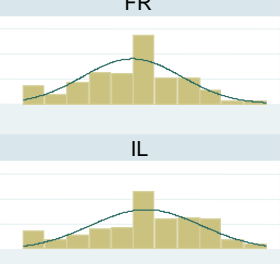

NL

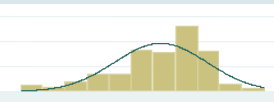

SE

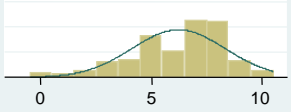


Figure 2

The empirical relationship between trust and income

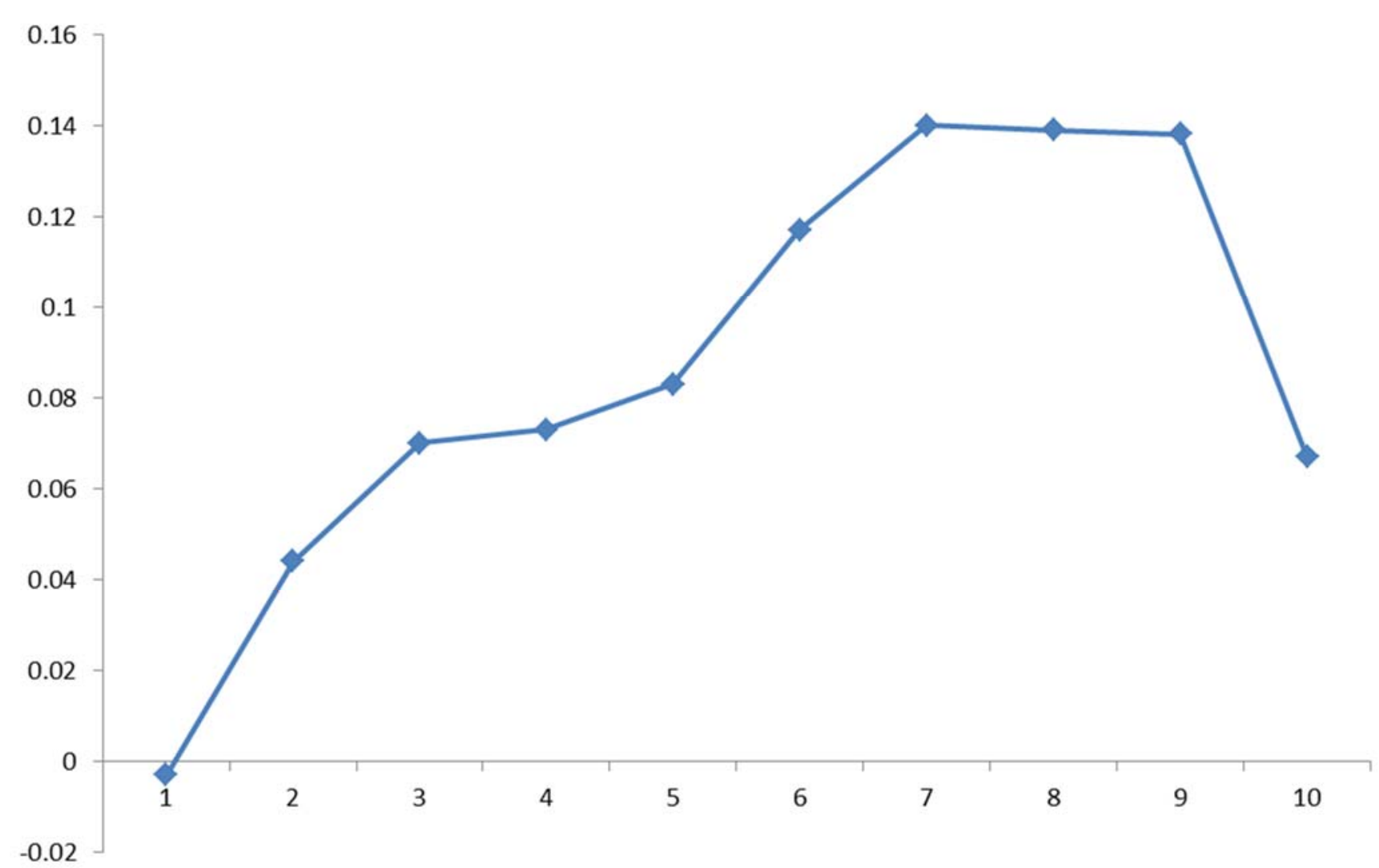


Figure 3

The empirical relationship between trust and income in low, average and high trust countries

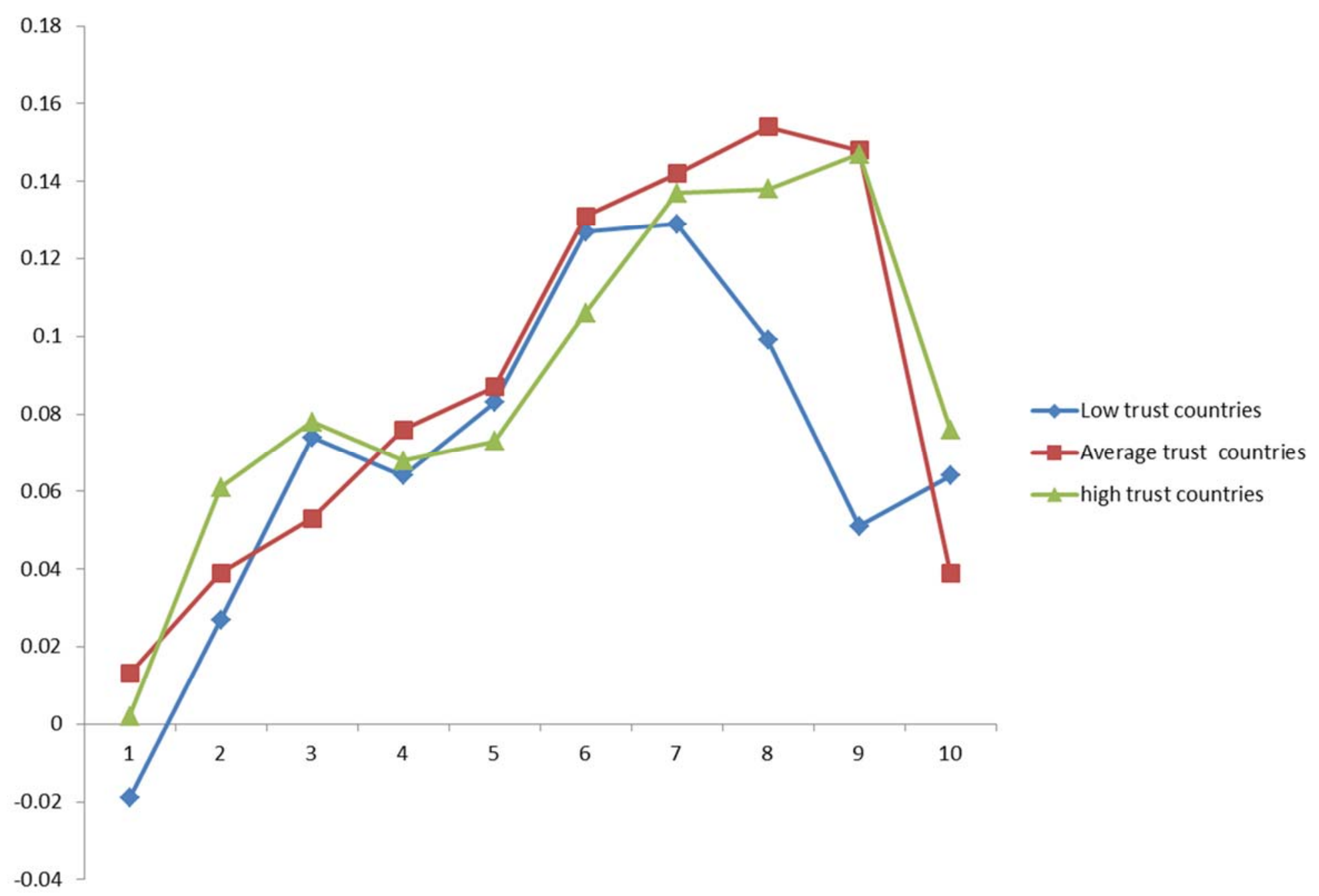


Figure 4. Trust maximing income, trust mistakes and income cost of of trust mistakes

A. Cross sectional distribution of the right amount of trust

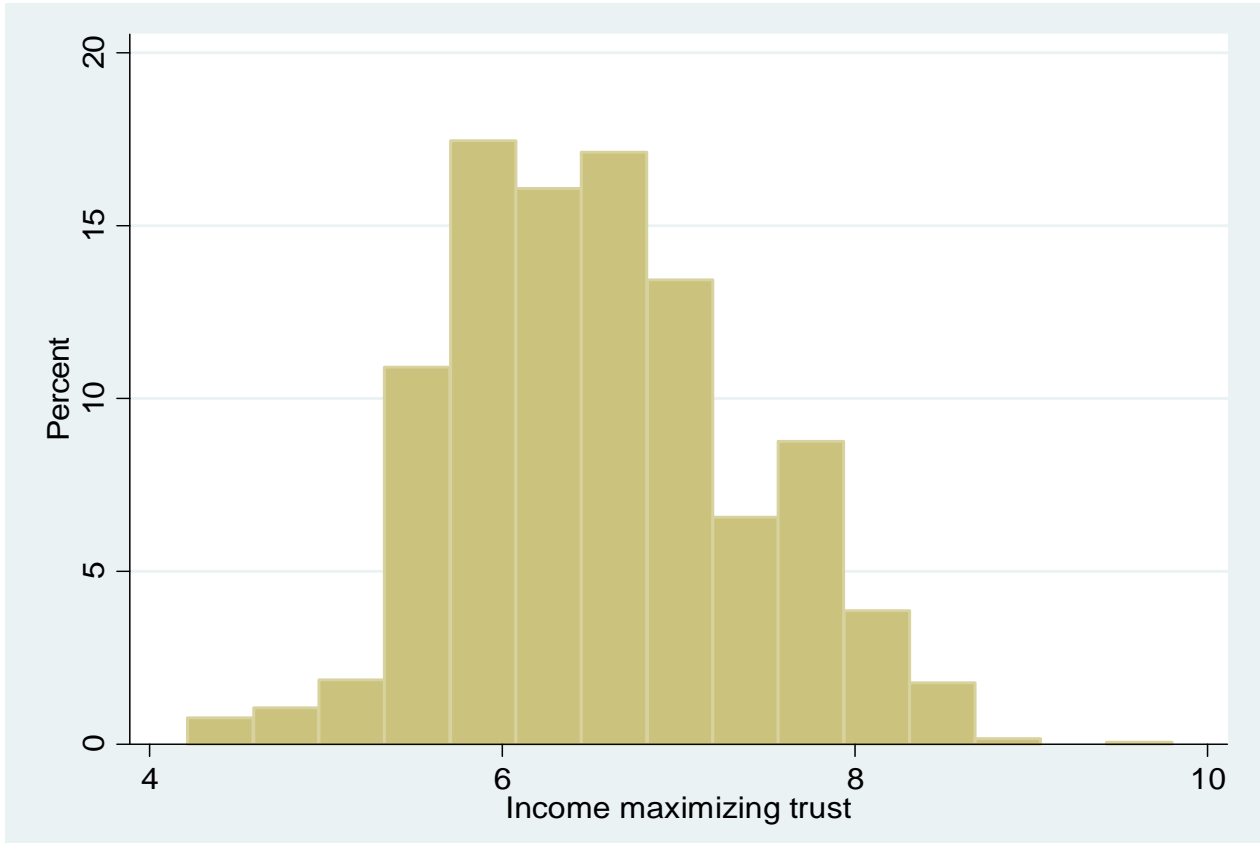

B. Cross sectional distribution of trust mistakes (Trust maximizing income- actual trust)

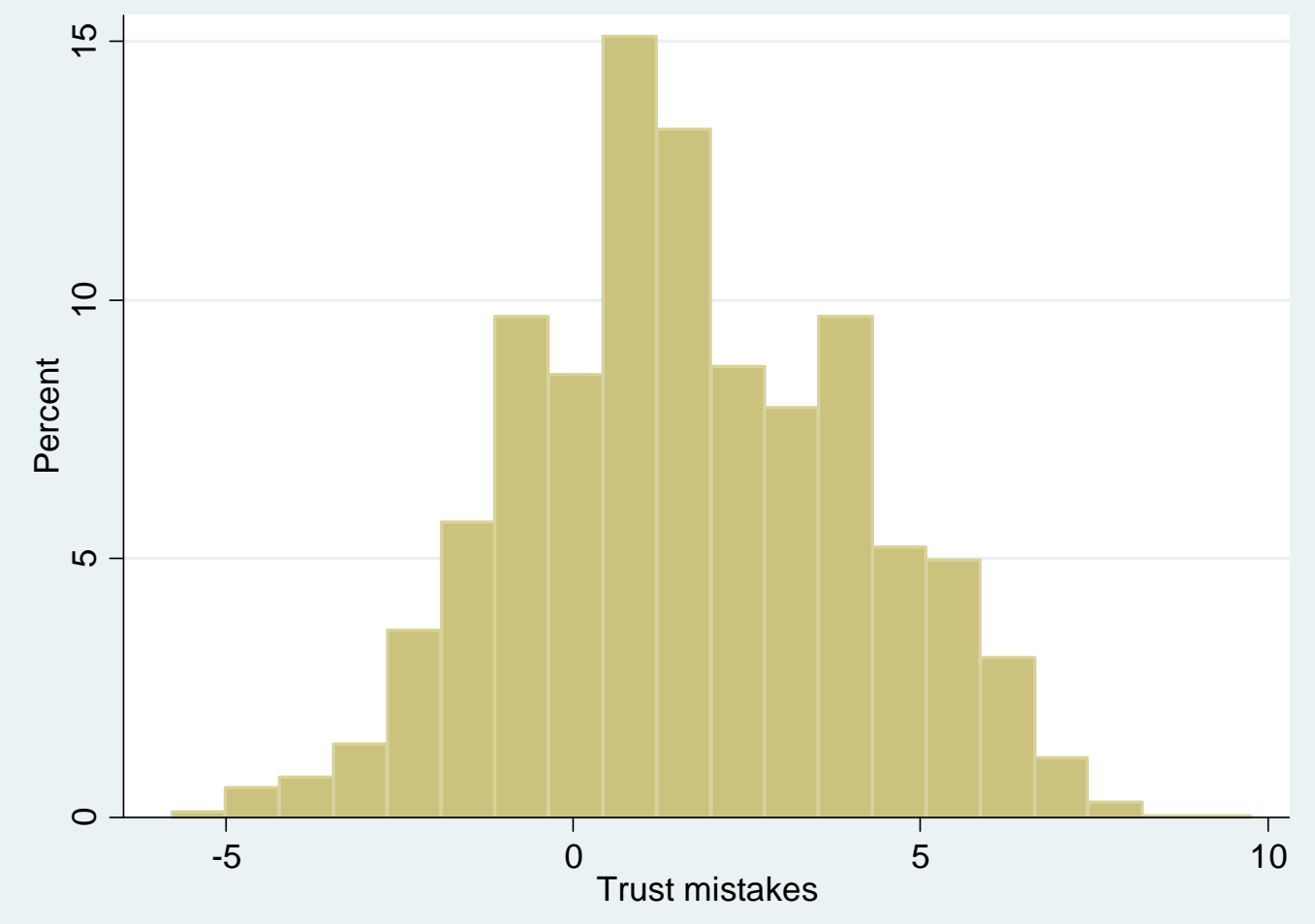




\section{Income cost of trust mistakes}

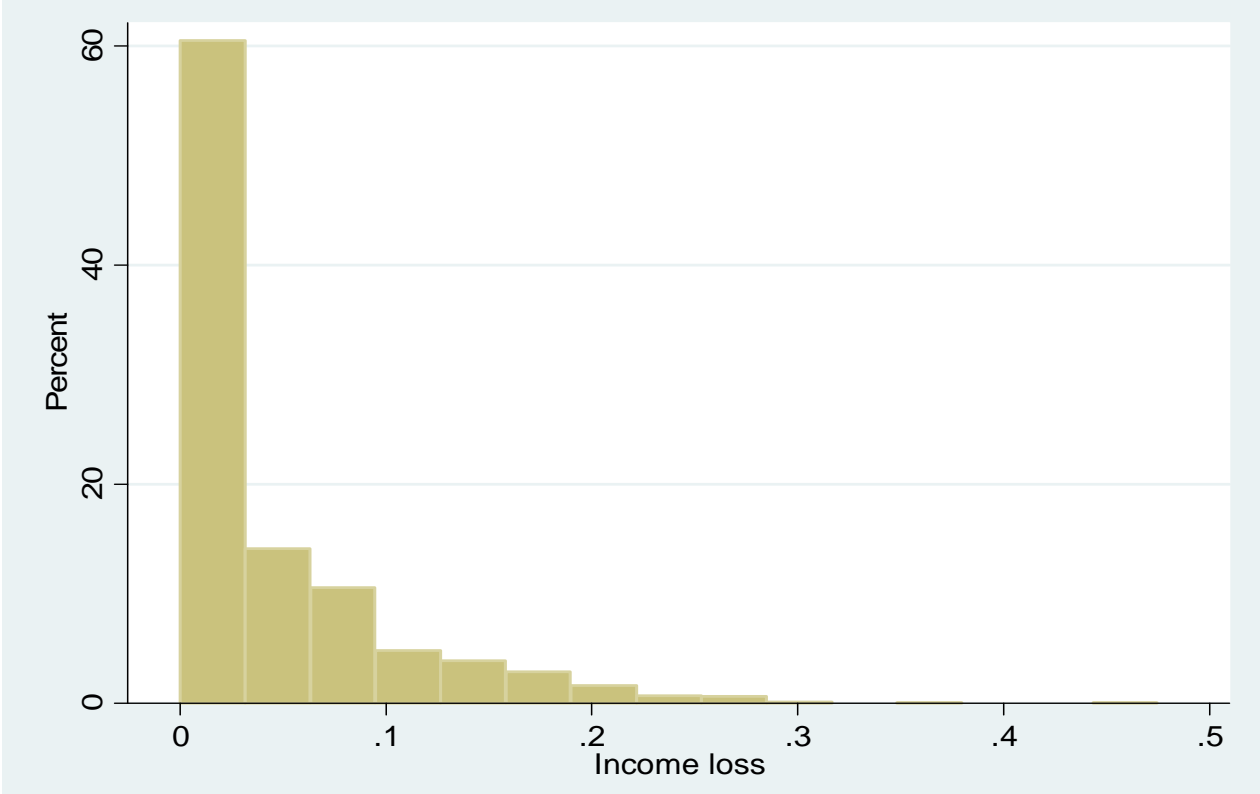

D. Income cost of trust mistakes and level of individual trust, by country

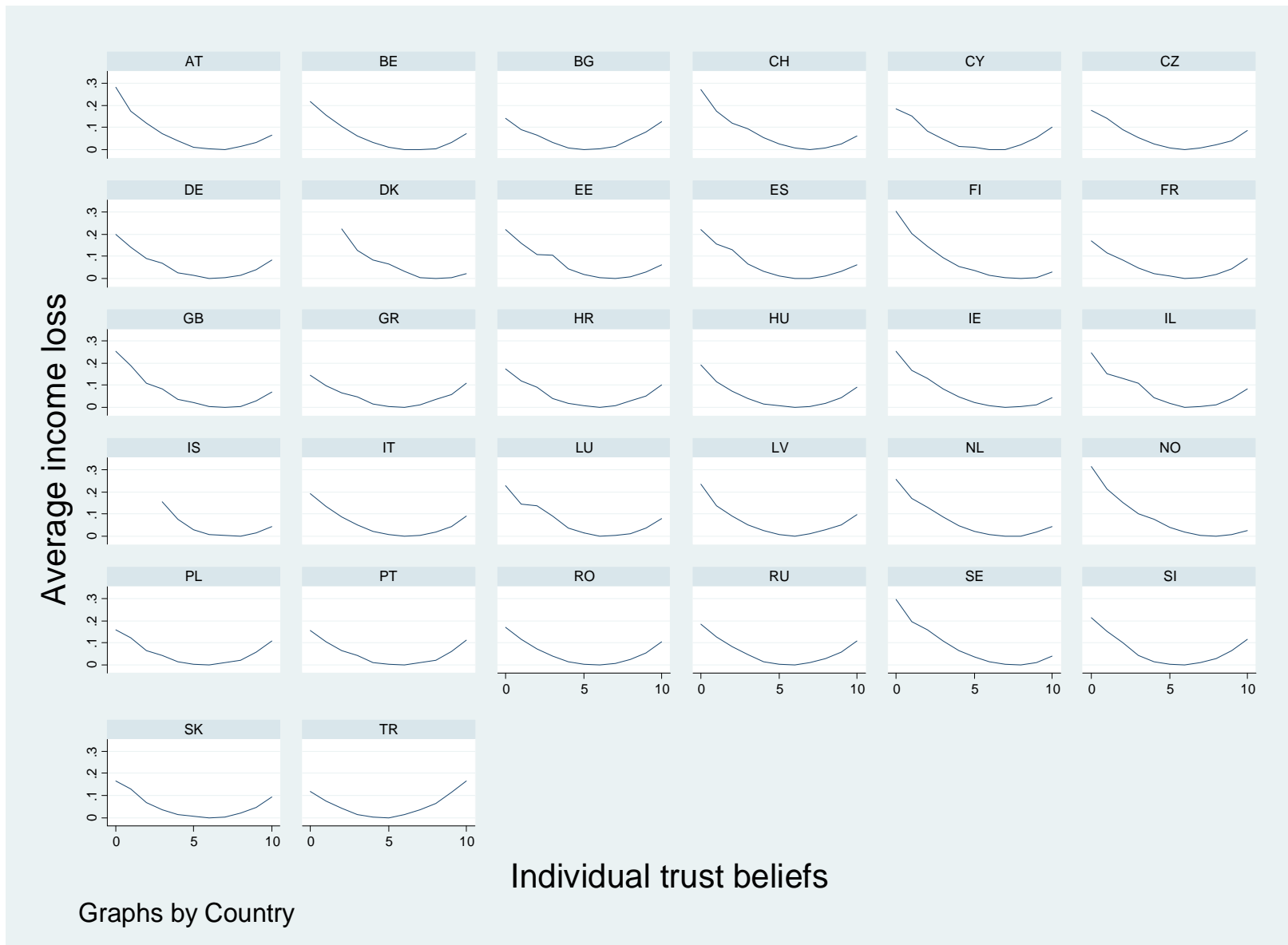


Figure 5

Number of times being cheated
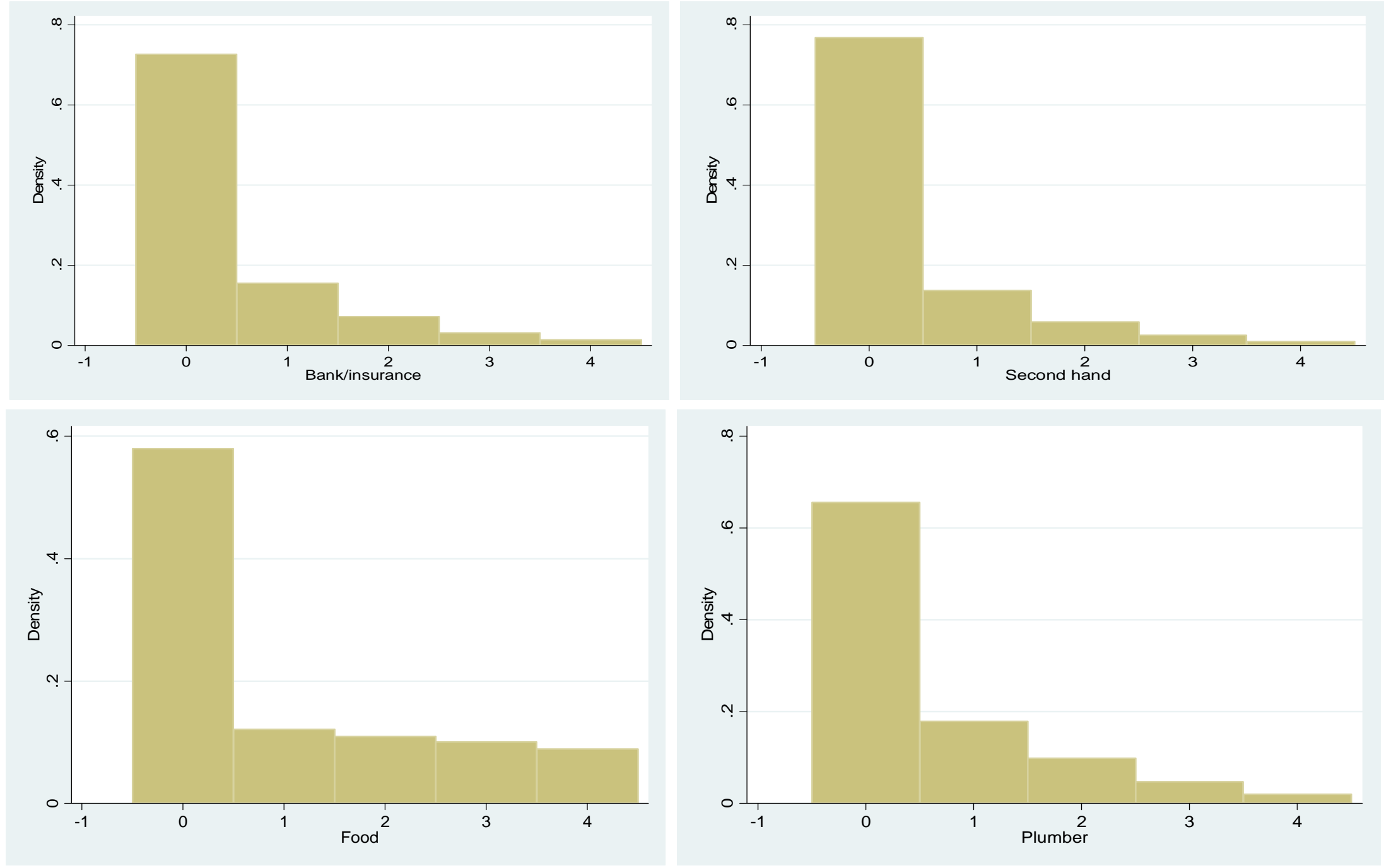
Table 1

The relationship between trust and income

\begin{tabular}{|c|c|c|c|c|c|}
\hline Dependent var.: Log (income) & $\begin{array}{c}(1) \\
\text { OLS }\end{array}$ & $\begin{array}{c}(2) \\
\text { Heckman }\end{array}$ & $\begin{array}{l}\text { (3) } \\
\text { OLS }\end{array}$ & $\begin{array}{c}\text { (4) } \\
\text { OLS }\end{array}$ & $\begin{array}{c}(5) \\
\text { OLS }\end{array}$ \\
\hline Trust 1 & $\begin{array}{l}-0.003 \\
(0.013)\end{array}$ & $\begin{array}{c}0.002 \\
(0.014)\end{array}$ & $\begin{array}{c}0.004 \\
(0.015)\end{array}$ & $\begin{array}{l}-0.003 \\
(0.013)\end{array}$ & $\begin{array}{l}-0.004 \\
(0.013)\end{array}$ \\
\hline Trust 2 & $\begin{array}{c}0.044 * * * \\
(0.012)\end{array}$ & $\begin{array}{c}0.054 * * * \\
(0.013)\end{array}$ & $\begin{array}{c}0.041 * * * \\
(0.014)\end{array}$ & $\begin{array}{c}0.040 * * * \\
(0.012)\end{array}$ & $\begin{array}{c}0.042 * * * \\
(0.012)\end{array}$ \\
\hline Trust 3 & $\begin{array}{c}0.070^{* * *} \\
(0.011)\end{array}$ & $\begin{array}{c}0.094 * * * \\
(0.012)\end{array}$ & $\begin{array}{c}0.070^{* * *} \\
(0.013)\end{array}$ & $\begin{array}{c}0.060^{* * *} * \\
(0.011)\end{array}$ & $\begin{array}{c}0.068^{* * *} \\
(0.011)\end{array}$ \\
\hline Trust 4 & $\begin{array}{c}0.073^{* * *} \\
(0.011)\end{array}$ & $\begin{array}{c}0.102^{* * *} \\
(0.013)\end{array}$ & $\begin{array}{c}0.059 * * * \\
(0.013)\end{array}$ & $\begin{array}{c}0.060^{* * *} \\
(0.011)\end{array}$ & $\begin{array}{c}0.070^{* * *} \\
(0.011)\end{array}$ \\
\hline Trust 5 & $\begin{array}{c}0.083 * * * \\
(0.010)\end{array}$ & $\begin{array}{c}0.107 * * * \\
(0.011)\end{array}$ & $\begin{array}{c}0.071 * * * \\
(0.012)\end{array}$ & $\begin{array}{c}0.069 * * * \\
(0.010)\end{array}$ & $\begin{array}{c}0.081 * * * \\
(0.010)\end{array}$ \\
\hline Trust 6 & $\begin{array}{c}0.117 * * * \\
(0.011)\end{array}$ & $\begin{array}{c}0.159 * * * \\
(0.013)\end{array}$ & $\begin{array}{c}0.106^{* * *} * \\
(0.012)\end{array}$ & $\begin{array}{c}0.097 * * * \\
(0.011)\end{array}$ & $\begin{array}{c}0.114 * * * \\
(0.011)\end{array}$ \\
\hline Trust 7 & $\begin{array}{c}0.140^{* * *} \\
(0.010)\end{array}$ & $\begin{array}{c}0.176^{* * *} \\
(0.013)\end{array}$ & $\begin{array}{c}0.134 * * * \\
(0.012)\end{array}$ & $\begin{array}{c}0.116^{* * *} \\
(0.010)\end{array}$ & $\begin{array}{c}0.136 * * * \\
(0.010)\end{array}$ \\
\hline Trust 8 & $\begin{array}{c}0.139 * * * \\
(0.011)\end{array}$ & $\begin{array}{c}0.184 * * * \\
(0.014)\end{array}$ & $\begin{array}{c}0.128^{* * *} \\
(0.012)\end{array}$ & $\begin{array}{c}0.113^{* * *} \\
(0.011)\end{array}$ & $\begin{array}{c}0.136^{* * *} \\
(0.011)\end{array}$ \\
\hline Trust 9 & $\begin{array}{c}0.138^{* * *} \\
(0.014)\end{array}$ & $\begin{array}{c}0.174 * * * \\
(0.017)\end{array}$ & $\begin{array}{c}0.140 * * * \\
(0.015)\end{array}$ & $\begin{array}{c}0.115^{* * *} \\
(0.014)\end{array}$ & $\begin{array}{c}0.136 * * * \\
(0.014)\end{array}$ \\
\hline Trust 10 & $\begin{array}{c}0.067 * * * \\
(0.017)\end{array}$ & $\begin{array}{c}0.092^{* * *} \\
(0.002)\end{array}$ & $\begin{array}{c}0.071 * * * \\
(0.021)\end{array}$ & $\begin{array}{c}0.056^{* * *} \\
(0.017)\end{array}$ & $\begin{array}{c}0.066^{* * *} \\
(0.017)\end{array}$ \\
\hline Individual controls & yes & yes & yes & yes & yes \\
\hline Altruism, risk aversion, trustworthiness & yes & yes & yes & yes & yes \\
\hline Additional controls & no & no & yes & no & no \\
\hline Trust legal system (10 dum.) & no & no & no & yes & no \\
\hline Controlling for moderation & no & no & no & no & yes \\
\hline Observations & 102298 & 96782 & 64404 & 100449 & 102298 \\
\hline R-squared & 0.67 & & 0.72 & 0.67 & 0.67 \\
\hline Trust peak $=$ Trust 2 (p-values) & 0.00 & 0.00 & 0.00 & 0.00 & 0.00 \\
\hline Trust peak $=$ Trust $10(\mathrm{p}$-values $)$ & 0.00 & 0.00 & 0.00 & 0.00 & 0.00 \\
\hline \multicolumn{6}{|c|}{$\begin{array}{l}\text { Notes: [1] Each regression controls for country and wave fixed effects; [2] } * * * \text { significant at } 1 \%, * * \text { significant at } 5 \%, *{ }^{*} \\
\text { significant at } 10 \% \text {. [3] Trust is the answer to the following question: "Generally speaking would you say that most people } \\
\text { can be trusted or that you can't be too careful in dealing with people? Please tell me on a score of } 0 \text { to } 10 \text {, where } 0 \text { means } \\
\text { you can't be too careful and } 10 \text { means that most people can be trusted"; [4] Individual controls in column (1) include a } \\
\text { quadratic in age, gender, immigrant, marital and labor market status, years of education, education of the father and } \\
\text { dummies for city size. The specification also includes measures of risk aversion, altruism and trustworthiness. The } \\
\text { variables are described on p. } 4 \text { and p. } 6 \text { of the on line appendix. Additional controls in column (3) are a full set of age } \\
\text { dummies, a full set of education dummies and their interactions with country dummies, mother's and partner's education } \\
\text { and the number of people living at home. Column (4) includes } 10 \text { dummies for trust in the legal system, whereas column } \\
\text { (5) controls for a measure of moderation, including dummies for risk aversion. }\end{array}$} \\
\hline
\end{tabular}


Table 2

The relationship between income and trust, Sweden

\begin{tabular}{|c|c|c|}
\hline Dep. var.: $\log$ (income) & $(1)$ & $(2)$ \\
\hline Trust 1 & $\begin{array}{c}0.038 \\
(0.041)\end{array}$ & \\
\hline Trust 2 & $\begin{array}{c}0.170^{* * *} \\
(0.032)\end{array}$ & \\
\hline Trust 3 & $\begin{array}{c}0.205^{* * *} \\
(0.029)\end{array}$ & \\
\hline Trust 4 & $\begin{array}{c}0.222^{* * *} \\
(0.029)\end{array}$ & \\
\hline Trust 5 & $\begin{array}{c}0.210^{* * *} \\
(0.027)\end{array}$ & \\
\hline Trust 6 & $\begin{array}{c}0.275^{* * *} \\
(0.028)\end{array}$ & \\
\hline Trust 7 & $\begin{array}{c}0.295^{* * *} \\
(0.027)\end{array}$ & \\
\hline Trust 8 & $\begin{array}{c}0.319 * * * \\
(0.027)\end{array}$ & \\
\hline Trust 9 & $\begin{array}{c}0.337 * * * \\
(0.028)\end{array}$ & \\
\hline Trust 10 & $\begin{array}{c}0.260^{* * *} \\
(0.028)\end{array}$ & \\
\hline Trust & & $\begin{array}{c}.0653 * * * \\
(0.006)\end{array}$ \\
\hline Trust squared & & $\begin{array}{c}-.0036^{* * *} \\
(0.000)\end{array}$ \\
\hline Income maximizing trust & 9.0 & 9.10 \\
\hline Trust peak $=$ Trust $2 \quad(p$-value $)$ & 0.00 & \\
\hline Trust peak $=$ Trust $10(\mathrm{p}$-value $)$ & 0.00 & \\
\hline Observations & 38991 & 38991 \\
\hline R-squared & 0.29 & 0.29 \\
\hline
\end{tabular}

Notes: [1] ${ }^{* * *}$ significant at $1 \%,{ }^{* *}$ significant at $5 \%,{ }^{*}$ significant at $10 \%$. [2] Trust is the answer to the following question: "In your opinion, to what extent can one trust people in general?" The answers go from "Cannot trust people in general" (0) to "Can trust people in general" (10); [3] Each regression controls for a quadratic in age, marital and labor market status, rural and urban areas dummies, education, risk aversion, citizenship status, region and year of interview fixed effects. 
Table 3

The relationship between trust and income, dealing with causality and heterogeneity

\begin{tabular}{|c|c|c|c|c|}
\hline "Dependent variable: $\log ($ income $)$ & $\begin{array}{c}(1) \\
\text { OLS }\end{array}$ & IV & $\begin{array}{c}(3) \\
\text { Heterogeneity } \\
\text { No controls in } \\
\text { the first stage }\end{array}$ & $\begin{array}{c}\text { (4) } \\
\text { Heterogeneity } \\
\text { With controls in } \\
\text { the first stage }\end{array}$ \\
\hline Trust: $\beta_{1}$ & $\begin{array}{c}0.0397 * * * \\
(0.003)\end{array}$ & $\begin{array}{c}0.034 * * * \\
(0.003)\end{array}$ & $\begin{array}{c}0.026^{* * *} \\
(0.008)\end{array}$ & $\begin{array}{c}0.026^{* * *} \\
(0.007)\end{array}$ \\
\hline $\begin{array}{l}\text { Trust squared: }-\beta_{2} \\
\text { (Individual trust })^{*} \text { (avg trust): } \beta_{2}\end{array}$ & $\begin{array}{c}-0.00229^{* * *} \\
(0.000)\end{array}$ & $\begin{array}{c}-0.002^{* * *} \\
(0.000)\end{array}$ & $\begin{array}{c}-0.005^{* * *} \\
(0.002) \\
0.008^{*}\end{array}$ & $\begin{array}{l}-0.005^{* * *} \\
(0.001) \\
0.009^{* *}\end{array}$ \\
\hline & & & $(0.004)$ & $(0.004)$ \\
\hline Residuals: $\beta_{4}^{\prime}$ & & & $\begin{array}{l}-0.002 \\
(0.018)\end{array}$ & $\begin{array}{l}-0.003 \\
(0.018)\end{array}$ \\
\hline Residuals*average trust: $b \beta_{5}^{\prime}$ & & & $\begin{array}{c}0.001 \\
(0.004)\end{array}$ & $\begin{array}{c}0.001 \\
(0.004)\end{array}$ \\
\hline Residuals*individual trust: $-\beta_{5}^{\prime}$ & & & $\begin{array}{c}0.004 * * \\
(0.002)\end{array}$ & $\begin{array}{c}0.004^{* *} \\
(0.002)\end{array}$ \\
\hline Residuals*(avg trust squared): $b^{2} \beta_{6}$ & & & $\begin{array}{c}-0.001 * * \\
(0.000)\end{array}$ & $\begin{array}{c}-0.001 * * * \\
(0.000)\end{array}$ \\
\hline Residuals*(individual trust squared): $\beta_{6}$ & & & $\begin{array}{c}-0.001 * * * \\
(0.000)\end{array}$ & $\begin{array}{c}-0.001 * * * \\
(0.000)\end{array}$ \\
\hline Residuals*(indiv. trust)*(avg. trust): $-2 b \beta_{6}$ & & & $\begin{array}{l}0.001 * * * \\
(0.000)\end{array}$ & $\begin{array}{c}0.001 * * * \\
(0.000)\end{array}$ \\
\hline Income maximizing trust & 8.66 & 8.5 & $\begin{array}{l}\mathbf{6 . 6} \\
\text { for avg trust }=5\end{array}$ & $\begin{array}{c}7.1 \\
\text { for avg trust }=5\end{array}$ \\
\hline $\begin{array}{l}\text { Observations } \\
\text { R-squared }\end{array}$ & $\begin{array}{c}134682 \\
0.65\end{array}$ & 130825 & $\begin{array}{c}130825 \\
0.66\end{array}$ & $\begin{array}{c}130825 \\
0.66\end{array}$ \\
\hline & & First stage & \multicolumn{2}{|c|}{ Trust selection equation } \\
\hline Immigrants trust & & $\begin{array}{c}\text { Trust } \\
0.869^{* * *} \\
(0.003)\end{array}$ & $\begin{array}{c}0.972^{* * *} \\
(0.022)\end{array}$ & $\begin{array}{c}0.973 * * * \\
(0.022)\end{array}$ \\
\hline Immigrants trust sq. & & $\begin{array}{c}0.009 * * * \\
(0.000) \\
\text { Trust } \\
\text { squared }\end{array}$ & & \\
\hline Immigrant trust & & $\begin{array}{c}-1.065^{* * *} \\
(0.032)\end{array}$ & & \\
\hline Immigrant trust sq. & & $\begin{array}{c}0.930^{* * *} \\
(0.003) \\
\end{array}$ & & \\
\hline
\end{tabular}

Notes: [1] Each regression controls for country and wave fixed effects; [2] *** significant at 1\%, ** significant at 5\%, * significant at 10\%. [3] Trust is the answer to the following question: "Generally speaking would you say that most people can be trusted or that you can't be too careful in dealing with people? Please tell me on a score of 0 to 10, where 0 means you can't be too careful and 10 means that most people can be trusted"; [4] Individual controls (in the OLS and the first stage of the heterogeneity regression) include a quadratic in age, gender, immigrant, marital and labor market status, years of education, education of the father and dummies for city size. 


\section{Table 4}

\section{Trust and cheating: Instrumental variable regressions}

\begin{tabular}{|c|c|c|c|c|c|c|}
\hline \multicolumn{7}{|c|}{ PANEL A: Second stage } \\
\hline & $\begin{array}{c}\text { (1) } \\
\text { Bank } \\
\text { insurance }\end{array}$ & $\begin{array}{c}\text { (2) } \\
\text { Second } \\
\text { hand } \\
\text { things }\end{array}$ & $\begin{array}{c}(3) \\
\text { Food }\end{array}$ & $\begin{array}{c}\text { (4) } \\
\text { Plumber, } \\
\text { builder, } \\
\text { mechanic, } \\
\text { repairer }\end{array}$ & $\begin{array}{c}\text { (5) } \\
\text { Times } \\
\text { being } \\
\text { cheated } \\
\text { (sum) }\end{array}$ & $\begin{array}{c}\text { (6) } \\
\text { Being } \\
\text { cheated } \\
\text { (principal } \\
\text { component) }\end{array}$ \\
\hline Trust & $\begin{array}{c}0.740^{* * *} \\
(0.197)\end{array}$ & $\begin{array}{c}0.231^{* *} \\
(0.101)\end{array}$ & $\begin{array}{c}0.560^{* * *} \\
(0.191)\end{array}$ & $\begin{array}{c}0.517 * * * \\
(0.155)\end{array}$ & $\begin{array}{c}2.116^{* * *} \\
(0.567)\end{array}$ & $\begin{array}{c}1.085^{* * * *} \\
(0.290)\end{array}$ \\
\hline Observations & 22253 & 23798 & 24220 & 23626 & 20846 & 20846 \\
\hline
\end{tabular}

PANEL B: First stage

\begin{tabular}{lcccccc}
\hline & $(1)$ & $(2)$ & $(3)$ & $(4)$ & $(5)$ & $(6)$ \\
& Trust & Trust & Trust & Trust & Trust & Trust \\
\hline Trustworthiness & $.0084^{* * *}$ & $.0076^{* * *}$ & $.0080^{* * *}$ & $.0085^{* * *}$ & $.0088^{* * *}$ & $.0088^{* * *}$ \\
& $(.0020)$ & $(.0019)$ & $(.0019)$ & $(.0019)$ & $(.0020)$ & $(.0020)$ \\
Observations & 22253 & 23798 & 24220 & 23626 & 20846 & 20846 \\
F-stat & 18.25 & 16.27 & 17.86 & 19.77 & 18.79 & 18.79 \\
\hline
\end{tabular}

PANEL C: Reduced form

\begin{tabular}{|c|c|c|c|c|c|c|}
\hline & $\begin{array}{c}(1) \\
\text { Bank } \\
\text { insurance }\end{array}$ & $\begin{array}{l}(2) \\
\text { Second } \\
\text { hand } \\
\text { things }\end{array}$ & $\begin{array}{c}(3) \\
\text { Food }\end{array}$ & $\begin{array}{c}\text { (4) } \\
\text { Plumber, } \\
\text { builder, } \\
\text { mechanic, } \\
\text { repairer }\end{array}$ & $\begin{array}{c}(5) \\
\text { Times } \\
\text { being } \\
\text { cheated } \\
\text { (sum) }\end{array}$ & $\begin{array}{c}(6) \\
\text { Being } \\
\text { cheated } \\
\text { (principal } \\
\text { component) }\end{array}$ \\
\hline Trustworthiness & $\begin{array}{c}0.006^{* * *} \\
(0.001)\end{array}$ & $\begin{array}{c}0.002^{* * *} \\
(0.001)\end{array}$ & $\begin{array}{c}0.005^{* * *} \\
(0.001)\end{array}$ & $\begin{array}{c}0.004 * * * \\
(0.001)\end{array}$ & $\begin{array}{c}0.019 * * * \\
(0.002)\end{array}$ & $\begin{array}{c}0.010^{* * *} \\
(0.001)\end{array}$ \\
\hline Observations & 22280 & 23832 & 24252 & 23658 & 20867 & 20867 \\
\hline $\mathrm{R}$-squared & 0.10 & 0.10 & 0.13 & 0.08 & 0.14 & 0.14 \\
\hline \multicolumn{7}{|c|}{$\begin{array}{l}\text { Notes: [1] Each regression controls for country fixed effects and } 8 \text { occupational dummies; [2] *** significant at } 1 \%, * * \\
\text { significant at } 5 \% \text {, * significant at } 10 \% \text {. [3] Trust is the answer to the following question: "Generally speaking would you say } \\
\text { that most people can be trusted or that you can't be too careful in dealing with people? Please tell me on a score of } 0 \text { to } 10 \\
\text { where } 0 \text { means you can't be too careful and } 10 \text { means that most people can be trusted"; [4] Trust is instrumented using the } \\
\text { variable Trustworthiness obtained as the sum of the answers to the following three questions: "I am going to read out a list o } \\
\text { things about your working life. Using this card, please say how much the management at your work allows/allowed you to } \\
\text { 1) decide how your own daily work is/was organized; } 2 \text { ) influence policy decisions about the activities of the organization? } \\
\text { 3) to choose or change your pace of work?" The answer to each question can take values from } 0 \text { (I have/had no influence) } \\
\text { to } 10 \text { (I have/had complete control). [5] The excluded group for father education are people with college or more; the } \\
\text { excluded group for marital status is divorced or widower; the excluded group for labor status are people employed; the } \\
\text { excluded group for city size are people living in a country village, a farm or a home in the countryside. }\end{array}$} \\
\hline
\end{tabular}




\author{
Web Appendix for
}

\title{
The Right Amount of Trust
}

\author{
Jeff Butler \\ EIEF (Rome) \\ Paola Giuliano \\ UCLA, NBER, CEPR and IZA \\ Luigi Guiso \\ EIEF (Rome), CEPR \\ (NOT FOR PUBLICATION)
}

APRIL 2014 


\section{Introduction}

This appendix accompanies "The Right Amount of Trust” by Jeff Butler, Paola Giuliano and Luigi Guiso. Section 2 provides further details of the data used in the paper, as well as their sources. Section 3 reports additional tables discussed in the body of the paper, but not reported explicitly.

\section{Additional details on some of the datasets and their sources}

In this section we describe more in details some of the datasets and variable construction that have not been fully discussed in the body of the paper.

\subsection{European Social Survey}

The central aim of the European Social Survey (ESS) is to gather data about changing values, attitudes, attributes and behavioral patterns within European polities. Academically driven but designed to feed into key European policy debates, the ESS hopes to measure and explain how people's social values, cultural norms and behavior patterns are distributed; the ways in which they differ within and between nations; and the direction and speed at which they are changing.

Data collection takes place every two years, by means of face-to-face interviews lasting around one hour, which are followed by a short supplement. The questionnaire consists of a "core" module lasting about half an hour---which remains relatively constant from round to round--- plus two "rotating" modules, repeated at intervals. Each of these latter modules is devoted to a substantive topic or theme.

The purpose of the rotating modules is to provide an in-depth focus on a series of particular academic or policy concerns, while the core module aims instead at monitoring change or continuity in a wide range of socio-economic, socio-political, socio-psychological and socio-demographic variables.

For the income regressions, we use the five rounds of the ESS (conducted in 2002, 2004, 2006, 2008, 2010) containing the following 32 countries: Austria, Belgium, Bulgaria, Croatia, Cyprus, Czech Republic, Denmark, Estonia, Finland, France, Germany, Greece, Hungary, Iceland, Ireland, Israel, Italy, Latvia, Luxembourg, Netherland, Norway, Poland, Portugal, Romania, Russia, Slovakia, Slovenia, Spain, Sweden, Switzerland, Turkey, UK.

Questions about cheating have been asked only in the second round of the ESS, for that reason for the cheating regressions we use data only on the second round of the ESS, containing the following 26 countries: Austria, Belgium, Switzerland, Czech Republic, Germany, Denmark, Estonia, 
Spain, Finland, France, Great Britain, Greece, Hungary, Ireland, Iceland, Italy, Luxembourg, Netherlands, Norway, Poland, Portugal, Sweden, Slovenia, Slovakia, Turkey, Ukraine.

\section{A. Measuring performances in the ESS}

Each respondent in the ESS is asked to report which income category, identified with a letter, best approximates his or her household's total net income. The values, in euros, are defined according to the following table in the first three rounds.

\begin{tabular}{|l|l|l|l|}
\hline & Approximate weekly & Approximate monthly & Approximate annual \\
\hline $\mathrm{J}$ & Less than 40 & Less than 150 & Less than 1800 \\
\hline $\mathrm{R}$ & 40 to under 70 & 150 to under 300 & 1800 to 3600 \\
\hline $\mathrm{C}$ & 70 to under 120 & 300 to under 500 & 3600 to under 6000 \\
\hline $\mathrm{M}$ & 120 to under 230 & 500 to under 1000 & 6000 to under 12000 \\
\hline $\mathrm{F}$ & 230 to under 350 & 1000 to under 1500 & 12000 to under 18000 \\
\hline $\mathrm{S}$ & 350 to under 460 & 1500 to under 2000 & 18000 to under 24000 \\
\hline $\mathrm{K}$ & 460 to under 580 & 2000 to under 2500 & 24000 to under 30000 \\
\hline $\mathrm{P}$ & 580 to under 690 & 2500 to under 3000 & 30000 to under 36000 \\
\hline $\mathrm{D}$ & 690 to under 1150 & 3000 to under 5000 & 36000 to under 60000 \\
\hline H & 1150 to under 1730 & 5000 to under 7500 & 60000 to under 90000 \\
\hline U & 1730 to under 2310 & 7500 to under 10000 & 90000 to under 120000 \\
\hline N & 2310 or more & 10000 or more & 120000 or more \\
\hline
\end{tabular}

In rounds 4 and 5 a different method of measuring household income has been introduced. The categories are national categories based on deciles of the actual household income range in the given country. The deciles are derived from the best source for the country. Possible sources for the calculation of deciles used in the ESS are national register data, or representative countrywide surveys (for example the EU-SILC). The deciles are reported in national currency and the conversion rate to Euro is documented.

A show card with the 10 deciles is used in each country. The ten rows on the show card display the income ranges selected and be presented by the 10 letters which helps to ensure respondent confidentiality. The show card is similar to the one reported above for the first 3 rounds but with 10 categories instead of 12 . Each country can choose whether to include weekly, monthly, 
or annual amounts on the show card or whether they want to include more than one of these as appropriate.

For all the waves we convert all responses to their annual equivalent. To facilitate our analysis we identify each bracket with its mid-point. The last bracket for the top income is coded in a country specific way. In particular, to code the last income bracket, we use a variety of surveys. For most of the countries in our sample, we use the EU-SILC dataset; data for Switzerland and Turkey (the only two countries not covered by EU-SILC) have been obtained from the Luxembourg Income Study and the income and Living Condition Use Survey, respectively.

\section{B. Additional details on some of the independent variables}

Risk aversion and altruism. Our measures of risk aversion and altruism rely on questions eliciting attitudes on various domains by asking participants how a certain description applies to them. Respondents were asked the following question: "I will briefly describe some people. Please listen to each description and tell me how much each person is or is not like you." To obtain an indicator of risk attitudes we use the following description: "She/he looks for adventures and likes to take risks. She/he wants to have an exciting life." To obtain an indicator of altruism we rely on the following description: "It is important to her/him to be loyal to her/his friends. She/he wants to devote herself/himself to people close to her/him." For these questions, respondents provide answers between 1 and 6, with 1 meaning "very much like me," 6 meaning "Not like me at all" and values in between reflecting intermediate similarity. Thus higher values of the risk preference indicator signal high risk aversion and higher values of the altruistic preferences measure mean less altruism. In all of the analysis in the paper, we re-order responses to these questions so that higher values indicate higher risk tolerance and more altruism, respectively.

Religiosity. The question asks the respondent how religious he/she is. The question goes from "not at all religious" (0) to "very religious" (10).

Political ideology. The question asks the respondent his/her political ideology from left (0) to right (10).

Other measures of trust. The survey contains information on the following measures of trust, coded from "not trust at all" (0) to "complete trust" (10): trust in the legal system, trust in parliament, trust in the police, trust in politicians, trust in political parties and trust in the United Nations. 
Measure of trustworthiness in the cheating regressions and in Table A6. In the cheating regressions, trustworthiness is a measure of how much responsibility is delegated to individuals by their supervisors at work. Specifically, the ESS asks individuals to state, on a scale from zero to 10, how much latitude their manager grants them along three different dimensions. In particular, the survey asks: "Please say how much the management at your work allows/allowed you: a) ... to decide how your own daily work is/was organized; b) ... to influence policy decisions about the activities of the organization; c) ... to choose or change your pace of work". We construct a single measure of how much authority individuals' managers grant them on the job. This measure is called trustworthiness_b in the descriptive statistics. We also use the three disaggregated measures in Table A6.

Measure of trustworthiness in the income regressions. The income regressions also control for a measure of trustworthiness. This measure, called trustworthiness_a is the sum of only two of the three questions included in the trustsworthiness_ $b$ measure (on how work should be organized daily and on whether the person is able to influence policy decisions). The reason for doing that is that the question on choosing or change pace at work in only asked in the second round of the ESS, and we will therefore loose four waves of our sample.

\subsection{SOM, Sweden}

The SOM survey is a nationwide survey carried on in Sweden from the SOM Institute, a research and conference center studying Society, Opinion and Media at Goteborg University ${ }^{1}$. The survey collects information on politics, society, the use of media, public service, the environment, risks, new media technology and leisure-time activities. Starting from 1996, individuals were also asked the extent to which they believe that in general other people can be trusted. The trust question is asked, like in the ESS, on a scale from 0 to 10. We use all the years from 1996 to 2009.

Measuring performance in the SOM. The dependent variable is the log of household income before taxes (the definition includes pensions and study allowance). The variable is defined in brackets (there are 10 income brackets for the period between 1996 and 1998, 8 income brackets for the period between 1999 and 2007, and 9 income brackets for the 2008-2009 period). We assign the mid-point to each income bracket and correct for inflation. The brackets for the different years are reported below:

\footnotetext{
${ }^{1}$ The SOM Institute is jointly managed by the Institute for Journalism and Mass Communication, the Department of Political Science, and the School of Public Administration.
} 


\begin{tabular}{|l|l|l|l|}
\hline & From 1996 to 1998 & From 1999 to 2007 & From 2008 to 2009 \\
\hline 1 & Less than 100,000 & Less than 100,000 & Less than 100,000 \\
\hline 2 & $101,000-150,000$ & $101,000-200,000$ & $101,000-200,000$ \\
\hline 3 & $151,000-200,000$ & $201,000-300,000$ & $201,000-300,000$ \\
\hline 4 & $201,000-250,000$ & $301,000-400,000$ & $301,000-400,000$ \\
\hline 5 & $251,000-300,000$ & $401,000-500,000$ & $401,000-500,000$ \\
\hline 6 & $301,000-350,000$ & $501,000-600,000$ & $501,000-600,000$ \\
\hline 7 & $351,000-400,000$ & $601,000-700,000$ & $601,000-700,000$ \\
\hline 8 & $401,000-450,000$ & More than 700,000 & $701,000-800,000$ \\
\hline 9 & $451,000-500,000$ & & More than 800,000 \\
\hline 10 & More than 500,000 & & \\
\hline
\end{tabular}

\section{Additional details on some of the independent variables}

Risk aversion: "How often during the last 12 months have you gambled on sports, lotto (football, horses, etc)". The answer could take the following values: never (1), some time every year (2), some time every half a year (3), some time every quarter of a year (4), some time every month (5), some time every week (6), several times a week (7).

Rural and urban areas: we include dummies for "smaller conurbation", "city or bigger conurbation", and "Stockolm, Goteborg, Malmo". The excluded group is "rural area".

\section{Additional Tables and Figures}


Table A1

Descriptive Statistics

\begin{tabular}{|c|c|c|c|c|c|}
\hline \multicolumn{6}{|c|}{ A. European Social Survey } \\
\hline Variable & Mean & St. dev. & Variable & Mean & St. dev. \\
\hline Log income & 9.716 & 1.072 & Treated equally & 4.936 & 1.019 \\
\hline Age & 45.309 & 17.966 & Helping others & 3.843 & 0.792 \\
\hline Male & 0.476 & 0.499 & Choose pace at work & 5.734 & 3.611 \\
\hline Immigrant & 0.084 & 0.278 & Decide daily work & 6.160 & 3.490 \\
\hline Married & 0.552 & 0.497 & Influence policy decision & 4.041 & 3.601 \\
\hline Father primary education & 0.373 & 0.484 & Trustworthiness_a & 10.204 & 6.407 \\
\hline Unemployed & 0.047 & 0.212 & Trustworthiness_b & 16.237 & 9.398 \\
\hline Out of labor force & 0.519 & 0.500 & Religiosity & 4.585 & 2.953 \\
\hline Years of education & 12.182 & 4.127 & Left-right scale & 5.121 & 2.184 \\
\hline Big city & 0.331 & 0.471 & Trust & 5.097 & 2.489 \\
\hline Small city & 0.306 & 0.461 & 'Trust (immigrants' distribution) & 13.998 & 7.916 \\
\hline Partner primary education & 0.125 & 0.331 & Trust legal & 5.218 & 2.629 \\
\hline Mother primary education & 0.412 & 0.492 & Trust parliament & 4.594 & 2.537 \\
\hline Number of household members & 3.084 & 1.230 & Trust police & 5.973 & 2.547 \\
\hline Professionals & 0.138 & 0.345 & Trust politicians & 3.680 & 2.352 \\
\hline Technicians & 0.161 & 0.368 & Trust political parties & 3.681 & 2.329 \\
\hline Clerks & 0.110 & 0.313 & Trust United Nations & 5.324 & 2.490 \\
\hline Workers & 0.144 & 0.351 & Cheated: Bank & 1.508 & 0.905 \\
\hline Agricultural workers & 0.039 & 0.194 & Cheated: Second hand goods & 1.359 & 0.780 \\
\hline Mechan., repairers, textile work. & 0.134 & 0.341 & Cheated: Food & 2.045 & 1.419 \\
\hline Assemblers, operators, drivers & 0.078 & 0.269 & Cheated: Plumber, repairer & 1.617 & 0.995 \\
\hline Labourers, elementary occ. & 0.103 & 0.304 & Cheated (sum) & 2.486 & 2.754 \\
\hline Risk aversion & 3.034 & 1.412 & Cheated (princ. comp.) & 0.107 & 1.381 \\
\hline Altruism & 5.078 & 0.871 & Residuals (column 3, Table 4) & 0.054 & 2.104 \\
\hline People helpful & 4.897 & 2.325 & Residuals (column 4, Table 4) & 0.040 & 2.081 \\
\hline \multicolumn{6}{|c|}{ B. SOM Survey, Sweden } \\
\hline Log(income) & 12.546 & 0.652 & Women & 0.502 & 0.500 \\
\hline Trust & 6.464 & 2.246 & Unemployed & 0.043 & 0.202 \\
\hline Age & 47.723 & 17.510 & Out of labor force & 0.351 & 0.477 \\
\hline Married & 0.520 & 0.500 & Up to high school degree & 0.439 & 0.496 \\
\hline Smaller conurbation & 0.235 & 0.424 & University or higher & 0.313 & 0.464 \\
\hline City or bigger conurbation & 0.455 & 0.498 & Risk aversion & 3.264 & 2.176 \\
\hline Stockholm, Goterborg, Malmo & 0.149 & 0.356 & & & \\
\hline
\end{tabular}


Table A2

Distribution of trust, ESS Survey

\begin{tabular}{lccc}
\hline Trust & Freq. & Percent & Cum. \\
\hline 0 & 9,755 & 6.00 & 6.00 \\
1 & 7,067 & 4.35 & 10.34 \\
2 & 10,963 & 6.74 & 17.08 \\
3 & 16,467 & 10.13 & 27.21 \\
4 & 14,958 & 9.20 & 36.41 \\
5 & 31,955 & 19.65 & 56.05 \\
6 & 16,976 & 10.44 & 66.49 \\
7 & 24,832 & 15.27 & 81.76 \\
8 & 20,583 & 12.66 & 94.42 \\
9 & 5,683 & 3.49 & 97.91 \\
10 & 3,397 & 2.09 & 100.00 \\
Total & 162,636 & 100.00 & \\
\hline \hline
\end{tabular}

Table A3

Distribution of trust, SOM Survey, Sweden

\begin{tabular}{lccc}
\hline \hline Trust & Freq. & Percent & Cum. \\
\hline 0 & 729 & 1.87 & 1.87 \\
1 & 453 & 1.16 & 3.03 \\
2 & 1,147 & 2.94 & 5.97 \\
3 & 2,120 & 5.44 & 11.41 \\
4 & 2,041 & 5.23 & 16.64 \\
5 & 6,379 & 16.36 & 33.01 \\
6 & 3,545 & 9.09 & 42.10 \\
7 & 7,509 & 19.26 & 61.36 \\
8 & 9,295 & 23.84 & 85.19 \\
9 & 3,070 & 7.87 & 93.07 \\
10 & 2,703 & 6.93 & 100.00 \\
Total & 38,991 & 100.00 & \\
\hline \hline
\end{tabular}


Table A4

The relationship between trust and income

\begin{tabular}{|c|c|c|c|c|}
\hline Dependent variable: $\log ($ income $)$ & $\begin{array}{c}(1) \\
\text { OLS }\end{array}$ & $\begin{array}{c}(3) \\
\text { OLS }\end{array}$ & $\begin{array}{l}(4) \\
\text { OLS }\end{array}$ & $\begin{array}{c}5) \\
\text { OLS }\end{array}$ \\
\hline Trust 1 & $\begin{array}{l}-0.003 \\
(0.013)\end{array}$ & $\begin{array}{c}0.004 \\
(0.015)\end{array}$ & $\begin{array}{l}-0.003 \\
(0.013)\end{array}$ & $\begin{array}{l}-0.004 \\
(0.013)\end{array}$ \\
\hline Trust 2 & $\begin{array}{c}0.044^{* * *} * \\
(0.012)\end{array}$ & $\begin{array}{c}0.041 * * * \\
(0.014)\end{array}$ & $\begin{array}{c}0.040^{* * *} \\
(0.012)\end{array}$ & $\begin{array}{c}0.042 * * * \\
(0.012)\end{array}$ \\
\hline Trust 3 & $\begin{array}{c}0.070^{* * *} \\
(0.011)\end{array}$ & $\begin{array}{c}0.070^{* * *} \\
(0.013)\end{array}$ & $\begin{array}{c}0.060^{* * *} \\
(0.011)\end{array}$ & $\begin{array}{c}0.068^{* * *} \\
(0.011)\end{array}$ \\
\hline Trust 4 & $\begin{array}{c}0.073 * * * \\
(0.011)\end{array}$ & $\begin{array}{c}0.059 * * * \\
(0.013)\end{array}$ & $\begin{array}{c}0.060^{* * *} \\
(0.011)\end{array}$ & $\begin{array}{c}0.070^{* * *} \\
(0.011)\end{array}$ \\
\hline Trust 5 & $\begin{array}{c}0.083^{* * *} \\
(0.010)\end{array}$ & $\begin{array}{c}0.071 * * * \\
(0.012)\end{array}$ & $\begin{array}{c}0.069^{* * *} \\
(0.010)\end{array}$ & $\begin{array}{c}0.081 * * * \\
(0.010)\end{array}$ \\
\hline Trust 6 & $\begin{array}{c}0.117 * * * \\
(0.011)\end{array}$ & $\begin{array}{c}0.106^{* * *} \\
(0.012)\end{array}$ & $\begin{array}{c}0.097 * * * \\
(0.011)\end{array}$ & $\begin{array}{c}0.114 * * * \\
(0.011)\end{array}$ \\
\hline Trust 7 & $\begin{array}{c}0.140^{* * * *} \\
(0.010)\end{array}$ & $\begin{array}{c}0.134 * * * \\
(0.012)\end{array}$ & $\begin{array}{c}0.116^{* * *} \\
(0.010)\end{array}$ & $\begin{array}{c}0.136 * * * \\
(0.010)\end{array}$ \\
\hline Trust 8 & $\begin{array}{c}0.139 * * * \\
(0.011)\end{array}$ & $\begin{array}{c}0.128^{* * *} \\
(0.012)\end{array}$ & $\begin{array}{c}0.113^{* * *} \\
(0.011)\end{array}$ & $\begin{array}{c}0.136^{* * *} \\
(0.011)\end{array}$ \\
\hline Trust 9 & $\begin{array}{c}0.138^{* * *} \\
(0.014)\end{array}$ & $\begin{array}{c}0.140^{* * *} \\
(0.015)\end{array}$ & $\begin{array}{c}0.115^{* * *} \\
(0.014)\end{array}$ & $\begin{array}{c}0.136^{* * *} \\
(0.014)\end{array}$ \\
\hline Trust 10 & $\begin{array}{c}0.067 * * * \\
(0.017)\end{array}$ & $\begin{array}{c}0.071^{* * *} \\
(0.021)\end{array}$ & $\begin{array}{c}0.056^{* * *} \\
(0.017)\end{array}$ & $\begin{array}{c}0.066^{* * *} \\
(0.017)\end{array}$ \\
\hline Age & $\begin{array}{c}-0.002^{* *} \\
(0.001)\end{array}$ & & $\begin{array}{c}-0.001 * \\
(0.001)\end{array}$ & $\begin{array}{c}-0.002^{* *} \\
(0.001)\end{array}$ \\
\hline Age squared & $\begin{array}{c}-0.000 * * * \\
(0.000)\end{array}$ & & $\begin{array}{c}-0.000 * * * \\
(0.000)\end{array}$ & $\begin{array}{c}-0.000^{* * *} \\
(0.000)\end{array}$ \\
\hline Male & $\begin{array}{c}0.041^{* * *} \\
(0.004)\end{array}$ & $\begin{array}{c}-0.009 * \\
(0.005)\end{array}$ & $\begin{array}{c}0.040^{* * *} \\
(0.004)\end{array}$ & $\begin{array}{c}0.041^{* * *} \\
(0.004)\end{array}$ \\
\hline Immigrant & $\begin{array}{c}-0.098^{* * *} \\
(0.007)\end{array}$ & $\begin{array}{c}-0.091 * * * \\
(0.008)\end{array}$ & $\begin{array}{c}-0.097 * * * \\
(0.008)\end{array}$ & $\begin{array}{c}-0.097 * * * \\
(0.007)\end{array}$ \\
\hline Married & $\begin{array}{c}0.367 * * * \\
(0.004)\end{array}$ & $\begin{array}{c}0.033^{* * *} \\
(0.007)\end{array}$ & $\begin{array}{c}0.366^{* * *} \\
(0.004)\end{array}$ & $\begin{array}{c}0.366^{* * *} * \\
(0.004)\end{array}$ \\
\hline Father primary & $\begin{array}{c}-0.095^{* * *} \\
(0.005)\end{array}$ & $\begin{array}{c}-0.049 * * * \\
(0.007)\end{array}$ & $\begin{array}{c}-0.095^{* * *} \\
(0.005)\end{array}$ & $\begin{array}{c}-0.095^{* * *} \\
(0.005)\end{array}$ \\
\hline Unemployed & $\begin{array}{c}-0.515^{* * *} \\
(0.011)\end{array}$ & $\begin{array}{c}-0.481 * * * \\
(0.014)\end{array}$ & $\begin{array}{c}-0.510^{* * *} \\
(0.011)\end{array}$ & $\begin{array}{c}-0.514 * * * \\
(0.011)\end{array}$ \\
\hline Out of labor force & $\begin{array}{c}-0.175^{* * *} \\
(0.005)\end{array}$ & $\begin{array}{c}-0.126^{* * *} \\
(0.006)\end{array}$ & $\begin{array}{c}-0.175^{* * *} \\
(0.005)\end{array}$ & $\begin{array}{c}-0.174 * * * \\
(0.005)\end{array}$ \\
\hline Years of education & $\begin{array}{c}0.036^{* * * *} \\
(0.001)\end{array}$ & $\begin{array}{c}0.014 * * \\
(0.006)\end{array}$ & $\begin{array}{c}0.035^{* * *} \\
(0.001)\end{array}$ & $\begin{array}{c}0.035^{* * *} \\
(0.001)\end{array}$ \\
\hline Big city & $\begin{array}{c}0.082^{* * *} \\
(0.005)\end{array}$ & $\begin{array}{c}0.130^{* * *} \\
(0.006)\end{array}$ & $\begin{array}{c}0.081 \text { *** } \\
(0.005)\end{array}$ & $\begin{array}{c}0.082^{* * *} \\
(0.005)\end{array}$ \\
\hline Small city & $\begin{array}{c}0.022^{* * *} \\
(0.005)\end{array}$ & $\begin{array}{c}0.052^{* * *} \\
(0.005)\end{array}$ & $\begin{array}{c}0.022^{* * *} \\
(0.005)\end{array}$ & $\begin{array}{c}0.022^{* * *} \\
(0.005)\end{array}$ \\
\hline Risk tolerance & $\begin{array}{c}0.015^{* * *} \\
(0.002)\end{array}$ & $\begin{array}{c}0.016^{* * *} \\
(0.002)\end{array}$ & $\begin{array}{c}0.015^{* * *} \\
(0.002)\end{array}$ & \\
\hline Altruism & $\begin{array}{c}0.001 \\
(0.002)\end{array}$ & $\begin{array}{c}0.004 \\
(0.003)\end{array}$ & $\begin{array}{c}0.001 \\
(0.002)\end{array}$ & $\begin{array}{c}0.002 \\
(0.002)\end{array}$ \\
\hline Trustworthiness & $\begin{array}{c}0.011^{* * *} * \\
(0.000)\end{array}$ & $\begin{array}{c}0.009^{* * *} \\
(0.000)\end{array}$ & $\begin{array}{c}0.011^{* * *} * \\
(0.000)\end{array}$ & $\begin{array}{c}0.011^{* * *} \\
(0.000)\end{array}$ \\
\hline
\end{tabular}




\begin{tabular}{|c|c|c|c|c|}
\hline Risk tolerance 2 & & & & $\begin{array}{c}0.029 * * * \\
(0.006)\end{array}$ \\
\hline Risk tolerance 3 & & & & $\begin{array}{c}0.059 * * * \\
(0.007)\end{array}$ \\
\hline Risk tolerance 4 & & & & $\begin{array}{c}0.067 * * * \\
(0.007)\end{array}$ \\
\hline Risk tolerance 5 & & & & $\begin{array}{c}0.070^{* * *} \\
(0.008)\end{array}$ \\
\hline Risk tolerance 6 & & & & $\begin{array}{c}0.061^{* * *} \\
(0.011)\end{array}$ \\
\hline Trust legal 1 & & & $\begin{array}{c}0.023^{*} \\
(0.013)\end{array}$ & \\
\hline Trust legal 2 & & & $\begin{array}{c}0.051 * * * \\
(0.011)\end{array}$ & \\
\hline Trust legal 3 & & & $\begin{array}{c}0.054 * * * \\
(0.010)\end{array}$ & \\
\hline Trust legal 4 & & & $\begin{array}{c}0.069 * * * \\
(0.011)\end{array}$ & \\
\hline Trust legal 5 & & & $\begin{array}{c}0.056^{* * * *} \\
(0.010)\end{array}$ & \\
\hline Trust legal 6 & & & $\begin{array}{c}0.096 * * * \\
(0.010)\end{array}$ & \\
\hline Trust legal 7 & & & $\begin{array}{c}0.104 * * * \\
(0.010)\end{array}$ & \\
\hline Trust legal 8 & & & $\begin{array}{c}0.108 * * * \\
(0.010)\end{array}$ & \\
\hline Trust legal 9 & & & $\begin{array}{c}0.121 * * * \\
(0.012)\end{array}$ & \\
\hline Trust legal 10 & & & $\begin{array}{l}0.028^{*} \\
(0.015)\end{array}$ & \\
\hline Mother primary education & & $\begin{array}{c}-0.042 * * * \\
(0.007)\end{array}$ & & \\
\hline Partner primary education & & $\begin{array}{c}-0.183^{* * *} \\
(0.008)\end{array}$ & & \\
\hline Number of household members & & $\begin{array}{c}0.039 * * * \\
(0.002)\end{array}$ & & \\
\hline Age dummies & & yes & & \\
\hline Education dummies*country dummies & & yes & & \\
\hline Observations & 102298 & 64404 & 100449 & 102298 \\
\hline R-squared & 0.67 & 0.72 & 0.67 & 0.67 \\
\hline
\end{tabular}

Notes: [1] Each regression controls for country and wave fixed effects; [2] *** significant at 1\%, ** significant at 5\%, * significant at $10 \%$. [3] Trust is the answer to the following question: "Generally speaking would you say that most people can be trusted or that you can't be too careful in dealing with people? Please tell me on a score of 0 to 10, where 0 means you can't be too careful and 10 means that most people can be trusted"; [4] Individual controls in column (1) include a quadratic in age, gender, immigrant, marital and labor market status, years of education, education of the father, dummies for city size and measures of risk aversion, altruism and trustworthiness. The variables are described on p. 4 and p. 6 of the on line appendix. Additional controls in column (3) are a full set of age dummies, a full set of education dummies and their interactions with country dummies, mother's and partner's education and the number of people living at home. Column (4) includes 10 dummies for trust in the legal system; whereas column (5) controls for a measure of moderation, using dummies for risk aversion. 
Table A5

Heckman selection model (corresponding to column 2 of Table 1 in the paper)

\begin{tabular}{|c|c|c|}
\hline & $\begin{array}{c}\text { (1) } \\
\log (\text { income) }\end{array}$ & $\begin{array}{c}(2) \\
\text { Selection }\end{array}$ \\
\hline Trust 1 & $\begin{array}{c}0.002 \\
(0.014)\end{array}$ & $\begin{array}{c}0.016 \\
(0.023)\end{array}$ \\
\hline Trust 2 & $\begin{array}{c}0.054 * * * \\
(0.013)\end{array}$ & $\begin{array}{c}0.045^{* *} \\
(0.021)\end{array}$ \\
\hline Trust 3 & $\begin{array}{c}0.094^{* * *} \\
(0.012)\end{array}$ & $\begin{array}{c}0.082^{* * *} \\
(0.020)\end{array}$ \\
\hline Trust 4 & $\begin{array}{c}0.102^{* * *} \\
(0.013)\end{array}$ & $\begin{array}{c}0.103^{* * *} \\
(0.021)\end{array}$ \\
\hline Trust 5 & $\begin{array}{c}0.107 * * * \\
(0.011)\end{array}$ & $\begin{array}{c}0.080^{* * *} \\
(0.018)\end{array}$ \\
\hline Trust 6 & $\begin{array}{c}0.159 * * * \\
(0.013)\end{array}$ & $\begin{array}{c}0.142 * * * \\
(0.021)\end{array}$ \\
\hline Trust 7 & $\begin{array}{c}0.176^{* * *} \\
(0.013)\end{array}$ & $\begin{array}{c}0.135^{* * *} \\
(0.020)\end{array}$ \\
\hline Trust 8 & $\begin{array}{c}0.184^{* * *} \\
(0.014)\end{array}$ & $\begin{array}{c}0.175^{* * *} \\
(0.021)\end{array}$ \\
\hline Trust 9 & $\begin{array}{c}0.174 * * * \\
(0.017)\end{array}$ & $\begin{array}{c}0.134 * * * \\
(0.030)\end{array}$ \\
\hline Trust 10 & $\begin{array}{c}0.092^{* * * *} \\
(0.019)\end{array}$ & $\begin{array}{c}0.083 * * \\
(0.036)\end{array}$ \\
\hline Age & $\begin{array}{c}0.005^{* *} \\
(0.001)\end{array}$ & $\begin{array}{c}0.029 * * * \\
(0.001)\end{array}$ \\
\hline Age squared & $\begin{array}{c}-0.000^{* * *} \\
(0.000)\end{array}$ & $\begin{array}{c}-0.000^{* * *} \\
(0.000)\end{array}$ \\
\hline Male & $\begin{array}{c}0.052^{* * *} \\
(0.005)\end{array}$ & $\begin{array}{c}0.052^{* * *} \\
(0.009)\end{array}$ \\
\hline Immigrant & $\begin{array}{c}-0.098^{* * *} \\
(0.009)\end{array}$ & $\begin{array}{c}0.014 \\
(0.016)\end{array}$ \\
\hline Married & $\begin{array}{c}0.365^{* * *} \\
(0.005)\end{array}$ & $\begin{array}{l}-0.014 \\
(0.009)\end{array}$ \\
\hline Father primary education & $\begin{array}{c}-0.081 * * * \\
(0.006)\end{array}$ & $\begin{array}{c}0.049 * * * \\
(0.011)\end{array}$ \\
\hline Unemployed & $\begin{array}{c}-0.521 * * * \\
(0.011)\end{array}$ & $\begin{array}{l}-0.018 \\
(0.019)\end{array}$ \\
\hline Out of labor force & $\begin{array}{c}-0.173^{* * *} \\
(0.006)\end{array}$ & $\begin{array}{c}0.026^{* * *} \\
(0.010)\end{array}$ \\
\hline Years of education & $\begin{array}{c}0.037 * * * \\
(0.001)\end{array}$ & $\begin{array}{c}0.005^{* * *} \\
(0.001)\end{array}$ \\
\hline Big city & $\begin{array}{c}0.093 * * * \\
(0.006)\end{array}$ & $\begin{array}{c}0.031 * * * \\
(0.011)\end{array}$ \\
\hline Small city & $\begin{array}{c}0.033^{* * *} \\
(0.006)\end{array}$ & $\begin{array}{c}0.046^{* * *} \\
(0.010)\end{array}$ \\
\hline Risk aversion & $\begin{array}{c}0.015^{* * *} \\
(0.002)\end{array}$ & $\begin{array}{l}-0.001 \\
(0.003)\end{array}$ \\
\hline Altruism & $\begin{array}{l}-0.001 \\
(0.003)\end{array}$ & $\begin{array}{l}-0.002 \\
(0.005)\end{array}$ \\
\hline
\end{tabular}




\begin{tabular}{lcc}
\hline Trustworthiness & $0.010^{* * *}$ & $-0.002^{* * *}$ \\
& $(0.000)$ & $(0.001)$ \\
Distance from the filing taxes month & & $-0.006^{* * *}$ \\
& & $(0.001)$ \\
Inverse Mills ratio & $0.652^{* * *}$ & \\
& $(0.101)$ & \\
Observations & 96782 & 96782 \\
\hline \hline
\end{tabular}

Notes: [1] Each regression controls for country and wave fixed effects; [2] *** significant at $1 \%,{ }^{* *}$ significant at $5 \%,{ }^{*}$ significant at $10 \%$. [3] Trust is the answer to the following question: "Generally speaking would you say that most people can be trusted or that you can't be too careful in dealing with people? Please tell me on a score of 0 to 10 , where 0 means you can't be too careful and 10 means that most people can be trusted". 


\section{Table A6}

\section{Trust and income, controlling for regional dummies}

\begin{tabular}{lcccc}
\hline \hline Dependent var.: Log (income) & $(1)$ & $(3)$ & $(4)$ & $(5)$ \\
& OLS & OLS & OLS & OLS \\
\hline Trust 1 & -0.004 & -0.003 & -0.014 & -0.005 \\
& $(0.017)$ & $(0.016)$ & $(0.017)$ & $(0.017)$ \\
Trust 2 & $0.082^{* * *}$ & $0.032^{* *}$ & $0.057^{* * *}$ & $0.081^{* * *}$ \\
& $(0.015)$ & $(0.014)$ & $(0.015)$ & $(0.015)$ \\
Trust 3 & $0.135^{* * *}$ & $0.059^{* * *}$ & $0.096^{* * *}$ & $0.133^{* * *}$ \\
& $(0.013)$ & $(0.013)$ & $(0.014)$ & $(0.013)$ \\
Trust 4 & $0.165^{* * *}$ & $0.048^{* * *}$ & $0.116^{* * *}$ & $0.162^{* * *}$ \\
& $(0.014)$ & $(0.013)$ & $(0.014)$ & $(0.014)$ \\
Trust 5 & $0.199^{* * *}$ & $0.060^{* * *}$ & $0.141^{* * *}$ & $0.196^{* * *}$ \\
& $(0.012)$ & $(0.012)$ & $(0.013)$ & $(0.012)$ \\
Trust 6 & $0.272^{* * *}$ & $0.090^{* * *}$ & $0.193^{* * *}$ & $0.268^{* * *}$ \\
& $(0.013)$ & $(0.013)$ & $(0.014)$ & $(0.013)$ \\
Trust 7 & $0.329^{* * *}$ & $0.119^{* * *}$ & $0.234^{* * *}$ & $0.326^{* * *}$ \\
& $(0.013)$ & $(0.012)$ & $(0.013)$ & $(0.013)$ \\
Trust 8 & $0.349^{* * *}$ & $0.113^{* * *}$ & $0.243^{* * *}$ & $0.347^{* * *}$ \\
& $(0.013)$ & $(0.013)$ & $(0.014)$ & $(0.013)$ \\
Trust 9 & $0.341^{* * *}$ & $0.128^{* * *}$ & $0.237^{* * *}$ & $0.338^{* * *}$ \\
& $(0.018)$ & $(0.016)$ & $(0.018)$ & $(0.018)$ \\
Trust 10 & $0.191^{* * *}$ & $0.060^{* * *}$ & $0.120^{* * *}$ & $0.190^{* * *}$ \\
& $(0.022)$ & $(0.022)$ & $(0.022)$ & $(0.022)$ \\
Individual controls & yes & yes & yes & yes \\
Altruism, risk avers., trustworthiness & yes & yes & yes & yes \\
Additional controls & no & yes & no & no \\
Trust legal system (10 dum.) & no & no & yes & no \\
Controlling for moderation & no & no & no & yes \\
Observations & 91231 & 57505 & 89594 & 91231 \\
R-squared & 0.55 & 0.52 & 0.56 & 0.55 \\
Trust peak = Trust 2 (p-values) & 0.00 & 0.00 & 0.00 & 0.00 \\
Trust peak = Trust 10 (p-values) & 0.00 & 0.00 & 0.00 & 0.00 \\
\hline \hline
\end{tabular}

Notes: [1] Each regression controls for wave fixed effects; [2] *** significant at 1\%,** significant at $5 \%,{ }^{*}$ significant at $10 \%$. [3] Trust is the answer to the following question: "Generally speaking would you say that most people can be trusted or that you can't be too careful in dealing with people? Please tell me on a score of 0 to 10 , where 0 means you can't be too careful and 10 means that most people can be trusted"; [4] Individual controls in column (1) include a quadratic in age, gender, immigrant, marital and labor market status, years of education, education of the father, dummies for city size, measures of risk aversion, altruism and trustworthiness. The variables are described on p. 4 and p. 6 of the on line appendix. Additional controls in column (3) are a full set of age dummies, a full set of education dummies and their interactions with country dummies, mother's and partner's education and the number of people living at home. Column (4) includes 10 dummies for trust in the legal system, whereas column (5) controls for moderation with the inclusions of dummies for risk aversion. 
Table A7

Trust and income, controlling for other measures of trust

\begin{tabular}{lccccc}
\hline \hline Dependent variable: Log(income) & $(1)$ & $(2)$ & $(3)$ & $(4)$ & $(5)$ \\
\hline Trust 1 & -0.004 & -0.005 & -0.009 & -0.008 & -0.000 \\
& $(0.013)$ & $(0.013)$ & $(0.013)$ & $(0.013)$ & $(0.014)$ \\
Trust 2 & $0.034^{* * *}$ & $0.035^{* * *}$ & $0.034^{* * *}$ & $0.036^{* * *}$ & $0.040^{* * *}$ \\
& $(0.012)$ & $(0.012)$ & $(0.012)$ & $(0.012)$ & $(0.012)$ \\
Trust 3 & $0.051^{* * *}$ & $0.055^{* * *}$ & $0.054^{* * *}$ & $0.056^{* * *}$ & $0.055^{* * *}$ \\
& $(0.011)$ & $(0.011)$ & $(0.011)$ & $(0.011)$ & $(0.011)$ \\
Trust 4 & $0.050^{* * *}$ & $0.057^{* * *}$ & $0.053^{* * *}$ & $0.055^{* * *}$ & $0.055^{* * *}$ \\
& $(0.011)$ & $(0.011)$ & $(0.011)$ & $(0.011)$ & $(0.012)$ \\
Trust 5 & $0.062^{* * *}$ & $0.069^{* * *}$ & $0.066^{* * *}$ & $0.067^{* * *}$ & $0.068^{* * *}$ \\
& $(0.010)$ & $(0.010)$ & $(0.010)$ & $(0.010)$ & $(0.011)$ \\
Trust 6 & $0.087^{* * *}$ & $0.096^{* * *}$ & $0.092^{* * *}$ & $0.094^{* * *}$ & $0.092^{* * *}$ \\
& $(0.011)$ & $(0.011)$ & $(0.011)$ & $(0.011)$ & $(0.011)$ \\
Trust 7 & $0.107^{* * *}$ & $0.118^{* * *}$ & $0.114^{* * *}$ & $0.117^{* * *}$ & $0.114^{* * *}$ \\
& $(0.010)$ & $(0.010)$ & $(0.010)$ & $(0.010)$ & $(0.011)$ \\
Trust 8 & $0.108^{* * *}$ & $0.120^{* * *}$ & $0.114^{* * *}$ & $0.118^{* * *}$ & $0.115^{* * *}$ \\
& $(0.011)$ & $(0.011)$ & $(0.011)$ & $(0.011)$ & $(0.011)$ \\
Trust 9 & $0.105^{* * *}$ & $0.116^{* * *}$ & $0.111^{* * *}$ & $0.116^{* * *}$ & $0.112^{* * *}$ \\
& $(0.014)$ & $(0.014)$ & $(0.014)$ & $(0.014)$ & $(0.014)$ \\
Trust 10 & $0.059^{* * *}$ & $0.066^{* * *}$ & $0.057^{* * *}$ & $0.061^{* * *}$ & $0.054^{* * *}$ \\
& $(0.017)$ & $(0.017)$ & $(0.017)$ & $(0.017)$ & $(0.018)$ \\
Trust parliament & yes & & & & \\
Trust police & & yes & & & \\
Trust politicians & & & & & yes \\
Trust political parties & & & & & yes \\
Trust united nations & 104300 & 105276 & 104712 & 104221 & 97282 \\
Observations & 0.67 & 0.67 & 0.67 & 0.67 & 0.65 \\
R-squared & & & & & \\
\hline \hline
\end{tabular}

Notes: [1] Each regression controls for country and wave fixed effects; [2] *** significant at 1\%, ** significant at $5 \%$, * significant at 10\%. [2] Individual controls include a quadratic in age, gender, immigrant, marital and labor market status, years of education, education of the father and dummies for city size. 
Table A8

Trust and income, controlling for moderation

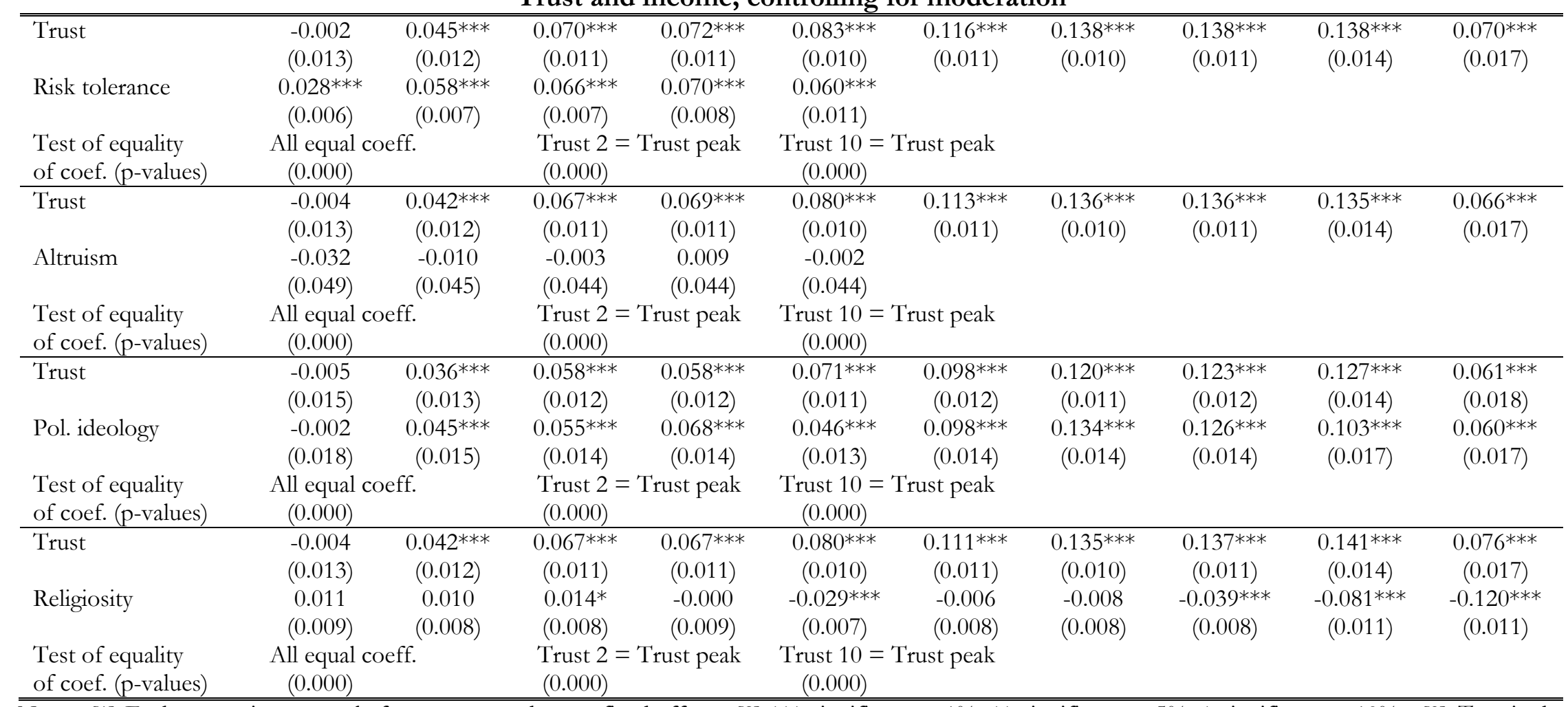

Notes: [1] Each regression controls for country and wave fixed effects; [2] *** significant at 1\%, ** significant at 5\%, $*$ significant at $10 \%$. [3] Trust is the answer to the following question: "Generally speaking would you say that most people can be trusted or that you can't be too careful in dealing with people? Please tell me on a score of 0 to 10, where 0 means you can't be too careful and 10 means that most people can be trusted"; [4] Individual controls include a quadratic in age, gender, immigrant, marital and labor market status, years of education, education of the father and dummies for city size. 
Table A9

Variance of income and trust

\begin{tabular}{lcc}
\hline \hline & $(1)$ & $(2)$ \\
& St. dev. income & St. dev. income \\
\hline Trust & $212.410^{* * *}$ & $272.714 * * *$ \\
& $(79.724)$ & $(64.653)$ \\
Country fixed effects & Yes & yes \\
Wave fixed effects & No & yes \\
Observations & 363 & 1199 \\
R-squared & 0.89 & 0.75 \\
\hline \hline$* * *$ significant at $1 \%, * *$ significant at $5 \%, *$ significant at $10 \%$.
\end{tabular}

Table A10

Differences in means for observable characteristics between individuals reporting 10 and the median person in each country

\begin{tabular}{lcc}
\hline \hline & $\begin{array}{c}\text { Difference } \\
\text { in means }\end{array}$ & p-value \\
\hline Age & 5.735 & 0.000 \\
Male & -0.054 & 0.003 \\
Immigrant & 0.022 & 0.127 \\
Married & -0.023 & 0.240 \\
Father primary educ. & 0.01 & 0.799 \\
Unemployed & -0.01 & 0.071 \\
Years of education & -0.285 & 0.353 \\
Big city & -0.005 & 0.781 \\
Small city & -0.005 & 0.755 \\
Risk aversion & 0.061 & 0.416 \\
Trustworthiness & 0.613 & 0.154 \\
\hline \hline
\end{tabular}


Table A11

The relationship between trust and income in low, average and high trust countries

\begin{tabular}{|c|c|c|c|c|c|c|}
\hline Dependent variable: $\log$ (inc.) & $\begin{array}{c}(1) \\
\text { Low trust }\end{array}$ & $\begin{array}{c}(2) \\
\text { Aver. trust }\end{array}$ & $\begin{array}{c}\text { (3) } \\
\text { High trust }\end{array}$ & $\begin{array}{c}(4) \\
\text { Low trust }\end{array}$ & $\begin{array}{c}\text { (5) } \\
\text { Aver. trust }\end{array}$ & $\begin{array}{c}(6) \\
\text { High trust }\end{array}$ \\
\hline Trust 1 & $\begin{array}{l}-0.019 \\
(0.021)\end{array}$ & $\begin{array}{c}0.013 \\
(0.021)\end{array}$ & $\begin{array}{c}0.002 \\
(0.029)\end{array}$ & & & \\
\hline Trust 2 & $\begin{array}{c}0.027 \\
(0.020)\end{array}$ & $\begin{array}{c}0.039 * * \\
(0.018)\end{array}$ & $\begin{array}{c}0.061^{* * *} \\
(0.023)\end{array}$ & & & \\
\hline Trust 3 & $\begin{array}{c}0.074 * * * \\
(0.019)\end{array}$ & $\begin{array}{c}0.053^{* * *} \\
(0.017)\end{array}$ & $\begin{array}{c}0.078^{* * *} \\
(0.021)\end{array}$ & & & \\
\hline Trust 4 & $\begin{array}{c}0.064^{* * *} * \\
(0.021)\end{array}$ & $\begin{array}{c}0.076^{* * *} * \\
(0.017)\end{array}$ & $\begin{array}{c}0.068^{* * *} * \\
(0.021)\end{array}$ & & & \\
\hline Trust 5 & $\begin{array}{c}0.083 * * * \\
(0.018)\end{array}$ & $\begin{array}{c}0.087 * * * \\
(0.016)\end{array}$ & $\begin{array}{c}0.073 * * * \\
(0.020)\end{array}$ & & & \\
\hline Trust 6 & $\begin{array}{c}0.127 * * * \\
(0.023)\end{array}$ & $\begin{array}{c}0.131^{* * *} \\
(0.018)\end{array}$ & $\begin{array}{c}0.106^{* * *} \\
(0.020)\end{array}$ & & & \\
\hline Trust 7 & $\begin{array}{c}0.129 * * * \\
(0.022)\end{array}$ & $\begin{array}{c}0.142^{* * *} \\
(0.017)\end{array}$ & $\begin{array}{c}0.137 * * * \\
(0.019)\end{array}$ & & & \\
\hline Trust 8 & $\begin{array}{c}0.099 * * * \\
(0.024)\end{array}$ & $\begin{array}{c}0.154 * * * \\
(0.019)\end{array}$ & $\begin{array}{c}0.138^{* * *} \\
(0.020)\end{array}$ & & & \\
\hline Trust 9 & $\begin{array}{c}0.051 \\
(0.037)\end{array}$ & $\begin{array}{c}0.148 * * * \\
(0.031)\end{array}$ & $\begin{array}{c}0.147 * * * \\
(0.022)\end{array}$ & & & \\
\hline Trust 10 & $\begin{array}{l}0.064^{*} \\
(0.038)\end{array}$ & $\begin{array}{c}0.039 \\
(0.038)\end{array}$ & $\begin{array}{c}0.076^{* * * *} \\
(0.026)\end{array}$ & & & \\
\hline Trust & & & & $\begin{array}{c}0.036^{* * *} \\
(0.007)\end{array}$ & $\begin{array}{c}0.032 * * * \\
(0.006)\end{array}$ & $\begin{array}{c}0.033^{* * *} \\
(0.005)\end{array}$ \\
\hline Trust squared & & & & $\begin{array}{c}-0.003 * * * \\
(0.001)\end{array}$ & $\begin{array}{c}-0.002^{* * *} \\
(0.001)\end{array}$ & $\begin{array}{c}-0.002 * * * \\
(0.000)\end{array}$ \\
\hline Optimal trust & & & & 6 & 8 & 8.25 \\
\hline Observations & 16777 & 30497 & 55024 & 16777 & 30497 & 55024 \\
\hline R-squared & 0.63 & 0.56 & 0.47 & 0.63 & 0.56 & 0.47 \\
\hline
\end{tabular}

The specification for each column corresponds to the one of column 1, Table 2. Low trust countries are Bulgaria, Cyprus, Greece, Romania, Russia, Slovenia, Slovakia and Turkey. Average trust countries are: Croatia, Czech Republic, France, Germany, Hungary, Italy, Latvia, Lithuania, Poland and Portugal. High trust countries are Austria, Belgium, Denmark, Estonia, Finland, Great Britain, Ireland, Israel, Island, Luxembourg, Netherlands, Norway, Spain, Sweden, Switzerland. 
Table A12

The relationship between trust and income, SOM survey, Sweden

\begin{tabular}{|c|c|}
\hline Dependent variable: $\log$ (income) & (1) \\
\hline Trust 1 & $\begin{array}{c}0.038 \\
(0.041)\end{array}$ \\
\hline Trust 2 & $\begin{array}{c}0.170^{* * *} \\
(0.032)\end{array}$ \\
\hline Trust 3 & $\begin{array}{c}0.205^{* * *} \\
(0.029)\end{array}$ \\
\hline Trust 4 & $\begin{array}{c}0.222^{* * *} \\
(0.029)\end{array}$ \\
\hline Trust 5 & $\begin{array}{c}0.210^{* * *} \\
(0.027)\end{array}$ \\
\hline Trust 6 & $\begin{array}{c}0.275^{* * *} \\
(0.028)\end{array}$ \\
\hline Trust 7 & $\begin{array}{c}0.295^{* * *} \\
(0.027)\end{array}$ \\
\hline Trust 8 & $\begin{array}{c}0.319 \text { *** } \\
(0.027)\end{array}$ \\
\hline Trust 9 & $\begin{array}{c}0.337 * * * \\
(0.028)\end{array}$ \\
\hline Trust 10 & $\begin{array}{c}0.260^{* * *} \\
(0.028)\end{array}$ \\
\hline Age & $\begin{array}{c}0.010^{* * *} \\
(0.001)\end{array}$ \\
\hline Age squared & $\begin{array}{c}-0.000^{* * *} \\
(0.000)\end{array}$ \\
\hline Married & $\begin{array}{c}0.336^{* * *} \\
(0.006)\end{array}$ \\
\hline Smaller conurbation & $\begin{array}{c}0.049 * * * \\
(0.009)\end{array}$ \\
\hline City or bigger conurbation & $\begin{array}{c}0.028^{* * *} \\
(0.008)\end{array}$ \\
\hline Stockolm, Gotenborg, Malmo & $\begin{array}{c}-0.048^{* * *} \\
(0.012)\end{array}$ \\
\hline Female & $\begin{array}{c}-0.089 * * * \\
(0.006)\end{array}$ \\
\hline Non-Swedish citizen & $\begin{array}{c}-0.208^{* * *} \\
(0.020)\end{array}$ \\
\hline Unemployed & $\begin{array}{c}-0.409 * * * \\
(0.018)\end{array}$ \\
\hline Out of labor force & $\begin{array}{c}-0.391 \text { *** } \\
(0.010)\end{array}$ \\
\hline Up to high school & $\begin{array}{c}0.197 * * * \\
(0.008)\end{array}$ \\
\hline University or higher & $\begin{array}{c}0.258^{* * *} \\
(0.008)\end{array}$ \\
\hline
\end{tabular}


Risk tolerance

Observations

$0.005^{* * *}$

$(0.001)$

38991

R-squared

0.29

Notes: [1] Each regression controls for region and year of interview fixed effects; [2] *** significant at 1\%, ** significant at $5 \%, *$ significant at $10 \%$. [3] Trust is the answer to the following question: "In your opinion, to what extent can one trust people in general?" The answers go from "Cannot trust people in general" (0) to "Can trust people in general" (10). 
Table A13

SOM survey, Sweden: Splitting the sample according to observables

\begin{tabular}{|c|c|c|c|c|c|c|}
\hline Dependent variable: $\log$ (inc.) & $(1)$ & $(2)$ & (3) & $(4)$ & $(5)$ & $(6)$ \\
\hline & $\begin{array}{l}\text { Up to high } \\
\text { school }\end{array}$ & $\begin{array}{l}\text { More than } \\
\text { high school }\end{array}$ & Employed & $\begin{array}{c}\text { Unemployed, } \\
\text { out of the } \\
\text { labor force }\end{array}$ & Entrepreneurs & $\begin{array}{c}\text { White } \\
\text { collars, } \\
\text { workers, } \\
\text { farmers }\end{array}$ \\
\hline \multirow[t]{2}{*}{ Trust 1} & 0.038 & 0.005 & 0.077 & -0.001 & -0.106 & 0.028 \\
\hline & $(0.044)$ & $(0.102)$ & $(0.052)$ & $(0.062)$ & $(0.168)$ & $(0.045)$ \\
\hline \multirow[t]{2}{*}{ Trust 2} & $0.170 * * *$ & $0.193^{* *}$ & $0.181 * * *$ & $0.153^{* * *}$ & 0.117 & $0.141^{* * *}$ \\
\hline & $(0.034)$ & $(0.080)$ & $(0.040)$ & $(0.049)$ & $(0.111)$ & $(0.034)$ \\
\hline \multirow[t]{2}{*}{ Trust 3} & $0.206^{* * *}$ & $0.239 * * *$ & $0.213^{* * *}$ & $0.194 * * *$ & 0.126 & $0.168^{* * *}$ \\
\hline & $(0.031)$ & $(0.075)$ & $(0.038)$ & $(0.043)$ & $(0.104)$ & $(0.031)$ \\
\hline \multirow[t]{2}{*}{ Trust 4} & $0.215^{* * *}$ & $0.274^{* * *}$ & $0.225^{* * *}$ & $0.218^{* * *}$ & $0.190^{*}$ & $0.193^{* * *}$ \\
\hline & $(0.031)$ & $(0.075)$ & $(0.038)$ & $(0.043)$ & $(0.107)$ & $(0.031)$ \\
\hline \multirow[t]{2}{*}{ Trust 5} & $0.224 * * *$ & $0.203^{* * *}$ & $0.222 * * *$ & $0.198^{* * *}$ & 0.143 & $0.191^{* * *}$ \\
\hline & $(0.029)$ & $(0.072)$ & $(0.036)$ & $(0.039)$ & $(0.096)$ & $(0.029)$ \\
\hline \multirow[t]{2}{*}{ Trust 6} & $0.287 * * *$ & $0.290 * * *$ & $0.278^{* * *}$ & $0.273^{* * *}$ & $0.197 * *$ & $0.242^{* * *}$ \\
\hline & $(0.030)$ & $(0.072)$ & $(0.036)$ & $(0.041)$ & $(0.098)$ & $(0.029)$ \\
\hline \multirow[t]{2}{*}{ Trust 7} & $0.317 * * *$ & $0.289 * * *$ & $0.291 * * *$ & $0.304 * * *$ & $0.226 * *$ & $0.261 * * *$ \\
\hline & $(0.029)$ & $(0.071)$ & $(0.036)$ & $(0.039)$ & $(0.096)$ & $(0.029)$ \\
\hline \multirow[t]{2}{*}{ Trust 8} & $0.338^{* * *}$ & $0.312^{* * *}$ & $0.312^{* * *}$ & $0.328^{* * *}$ & $0.282^{* * *}$ & $0.282^{* * *}$ \\
\hline & $(0.029)$ & $(0.070)$ & $(0.035)$ & $(0.038)$ & $(0.094)$ & $(0.028)$ \\
\hline \multirow[t]{2}{*}{ Trust 9} & $0.342^{* * *}$ & $0.340 * * *$ & $0.329 * * *$ & $0.347 * * *$ & $0.282^{* * *}$ & $0.300 * * *$ \\
\hline & $(0.031)$ & $(0.071)$ & $(0.036)$ & $(0.043)$ & $(0.100)$ & $(0.029)$ \\
\hline \multirow[t]{2}{*}{ Trust 10} & $0.264 * * *$ & $0.277 * * *$ & $0.284 * * *$ & $0.224 * * *$ & $0.230 * *$ & $0.233^{* * *}$ \\
\hline & $(0.031)$ & $(0.072)$ & $(0.037)$ & $(0.041)$ & $(0.099)$ & $(0.030)$ \\
\hline Observations & 26805 & 12186 & 23633 & 15358 & 2635 & 31377 \\
\hline R-squared & 0.25 & 0.39 & 0.20 & 0.13 & 0.28 & 0.33 \\
\hline
\end{tabular}

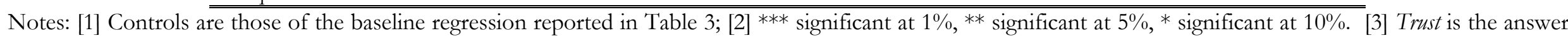

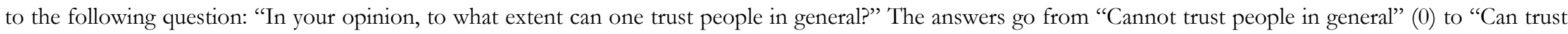
people in general" (10). 
Table A13, continued:

SOM survey, Sweden: splitting the sample according to observables

\begin{tabular}{|c|c|c|c|c|c|c|c|c|}
\hline Dependent variable: $\log$ (inc.) & (1) & (2) & (3) & (4) & (5) & (6) & (7) & (8) \\
\hline & $\begin{array}{l}\text { Low risk } \\
\text { aversion }\end{array}$ & $\begin{array}{l}\text { High risk } \\
\text { aversion }\end{array}$ & Citizen & $\begin{array}{c}\text { Not } \\
\text { citizen }\end{array}$ & $\begin{array}{l}\text { Grew up } \\
\text { in } \\
\text { Sweden }\end{array}$ & $\begin{array}{c}\text { Grew up } \\
\text { outside } \\
\text { Sweden }\end{array}$ & Men & Women \\
\hline Trust 1 & $\begin{array}{c}0.079 \\
(0.059)\end{array}$ & $\begin{array}{c}0.047 \\
(0.054)\end{array}$ & $\begin{array}{c}0.039 \\
(0.042)\end{array}$ & $\begin{array}{c}0.035 \\
(0.194)\end{array}$ & $\begin{array}{c}0.025 \\
(0.043)\end{array}$ & $\begin{array}{l}-0.080 \\
(0.120)\end{array}$ & $\begin{array}{c}0.085 \\
(0.056)\end{array}$ & $\begin{array}{l}-0.013 \\
(0.060)\end{array}$ \\
\hline Trust 2 & $\begin{array}{c}0.186 * * * \\
(0.047)\end{array}$ & $\begin{array}{c}0.199 * * * \\
(0.043)\end{array}$ & $\begin{array}{c}0.180 * * * \\
(0.032)\end{array}$ & $\begin{array}{l}-0.021 \\
(0.161)\end{array}$ & $\begin{array}{c}0.157 * * * \\
(0.033)\end{array}$ & $\begin{array}{l}-0.007 \\
(0.118)\end{array}$ & $\begin{array}{c}0.203^{* * *} \\
(0.043)\end{array}$ & $\begin{array}{c}0.133^{* * *} * \\
(0.047)\end{array}$ \\
\hline Trust 3 & $\begin{array}{c}0.219 * * * \\
(0.042)\end{array}$ & $\begin{array}{c}0.234 * * * \\
(0.039)\end{array}$ & $\begin{array}{c}0.208^{* * *} \\
(0.029)\end{array}$ & $\begin{array}{c}0.125 \\
(0.139)\end{array}$ & $\begin{array}{c}0.175^{* * *} \\
(0.030)\end{array}$ & $\begin{array}{c}0.202^{* *} \\
(0.102)\end{array}$ & $\begin{array}{c}0.237 * * * \\
(0.040)\end{array}$ & $\begin{array}{c}0.169 * * * \\
(0.042)\end{array}$ \\
\hline Trust 4 & $\begin{array}{c}0.254 * * * \\
(0.042)\end{array}$ & $\begin{array}{c}0.234 * * * \\
(0.040)\end{array}$ & $\begin{array}{c}0.226 * * * \\
(0.029)\end{array}$ & $\begin{array}{c}0.165 \\
(0.142)\end{array}$ & $\begin{array}{c}0.202^{* * *} \\
(0.030)\end{array}$ & $\begin{array}{c}0.211^{* *} \\
(0.102)\end{array}$ & $\begin{array}{c}0.245^{* * *} \\
(0.040)\end{array}$ & $\begin{array}{c}0.195^{* * *} \\
(0.042)\end{array}$ \\
\hline Trust 5 & $\begin{array}{c}0.242^{* * *} \\
(0.039)\end{array}$ & $\begin{array}{c}0.225^{* * *} \\
(0.037)\end{array}$ & $\begin{array}{c}0.215^{* * *} \\
(0.027)\end{array}$ & $\begin{array}{c}0.063 \\
(0.128)\end{array}$ & $\begin{array}{c}0.190^{* * *} \\
(0.028)\end{array}$ & $\begin{array}{c}0.098 \\
(0.092)\end{array}$ & $\begin{array}{c}0.232 * * * \\
(0.037)\end{array}$ & $\begin{array}{c}0.186 * * * \\
(0.039)\end{array}$ \\
\hline Trust 6 & $\begin{array}{c}0.321 * * * \\
(0.040)\end{array}$ & $\begin{array}{c}0.276^{* * *} \\
(0.038)\end{array}$ & $\begin{array}{c}0.279 * * * \\
(0.028)\end{array}$ & $\begin{array}{c}0.192 \\
(0.139)\end{array}$ & $\begin{array}{c}0.247 * * * \\
(0.029)\end{array}$ & $\begin{array}{c}0.207 * * \\
(0.103)\end{array}$ & $\begin{array}{c}0.276 * * * \\
(0.038)\end{array}$ & $\begin{array}{c}0.271 * * * \\
(0.040)\end{array}$ \\
\hline Trust 7 & $\begin{array}{c}0.343^{* * *} \\
(0.038)\end{array}$ & $\begin{array}{c}0.290^{* * *} \\
(0.037)\end{array}$ & $\begin{array}{c}0.296^{* * *} \\
(0.027)\end{array}$ & $\begin{array}{l}0.249 * \\
(0.128)\end{array}$ & $\begin{array}{c}0.257 * * * \\
(0.028)\end{array}$ & $\begin{array}{c}0.294 * * * \\
(0.094)\end{array}$ & $\begin{array}{c}0.306^{* * *} * \\
(0.037)\end{array}$ & $\begin{array}{c}0.281 * * * \\
(0.039)\end{array}$ \\
\hline Trust 8 & $\begin{array}{c}0.360^{* * *} \\
(0.038)\end{array}$ & $\begin{array}{c}0.327 * * * \\
(0.037)\end{array}$ & $\begin{array}{c}0.320^{* * *} * \\
(0.027)\end{array}$ & $\begin{array}{c}0.273^{* *} \\
(0.128)\end{array}$ & $\begin{array}{c}0.280^{* * *} \\
(0.028)\end{array}$ & $\begin{array}{c}0.263^{* * *} \\
(0.094)\end{array}$ & $\begin{array}{c}0.343^{* * *} * \\
(0.037)\end{array}$ & $\begin{array}{c}0.292^{* * *} \\
(0.038)\end{array}$ \\
\hline Trust 9 & $\begin{array}{c}0.385^{* * *} \\
(0.039)\end{array}$ & $\begin{array}{c}0.330^{* * *} \\
(0.039)\end{array}$ & $\begin{array}{c}0.338^{* * *} * \\
(0.028)\end{array}$ & $\begin{array}{c}0.318^{* *} \\
(0.148)\end{array}$ & $\begin{array}{c}0.299 * * * \\
(0.029)\end{array}$ & $\begin{array}{l}0.214^{*} \\
(0.122)\end{array}$ & $\begin{array}{c}0.342^{* * *} \\
(0.038)\end{array}$ & $\begin{array}{c}0.326^{* * *} \\
(0.040)\end{array}$ \\
\hline Trust 10 & $\begin{array}{c}0.318^{* * *} \\
(0.040)\end{array}$ & $\begin{array}{c}0.237^{* * *} \\
(0.039)\end{array}$ & $\begin{array}{c}0.264^{* * *} \\
(0.028)\end{array}$ & $\begin{array}{c}0.145 \\
(0.144)\end{array}$ & $\begin{array}{c}0.225^{* * *} \\
(0.029)\end{array}$ & $\begin{array}{c}0.181 \\
(0.117)\end{array}$ & $\begin{array}{c}0.282^{* * *} \\
(0.039)\end{array}$ & $\begin{array}{c}0.243^{* * *} \\
(0.040)\end{array}$ \\
\hline Observations & 21048 & 18712 & 37768 & 1223 & 36098 & 1710 & 19414 & 19577 \\
\hline R-squared & 0.28 & 0.32 & 0.29 & 0.26 & 0.29 & 0.23 & 0.28 & 0.30 \\
\hline
\end{tabular}

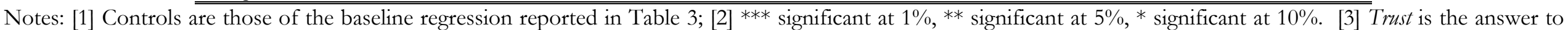

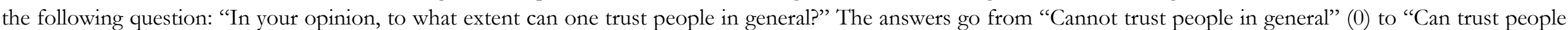

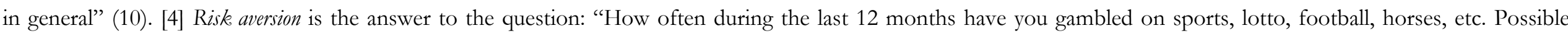

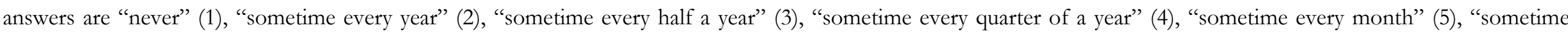
every week" (6), "several times a week" (7). Low risk aversion includes all values from 1 to 3 . High risk aversion, values higher than 3. 
Table A13, continued:

SOM survey, Sweden: splitting the sample according to observables

\begin{tabular}{|c|c|c|c|c|c|c|c|c|c|c|}
\hline Dependent variable: $\log$ (inc.) & $(1)$ & $(2)$ & (3) & (4) & (5) & $(6)$ & $(7)$ & $(8)$ & $(9)$ & $(10)$ \\
\hline & Young & Old & Married & Not married & Rural & Urban & Region 1 & Region 2 & Region 3 & Region4 \\
\hline \multirow[t]{2}{*}{ Trust 1} & 0.019 & 0.047 & 0.011 & 0.053 & 0.045 & 0.037 & 0.138 & $0.227^{*}$ & 0.232 & -0.026 \\
\hline & $(0.062)$ & $(0.051)$ & $(0.052)$ & $(0.059)$ & $(0.060)$ & $(0.055)$ & $(0.096)$ & $(0.126)$ & $(0.169)$ & $(0.050)$ \\
\hline \multirow[t]{2}{*}{ Trust 2} & $0.179 * * *$ & $0.146^{* * *}$ & $0.116^{* * *}$ & $0.198^{* * *}$ & $0.161 * * *$ & $0.193^{* * *}$ & $0.252 * * *$ & 0.145 & $0.290^{*}$ & $0.150 * * *$ \\
\hline & $(0.048)$ & $(0.039)$ & $(0.042)$ & $(0.045)$ & $(0.048)$ & $(0.042)$ & $(0.080)$ & $(0.108)$ & $(0.149)$ & $(0.037)$ \\
\hline \multirow[t]{2}{*}{ Trust 3} & $0.236^{* * *}$ & $0.166^{* * *}$ & $0.136 * * *$ & $0.244^{* * *}$ & $0.194^{* * *}$ & $0.225^{* * *}$ & $0.308^{* * *}$ & $0.217 * *$ & $0.382 * * *$ & $0.168^{* * *}$ \\
\hline & $(0.045)$ & $(0.035)$ & $(0.037)$ & $(0.042)$ & $(0.044)$ & $(0.038)$ & $(0.074)$ & $(0.092)$ & $(0.142)$ & $(0.034)$ \\
\hline \multirow[t]{2}{*}{ Trust 4} & $0.246^{* * *}$ & $0.186^{* * *}$ & $0.136 * * *$ & $0.273^{* * *}$ & $0.189^{* * *}$ & $0.250 * * *$ & $0.365^{* * *}$ & $0.237 * * *$ & $0.361^{* *}$ & $0.179 * * *$ \\
\hline & $(0.045)$ & $(0.035)$ & $(0.037)$ & $(0.042)$ & $(0.044)$ & $(0.038)$ & $(0.073)$ & $(0.092)$ & $(0.144)$ & $(0.034)$ \\
\hline \multirow[t]{2}{*}{ Trust 5} & $0.228^{* * *}$ & $0.184 * * *$ & $0.156^{* * *}$ & $0.246^{* * *}$ & $0.191^{* * *}$ & $0.233^{* * *}$ & $0.311 * * *$ & $0.216^{* *}$ & $0.352^{* *}$ & $0.179 * * *$ \\
\hline & $(0.043)$ & $(0.032)$ & $(0.034)$ & $(0.039)$ & $(0.041)$ & $(0.035)$ & $(0.069)$ & $(0.085)$ & $(0.137)$ & $(0.032)$ \\
\hline \multirow[t]{2}{*}{ Trust 6} & $0.319 * * *$ & $0.217 * * *$ & $0.215^{* * *}$ & $0.309 * * *$ & $0.258^{* * *}$ & $0.299 * * *$ & $0.420^{* * *}$ & $0.266^{* * *}$ & $0.400 * * *$ & $0.236^{* * *}$ \\
\hline & $(0.044)$ & $(0.033)$ & $(0.035)$ & $(0.041)$ & $(0.042)$ & $(0.036)$ & $(0.070)$ & $(0.087)$ & $(0.140)$ & $(0.033)$ \\
\hline \multirow[t]{2}{*}{ Trust 7} & $0.326^{* * *}$ & $0.255^{* * *}$ & $0.245^{* * *}$ & $0.321 * * *$ & $0.271 * * *$ & $0.322^{* * *}$ & $0.428^{* * *}$ & $0.313^{* * *}$ & $0.450 * * *$ & $0.252^{* * *}$ \\
\hline & $(0.042)$ & $(0.032)$ & $(0.034)$ & $(0.039)$ & $(0.041)$ & $(0.035)$ & $(0.068)$ & $(0.084)$ & $(0.136)$ & $(0.031)$ \\
\hline \multirow[t]{2}{*}{ Trust 8} & $0.350 * * *$ & $0.278^{* * *}$ & $0.257 * * *$ & $0.360^{* * *}$ & $0.296^{* * *}$ & $0.345^{* * *}$ & $0.460 * * *$ & $0.332^{* * *}$ & $0.448^{* * *}$ & $0.277 * * *$ \\
\hline & $(0.042)$ & $(0.032)$ & $(0.034)$ & $(0.039)$ & $(0.041)$ & $(0.035)$ & $(0.067)$ & $(0.083)$ & $(0.135)$ & $(0.031)$ \\
\hline \multirow[t]{2}{*}{ Trust 9} & $0.350 * * *$ & $0.303^{* * *}$ & $0.276^{* * *}$ & $0.367^{* * *}$ & $0.286^{* * *}$ & $0.377 * * *$ & $0.495^{* * *}$ & $0.355^{* * *}$ & $0.443^{* * *}$ & $0.289 * * *$ \\
\hline & $(0.044)$ & $(0.033)$ & $(0.035)$ & $(0.041)$ & $(0.043)$ & $(0.036)$ & $(0.069)$ & $(0.087)$ & $(0.140)$ & $(0.033)$ \\
\hline \multirow[t]{2}{*}{ Trust 10} & $0.314^{* * *}$ & $0.217 * * *$ & $0.219 * * *$ & $0.271 * * *$ & $0.205^{* * *}$ & $0.304^{* * *}$ & $0.410^{* * *}$ & $0.273^{* * *}$ & $0.431 * * *$ & $0.214^{* * *}$ \\
\hline & $(0.045)$ & $(0.033)$ & $(0.035)$ & $(0.042)$ & $(0.043)$ & $(0.036)$ & $(0.070)$ & $(0.089)$ & $(0.141)$ & $(0.033)$ \\
\hline Observations & 19799 & 19192 & 20281 & 18710 & 15436 & 23555 & 7132 & 3658 & 2165 & 26036 \\
\hline R-squared & 0.22 & 0.42 & 0.38 & 0.19 & 0.28 & 0.31 & 0.28 & 0.31 & 0.33 & 0.28 \\
\hline
\end{tabular}

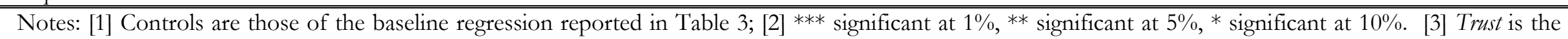

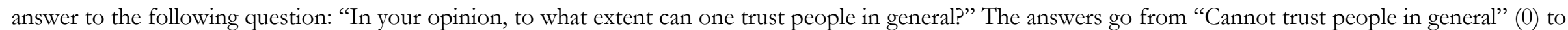
"Can trust people in general" (10). [4] "Old" include all people older than 48. 
Table A14

Trust and Cheating, IV Regressions, Robustness to the Inclusion of Additional Controls

\begin{tabular}{|c|c|c|c|c|c|c|}
\hline & $\begin{array}{c}(1) \\
\text { Bank } \\
\text { insurance }\end{array}$ & $\begin{array}{c}\text { (2) } \\
\text { Second } \\
\text { hand } \\
\text { things }\end{array}$ & $\begin{array}{c}(3) \\
\text { Food }\end{array}$ & $\begin{array}{c}\text { (4) } \\
\text { Plumber, } \\
\text { builder, } \\
\text { mechanic, } \\
\text { repairer }\end{array}$ & $\begin{array}{c}5) \\
\text { Times } \\
\text { being } \\
\text { cheated } \\
\text { (sum) }\end{array}$ & $\begin{array}{c}(6) \\
\text { Being } \\
\text { cheated } \\
\text { (principal } \\
\text { component) }\end{array}$ \\
\hline Trust & $\begin{array}{c}0.601 * * * \\
(0.197)\end{array}$ & $\begin{array}{c}0.087 \\
(0.090)\end{array}$ & $\begin{array}{c}0.499 * * \\
(0.194)\end{array}$ & $\begin{array}{c}0.361 * * * \\
(0.137)\end{array}$ & $\begin{array}{c}1.754 * * * \\
(0.574)\end{array}$ & $\begin{array}{c}0.887 * * * \\
(0.290)\end{array}$ \\
\hline Age & $\begin{array}{c}0.017 * * * \\
(0.004)\end{array}$ & $\begin{array}{c}-0.005^{* *} \\
(0.002)\end{array}$ & $\begin{array}{c}0.015^{* * *} \\
(0.004)\end{array}$ & $\begin{array}{c}0.012 * * * \\
(0.003)\end{array}$ & $\begin{array}{c}0.033^{* *} \\
(0.014)\end{array}$ & $\begin{array}{c}0.016^{* *} \\
(0.007)\end{array}$ \\
\hline Age squared & $\begin{array}{c}-0.000 * * * \\
(0.000)\end{array}$ & $\begin{array}{l}-0.000 \\
(0.000)\end{array}$ & $\begin{array}{c}-0.000 * * * \\
(0.000)\end{array}$ & $\begin{array}{c}-0.000^{* * *} \\
(0.000)\end{array}$ & $\begin{array}{c}-0.001 * * * \\
(0.000)\end{array}$ & $\begin{array}{c}-0.000^{* * *} \\
(0.000)\end{array}$ \\
\hline Male & $\begin{array}{c}0.085^{* * *} \\
(0.029)\end{array}$ & $\begin{array}{c}0.095^{* * *} \\
(0.013)\end{array}$ & $\begin{array}{c}-0.209 * * * \\
(0.029)\end{array}$ & $\begin{array}{c}0.087 * * * \\
(0.022)\end{array}$ & $\begin{array}{c}0.036 \\
(0.089)\end{array}$ & $\begin{array}{c}0.063 \\
(0.045)\end{array}$ \\
\hline Immigrant & $\begin{array}{c}0.032 \\
(0.045)\end{array}$ & $\begin{array}{l}0.041^{*} \\
(0.022)\end{array}$ & $\begin{array}{c}0.019 \\
(0.047)\end{array}$ & $\begin{array}{l}0.062^{*} \\
(0.036)\end{array}$ & $\begin{array}{c}0.139 \\
(0.141)\end{array}$ & $\begin{array}{c}0.077 \\
(0.071)\end{array}$ \\
\hline Married & $\begin{array}{c}-0.139 * * * \\
(0.052)\end{array}$ & $\begin{array}{c}-0.046^{* *} \\
(0.023)\end{array}$ & $\begin{array}{c}-0.091 * \\
(0.053)\end{array}$ & $\begin{array}{c}-0.139 * * * \\
(0.038)\end{array}$ & $\begin{array}{c}-0.472 * * * \\
(0.162)\end{array}$ & $\begin{array}{c}-0.246^{* * * *} \\
(0.082)\end{array}$ \\
\hline Single & $\begin{array}{c}-0.245^{* * *} \\
(0.060)\end{array}$ & $\begin{array}{l}-0.016 \\
(0.027)\end{array}$ & $\begin{array}{c}-0.211^{* * * *} \\
(0.061)\end{array}$ & $\begin{array}{c}-0.214 * * * \\
(0.044)\end{array}$ & $\begin{array}{c}-0.711 * * * \\
(0.179)\end{array}$ & $\begin{array}{c}-0.359^{* * *} \\
(0.090)\end{array}$ \\
\hline Years of educ. & $\begin{array}{l}-0.013 \\
(0.010)\end{array}$ & $\begin{array}{l}-0.002 \\
(0.005)\end{array}$ & $\begin{array}{l}-0.005 \\
(0.010)\end{array}$ & $\begin{array}{l}-0.006 \\
(0.007)\end{array}$ & $\begin{array}{l}-0.035 \\
(0.029)\end{array}$ & $\begin{array}{l}-0.018 \\
(0.015)\end{array}$ \\
\hline Father primary & $\begin{array}{l}0.161^{*} \\
(0.083)\end{array}$ & $\begin{array}{l}-0.013 \\
(0.038)\end{array}$ & $\begin{array}{c}0.074 \\
(0.082)\end{array}$ & $\begin{array}{c}0.011 \\
(0.059)\end{array}$ & $\begin{array}{c}0.241 \\
(0.230)\end{array}$ & $\begin{array}{c}0.127 \\
(0.116)\end{array}$ \\
\hline Father secondary & $\begin{array}{c}0.098 \\
(0.065)\end{array}$ & $\begin{array}{l}-0.017 \\
(0.031)\end{array}$ & $\begin{array}{l}-0.004 \\
(0.063)\end{array}$ & $\begin{array}{c}0.016 \\
(0.048)\end{array}$ & $\begin{array}{c}0.143 \\
(0.187)\end{array}$ & $\begin{array}{c}0.076 \\
(0.095)\end{array}$ \\
\hline Unemployed & $\begin{array}{c}0.154^{* *} \\
(0.073)\end{array}$ & $\begin{array}{l}0.069 * \\
(0.036)\end{array}$ & $\begin{array}{c}0.214 * * * \\
(0.077)\end{array}$ & $\begin{array}{l}0.105^{*} \\
(0.055)\end{array}$ & $\begin{array}{c}0.502^{* *} \\
(0.214)\end{array}$ & $\begin{array}{c}0.248^{* *} \\
(0.108)\end{array}$ \\
\hline Out of labor force & $\begin{array}{c}0.038 \\
(0.029)\end{array}$ & $\begin{array}{c}0.033^{* *} \\
(0.014)\end{array}$ & $\begin{array}{c}0.156^{* * *} \\
(0.032)\end{array}$ & $\begin{array}{c}0.050^{* *} \\
(0.024)\end{array}$ & $\begin{array}{c}0.246 * * * \\
(0.087)\end{array}$ & $\begin{array}{c}0.114 * * * \\
(0.044)\end{array}$ \\
\hline Risk tolerance & $\begin{array}{c}0.005 \\
(0.012)\end{array}$ & $\begin{array}{c}0.013^{* *} \\
(0.006)\end{array}$ & $\begin{array}{l}-0.024^{*} \\
(0.013)\end{array}$ & $\begin{array}{c}0.008 \\
(0.009)\end{array}$ & $\begin{array}{l}-0.004 \\
(0.037)\end{array}$ & $\begin{array}{c}0.003 \\
(0.018)\end{array}$ \\
\hline Log income & $\begin{array}{l}-0.013 \\
(0.026)\end{array}$ & $\begin{array}{l}-0.020^{*} \\
(0.012)\end{array}$ & $\begin{array}{l}-0.006 \\
(0.027)\end{array}$ & $\begin{array}{c}0.006 \\
(0.019)\end{array}$ & $\begin{array}{l}-0.048 \\
(0.075)\end{array}$ & $\begin{array}{l}-0.027 \\
(0.038)\end{array}$ \\
\hline Big city & $\begin{array}{c}0.078^{* *} \\
(0.038)\end{array}$ & $\begin{array}{c}0.014 \\
(0.018)\end{array}$ & $\begin{array}{c}0.167 * * * \\
(0.039)\end{array}$ & $\begin{array}{c}0.102 * * * \\
(0.029)\end{array}$ & $\begin{array}{c}0.418^{* * * *} \\
(0.111)\end{array}$ & $\begin{array}{c}0.201 * * * \\
(0.056)\end{array}$ \\
\hline Small city & $\begin{array}{c}0.092 * * \\
(0.039)\end{array}$ & $\begin{array}{c}0.040^{* *} \\
(0.017)\end{array}$ & $\begin{array}{c}0.129 * * * \\
(0.038)\end{array}$ & $\begin{array}{c}0.085^{* * * *} \\
(0.028)\end{array}$ & $\begin{array}{c}0.391 * * * \\
(0.118)\end{array}$ & $\begin{array}{c}0.195^{* * * *} \\
(0.059)\end{array}$ \\
\hline Establ. Size (10-24) & $\begin{array}{l}-0.021 \\
(0.035)\end{array}$ & $\begin{array}{c}-0.065^{* * *} * \\
(0.016)\end{array}$ & $\begin{array}{l}-0.041 \\
(0.035)\end{array}$ & $\begin{array}{l}-0.022 \\
(0.026)\end{array}$ & $\begin{array}{l}-0.118 \\
(0.106)\end{array}$ & $\begin{array}{l}-0.063 \\
(0.054)\end{array}$ \\
\hline Establ. Size (25-99) & $\begin{array}{c}-0.072^{* *} \\
(0.032)\end{array}$ & $\begin{array}{c}-0.055^{* * *} \\
(0.016)\end{array}$ & $\begin{array}{l}-0.047 \\
(0.035)\end{array}$ & $\begin{array}{c}-0.064^{* *} \\
(0.025)\end{array}$ & $\begin{array}{c}-0.180^{*} \\
(0.098)\end{array}$ & $\begin{array}{c}-0.097 * * \\
(0.049)\end{array}$ \\
\hline Establ. Size (100-499) & $\begin{array}{c}0.016 \\
(0.040)\end{array}$ & $\begin{array}{c}-0.074 * * * \\
(0.018)\end{array}$ & $\begin{array}{c}0.025 \\
(0.041)\end{array}$ & $\begin{array}{l}-0.007 \\
(0.031)\end{array}$ & $\begin{array}{l}-0.054 \\
(0.120)\end{array}$ & $\begin{array}{l}-0.036 \\
(0.061)\end{array}$ \\
\hline Establ. Size (500 or more) & $\begin{array}{c}0.015 \\
(0.047)\end{array}$ & $\begin{array}{c}-0.078^{* * *} * \\
(0.022)\end{array}$ & $\begin{array}{l}0.091 * \\
(0.050)\end{array}$ & $\begin{array}{c}0.007 \\
(0.037)\end{array}$ & $\begin{array}{l}-0.001 \\
(0.141)\end{array}$ & $\begin{array}{l}-0.015 \\
(0.071)\end{array}$ \\
\hline Supervising other employees & $\begin{array}{c}0.105^{* * *} \\
(0.028)\end{array}$ & $\begin{array}{l}0.024^{*} \\
(0.013)\end{array}$ & $\begin{array}{c}0.095^{* * *} \\
(0.030)\end{array}$ & $\begin{array}{c}0.095^{* * *} \\
(0.022)\end{array}$ & $\begin{array}{c}0.321 * * * \\
(0.085)\end{array}$ & $\begin{array}{c}0.164 * * * \\
(0.043)\end{array}$ \\
\hline Observations & 20722 & 22095 & 22446 & 21937 & 19448 & 19448 \\
\hline
\end{tabular}


Notes: [1] Each regression controls for country fixed effects, 8 occupational dummies and 9 industry dummies; the excluded group for establishment size is size "smaller than 10 " [2] *** significant at $1 \%$, ** significant at $5 \%$, * significant at $10 \%$. [3] Trust is the answer to the following question: "Generally speaking would you say that most people can be trusted or that you can't be too careful in dealing with people? Please tell me on a score of 0 to 10 , where 0 means you can't be too careful and 10 means that most people can be trusted"; [4] Trust is instrumented using the variable Trustworthiness obtained as the sum of the answers to the following three questions: "I am going to read out a list of things about your working life. Using this card, please say how much the management at your work allows/allowed you to 1) decide how your own daily work is/was organized; 2) influence policy decisions about the activities of the organization? 3) to choose or change your pace of work?" The answer to each question can take values from 0 (I have/had no influence) to 10 (I have/ had complete control). [5] The excluded group for father education are people with college or more; the excluded group for marital status is "divorced or widower"; the excluded group for labor status are people employed; the excluded group for city size are people living in a country village, a farm or a home in the countryside. 


\section{Table A15}

Trust and Cheating, OLS Regressions

\begin{tabular}{|c|c|c|c|c|c|c|}
\hline & $\begin{array}{c}(1) \\
\text { Bank } \\
\text { insurance }\end{array}$ & $\begin{array}{c}\text { (2) } \\
\text { Second } \\
\text { hand } \\
\text { things }\end{array}$ & $\begin{array}{c}(3) \\
\text { Food }\end{array}$ & $\begin{array}{l}\text { (4) } \\
\text { Plumber, } \\
\text { builder, } \\
\text { mechanic, } \\
\text { repairer }\end{array}$ & $\begin{array}{c}(5) \\
\text { Times } \\
\text { being } \\
\text { cheated }\end{array}$ & $\begin{array}{c}(6) \\
\text { Being } \\
\text { cheated } \\
\text { (principal } \\
\text { component) }\end{array}$ \\
\hline \multirow[t]{2}{*}{ Trust } & -0.022 & -0.017 & -0.027 & -0.031 & -0.096 & -0.049 \\
\hline & $(0.003)^{* * *}$ & $(0.002)^{* * *}$ & $(0.004) * * *$ & $(0.003)^{* * *}$ & $(0.008)^{* * *}$ & $(0.004) * * *$ \\
\hline \multirow[t]{2}{*}{ Age } & 0.017 & -0.006 & 0.016 & 0.013 & 0.038 & 0.018 \\
\hline & $(0.002) * * *$ & $(0.002)^{* * *}$ & $(0.003)^{* * *}$ & $(0.002)^{* * *}$ & $(0.007)^{* * *}$ & $(0.003)^{* * *}$ \\
\hline \multirow{2}{*}{ Age squared } & -0.000 & -0.000 & -0.000 & -0.000 & -0.001 & -0.000 \\
\hline & $(0.000)^{* * *}$ & $(0.000)$ & $(0.000)^{* * *}$ & $(0.000)^{* * *}$ & $(0.000)^{* * *}$ & $(0.000)^{* * *}$ \\
\hline \multirow[t]{2}{*}{ Male } & 0.138 & 0.098 & -0.152 & 0.124 & 0.238 & 0.162 \\
\hline & $(0.013)^{* * *}$ & $(0.011)^{* * *}$ & $(0.020)^{* * *}$ & $(0.014) * * *$ & $(0.041)^{* * *}$ & $(0.021)^{* * *}$ \\
\hline \multirow[t]{2}{*}{ Immigrant } & 0.023 & 0.036 & -0.002 & 0.049 & 0.101 & 0.057 \\
\hline & $(0.023)$ & $(0.020)^{*}$ & $(0.033)$ & $(0.026)^{*}$ & $(0.072)$ & $(0.036)$ \\
\hline \multirow[t]{2}{*}{ Married } & -0.007 & -0.015 & 0.026 & -0.063 & -0.044 & -0.028 \\
\hline & $(0.016)$ & $(0.014)$ & $(0.025)$ & $(0.018)^{* * *}$ & (0.051) & $(0.025)$ \\
\hline \multirow[t]{2}{*}{ Single } & -0.114 & 0.003 & -0.101 & -0.144 & -0.342 & -0.172 \\
\hline & $(0.021) * * *$ & $(0.018)$ & $(0.032)^{* * *}$ & $(0.023)^{* * *}$ & $(0.066)^{* * *}$ & $(0.033)^{* * *}$ \\
\hline \multirow[t]{2}{*}{ Years of education } & 0.015 & 0.002 & 0.021 & 0.012 & 0.047 & 0.023 \\
\hline & $(0.002) * * *$ & $(0.002)$ & $(0.003)^{* * *}$ & $(0.002)^{* * *}$ & $(0.006)^{* * *}$ & $(0.003)^{* * *}$ \\
\hline \multirow[t]{2}{*}{ Father primary } & -0.089 & -0.061 & -0.117 & -0.150 & -0.435 & -0.219 \\
\hline & $(0.025)^{* * *}$ & $(0.021)^{* * *}$ & $(0.037)^{* * *}$ & $(0.027)^{* * *}$ & $(0.076)^{* * *}$ & $(0.038)^{* * *}$ \\
\hline \multirow[t]{2}{*}{ Father secondary } & -0.083 & -0.041 & -0.126 & -0.103 & -0.347 & -0.175 \\
\hline & $(0.023) * * *$ & $(0.018)^{* *}$ & $(0.033)^{* * *}$ & $(0.024)^{* * *}$ & $(0.067)^{* * *}$ & $(0.034)^{* * *}$ \\
\hline \multirow[t]{2}{*}{ Unemployed } & 0.012 & 0.044 & 0.074 & 0.006 & 0.098 & 0.044 \\
\hline & $(0.028)$ & $(0.027)$ & $(0.043)^{*}$ & $(0.032)$ & $(0.089)$ & $(0.045)$ \\
\hline \multirow[t]{2}{*}{ Out of labor force } & 0.005 & 0.021 & 0.120 & 0.022 & 0.169 & 0.072 \\
\hline & $(0.015)$ & $(0.012)^{*}$ & $(0.022)^{* * *}$ & $(0.016)$ & $(0.045)^{* * *}$ & $(0.022)^{* * *}$ \\
\hline \multirow[t]{2}{*}{ Risk tolerance } & 0.027 & 0.016 & -0.001 & 0.023 & 0.066 & 0.038 \\
\hline & $(0.005) * * *$ & $(0.004)^{* * *}$ & $(0.007)$ & $(0.005)^{* * *}$ & $(0.014)^{* * *}$ & $(0.007)^{* * *}$ \\
\hline \multirow[t]{2}{*}{ Log income } & 0.049 & -0.016 & 0.046 & 0.047 & 0.127 & 0.061 \\
\hline & $(0.009) * * *$ & $(0.008)^{* *}$ & $(0.013)^{* * *}$ & $(0.010)^{* * *}$ & $(0.028)^{* * *}$ & $(0.014)^{* * *}$ \\
\hline \multirow[t]{2}{*}{ Big city } & 0.017 & -0.000 & 0.144 & 0.063 & 0.271 & 0.122 \\
\hline & $(0.017)$ & $(0.014)$ & $(0.025)^{* * *}$ & $(0.018)^{* * *}$ & $(0.051)^{* * *}$ & $(0.026)^{* * *}$ \\
\hline \multirow[t]{2}{*}{ Small city } & 0.012 & 0.029 & 0.087 & 0.044 & 0.174 & 0.084 \\
\hline & $(0.015)$ & $(0.013)^{* *}$ & $(0.022)^{* * *}$ & $(0.016) * * *$ & $(0.046)^{* * *}$ & $(0.023)^{* * *}$ \\
\hline Observations & 22720 & 24321 & 24766 & 24142 & 21276 & 21276 \\
\hline R-squared & 0.10 & 0.10 & 0.13 & 0.08 & 0.15 & 0.14 \\
\hline
\end{tabular}

Notes: [1] Each regression controls for country fixed effects and 8 occupational dummies; [2] *** significant at 1\%, ** significant at 5\%, * significant at 10\%.; [3] Trust is the answer to the following question: "Generally speaking would you say that most people can be trusted or that you can't be too careful in dealing with people? Please tell me on a score of 0 to 10 , where 0 means you can't be too careful and 10 means that most people can be trusted"; [4] The cheating variables are the answer to the following questions: "how often, if ever, have each of these things happened to you in the last five years? A bank or insurance company failed to offer you the best deal you were entitled to; you were sold something second-hand that quickly proved to be faulty; you were sold food that was packed to conceal the worse bits; A plumber, builder, car mechanic or other repair person overcharged you or did unnecessary work" The answer could take values Never (1), once (2), twice (3), 3 or 4 time (4) 5 times or more (5); [5] The excluded group for father education are people with college or more; the excluded group for marital status are divorced or widows; the excluded group for labor status are people employed; the excluded group for city size are people living in a country village, a farm or a home in the countryside. 
Figure A1

Trust standard deviation and income, by country
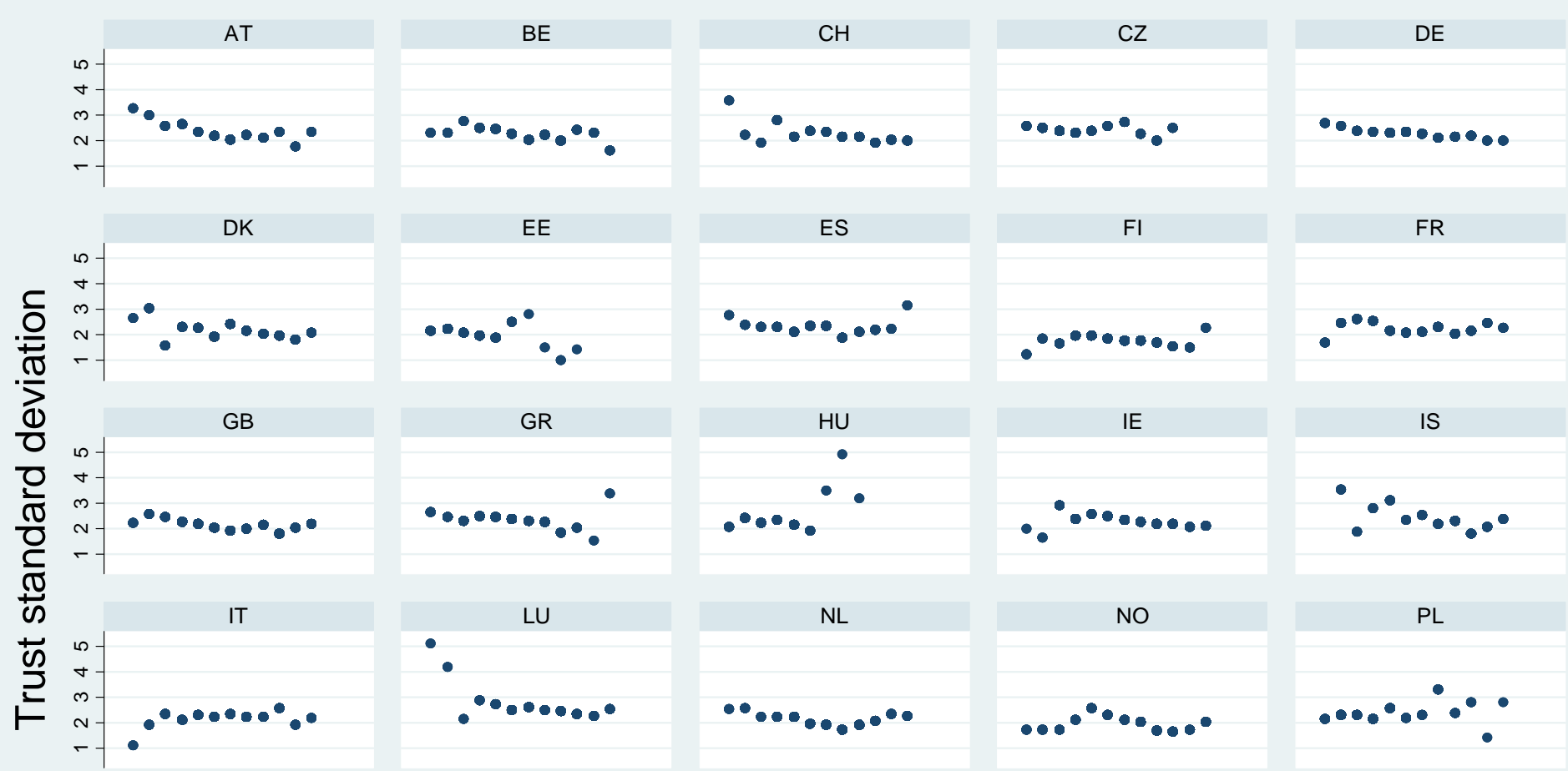

FR
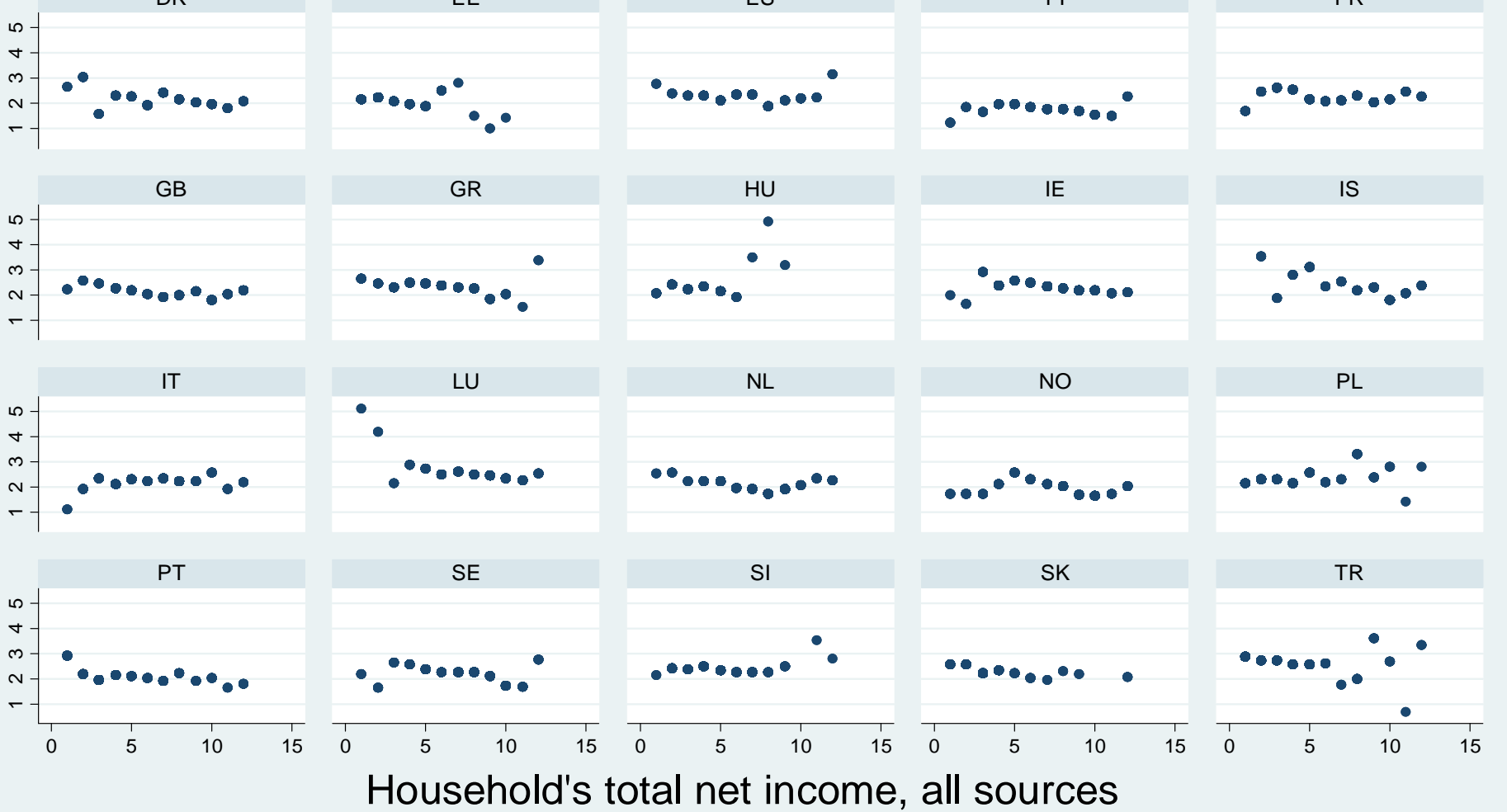

Graphs by Country

\section{Household's total net income, all sources}


Figure A2

Sweden: trust beliefs, density functions by region

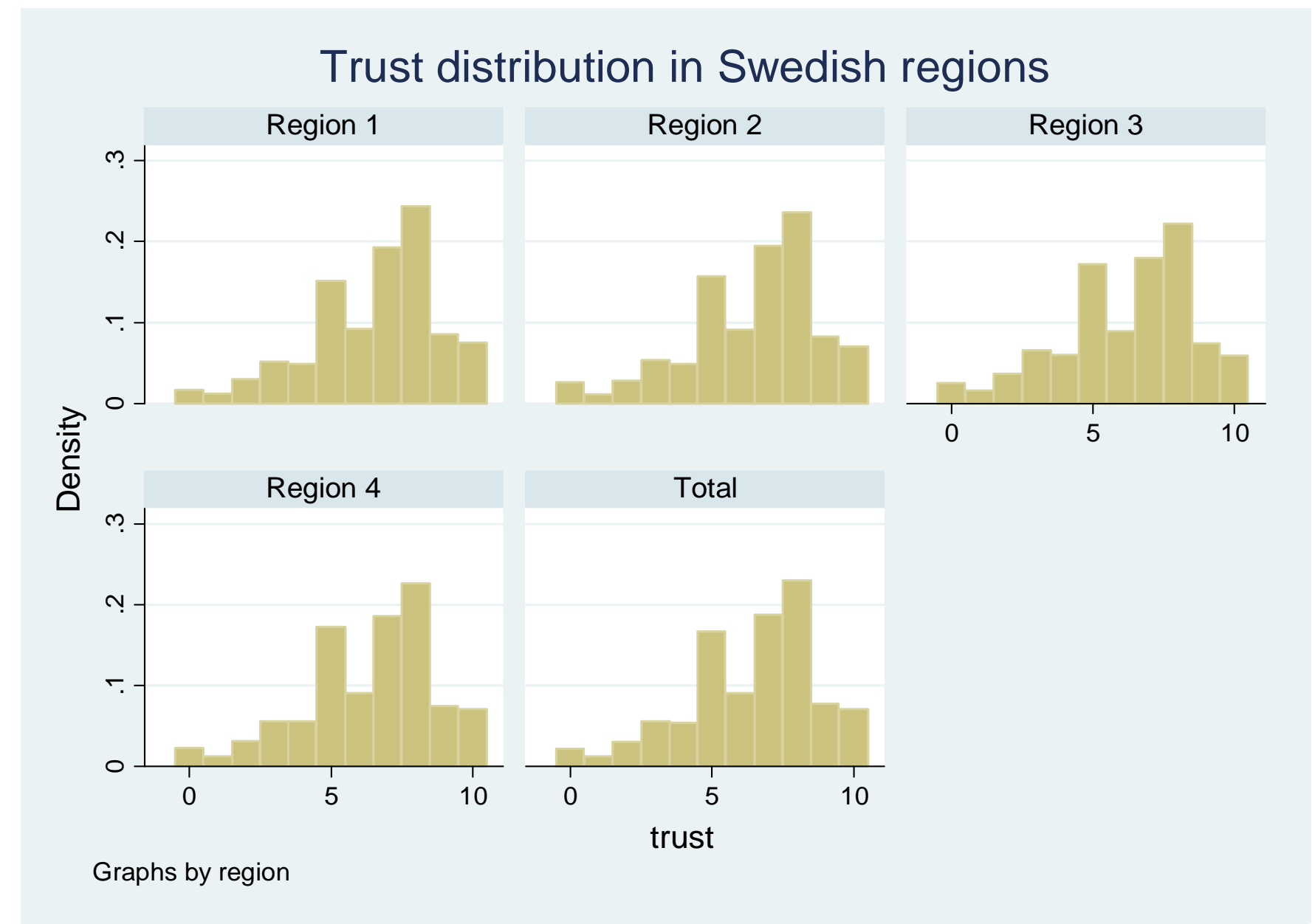

Region 1 indicates the Stockholm, Sodertalke A-region, Region 2 the Gothenburg's A-region

Region 3 includes Malmo/Lund/Trelleborg

Region 4 indicates all the other regions. 
Figure A3

Trust beliefs: density functions for second generation immigrants, by country of origin

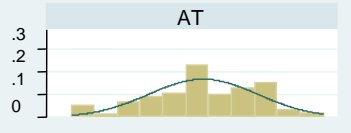

$\mathrm{DE}$
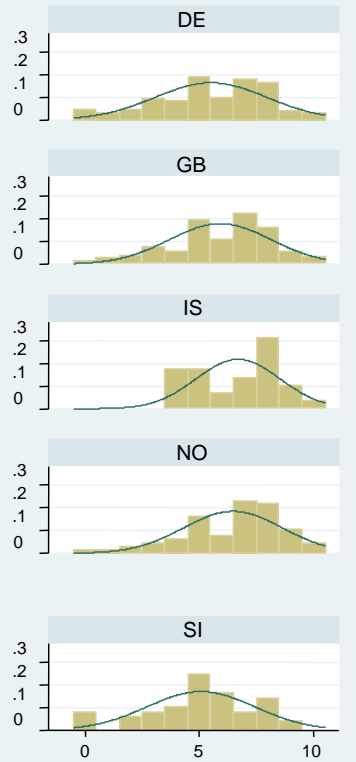

BE

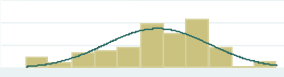

DK

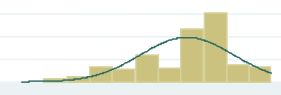

GR
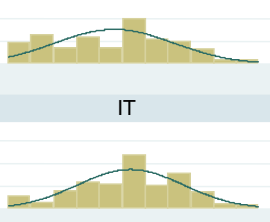

PL

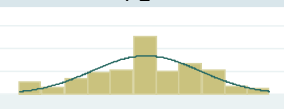

SK

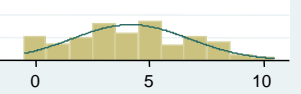

Most people can be trusted or you c

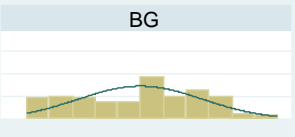

EE

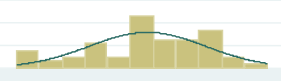

HR

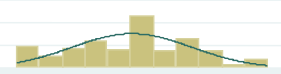

LT

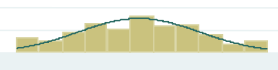

PT

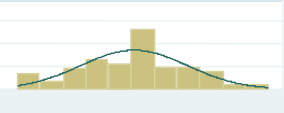

TR

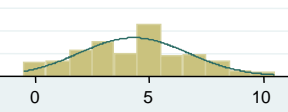

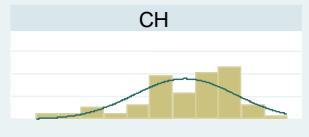

ES

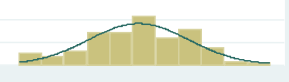

$\mathrm{HU}$

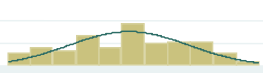

LU

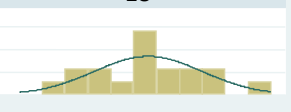

Ro
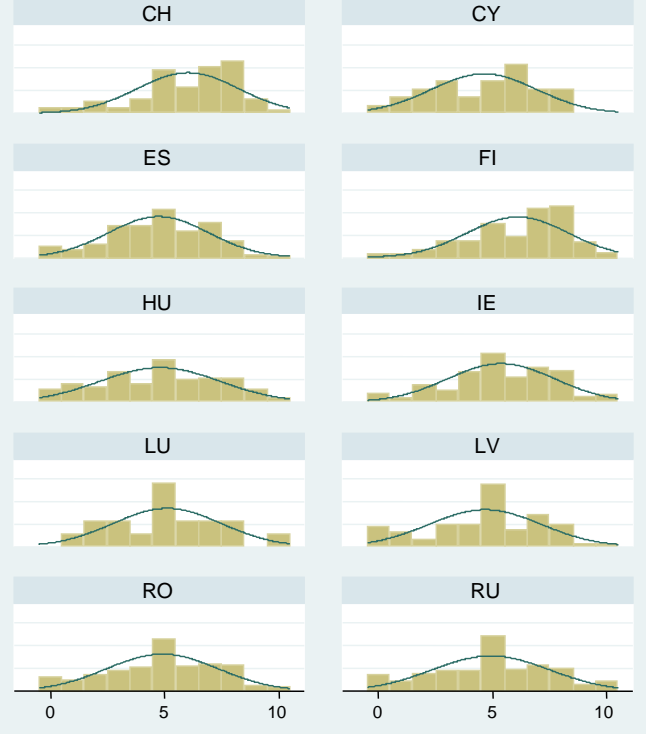

$\mathrm{FI}$

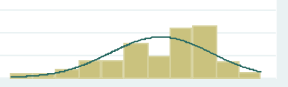

IE
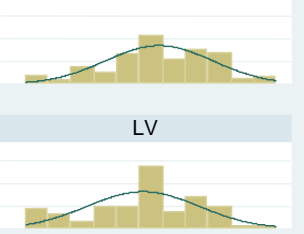

$\mathrm{RU}$

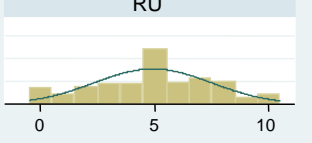

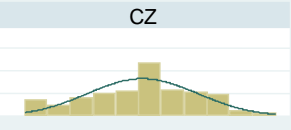

FR
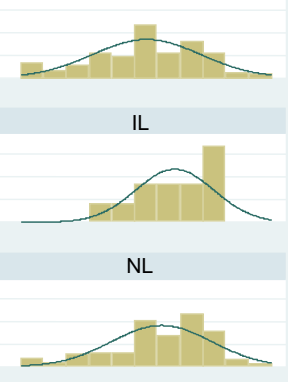

SE

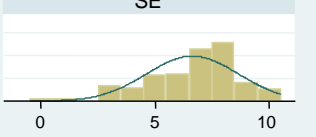

Most people can be trusted or you can't be too careful

Empirical Density

Fitted normal density 
Figure A4

Correlations between moments of trust distribution in countries of origin and among second generation immigrants

\section{Mean}

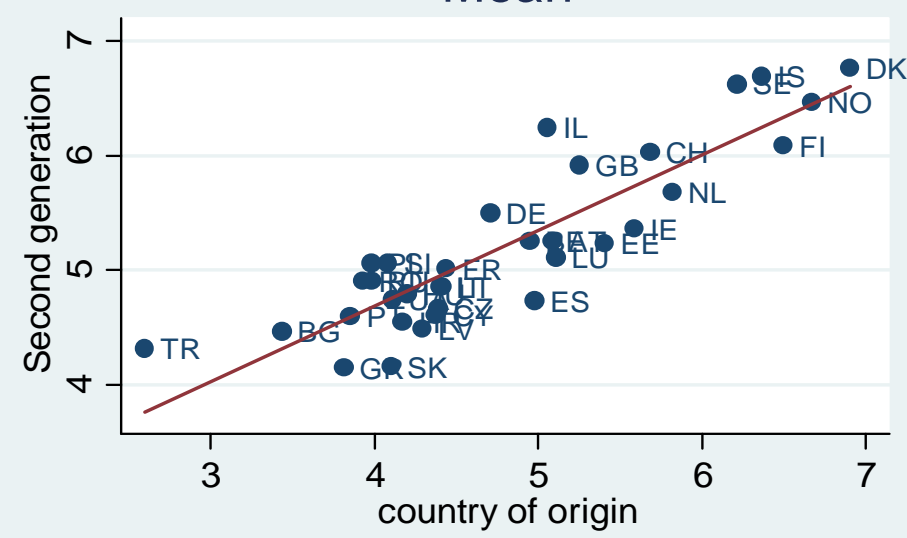

St. Dev.

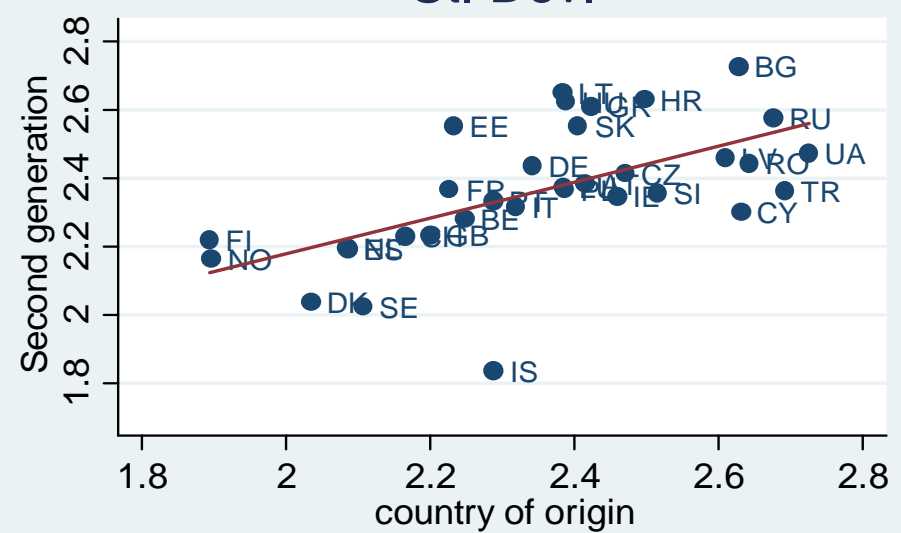

Median

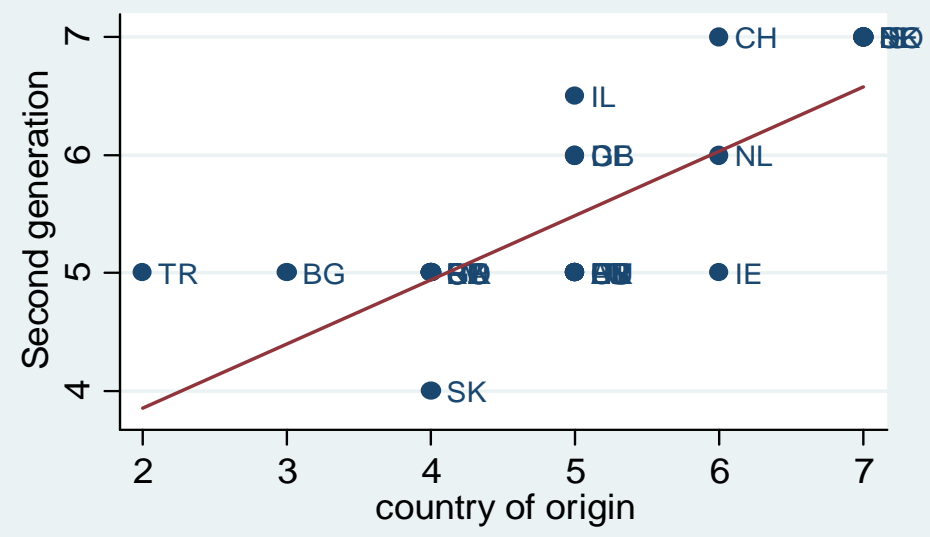

Skewness

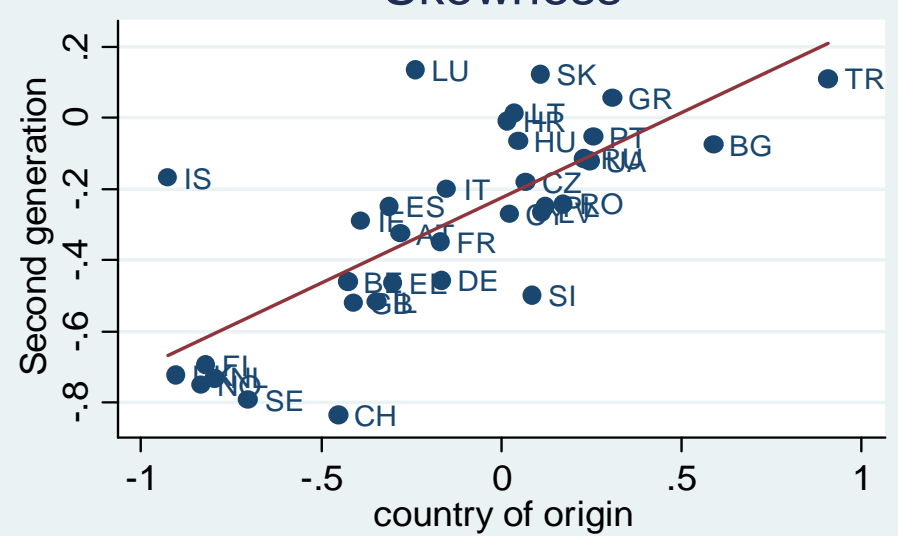




\section{Modeling heterogeneity}

\section{Derivation of equation (3)}

To model heterogeneity, we model the income of individual $i$ as:

$$
y_{i c}=y_{\max }\left(X_{i c}\right)-a_{i}\left(\pi_{i c}-\tau_{i c}\right)^{2}+\varsigma_{i}
$$

where $y_{i c}$ is the income of individual $i$ in country $c$; $y_{\max }$ is his or her maximum attainable income when trust beliefs are correct which depends on a vector of variables $\left(X_{i c}\right)$ capturing both features of the country and characteristics of the individual; $\pi_{i c}$ is the trustworthiness of the pool of people individual $i$ interacts with; $\tau_{i c}$ is individual $i$ 's level of trust; and $\varsigma_{i}$ is a random component orthogonal to the explanatory variables. The sensitivity to trust mistakes is captured by the parameter $a_{i}$.

We further model $\pi_{i c}$ as having two components: an observed heterogeneity component common to all individuals in the same country, $\pi_{c}$, and linearly related to the average trust in the country $\left(x_{c}\right)$ and an unobserved individual-specific component $\eta_{i}$. Thus: $\pi_{c}=$ $m+b x_{c}+\eta_{i}$.

We model $a_{i}$ as $a_{i}=a+\epsilon_{i}$ where $\epsilon_{i}$ is an individual specific component ${ }^{1}$.

After replacing $a_{i}$ and $\pi_{i c}$ in (2), the equation we want to estimate becomes:

$$
\begin{aligned}
& \begin{array}{l}
y_{i c}=y_{\max }\left(X_{i c}\right)-\left(a+\varepsilon_{i}\right)\left(m+b x_{c}+\eta_{i}-\tau_{i c}\right)^{2}+\varsigma_{i}= \\
=y_{\max }\left(X_{i c}\right)-a\left(m+b x_{c}+\eta_{i}-\tau_{i c}\right)^{2}-\varepsilon_{i}\left(m+b x_{c}+\eta_{i}-\tau_{i c}\right)^{2}+\varsigma_{i}= \\
=y_{\max }\left(X_{i c}\right)-a\left(m+b x_{c}-\tau_{i c}\right)^{2}-a \eta_{i}^{2}-2 a \eta_{i}\left(m+b x_{c}-\tau_{i c}\right)-\varepsilon_{i}\left(m+b x_{c}+\eta_{i}-\tau_{i c}\right)^{2}+\varsigma_{i} \\
\quad=y_{\max }\left(X_{i c}\right)-a m^{2}-a b^{2} x_{c}^{2}-2 a b m x_{c}+2 a m \tau_{i c}-a \tau_{i c}^{2}+2 a b x_{c} \tau_{i c}-a \eta_{i}^{2}-2 a \eta_{i}(m+ \\
\left.b x_{c}-\tau_{i c}\right)-\varepsilon_{i}\left(m+b x_{c}-\tau_{i c}\right)^{2}-\varepsilon_{i} \eta_{i}^{2}-2 \varepsilon_{i} \eta_{i}\left(m+b x_{c}-\tau_{i c}\right)+\varsigma_{i} \\
\quad=y_{\max }\left(X_{i c}\right)-a m^{2}-a b^{2} x_{c}^{2}-2 a b m x_{c}+2 a m \tau_{i c}-a \tau_{i c}^{2}+2 a b x_{c} \tau_{i c}-\left(a+\varepsilon_{i}\right) \eta_{i}^{2}-2 \eta_{i}(a+ \\
\left.\varepsilon_{i}\right)\left(m+b x_{c}-\tau_{i c}\right)-\varepsilon_{i}\left(m+b x_{c}-\tau_{i c}\right)^{2}+\varsigma_{i} \\
=\kappa+\beta_{1} \tau_{i c}-\beta_{2} \tau_{i c}^{2}+\beta_{3} x_{c} \tau_{i c}+v_{i}
\end{array}
\end{aligned}
$$

where $\quad \kappa=y_{\max }\left(X_{i c}\right)-a m^{2}-a b^{2} x_{c}^{2}-2 a b m x_{c}, \beta_{1}=2 a m ; \beta_{2}=a ; \beta_{3}=2 a b$ and $v_{i}=\varsigma_{i}-\left(a+\varepsilon_{i}\right) \eta_{i}^{2}-2 \eta_{i}\left(a+\varepsilon_{i}\right)\left(m+b x_{c}-\tau_{i c}\right)-\varepsilon_{i}\left(m+b x_{c}-\tau_{i c}\right)^{2}$.

\section{Derivation of equation (6)}

Equation (3) allows us to estimate the optimal amount of trust, after having modelled the heterogeneity of the group with which individuals interact and the sensitivity to trust mistakes. The OLS estimation of equation (3) would deliver consistent estimates ${ }^{2}$ only if individual trust $\tau_{i c}$ were exogenous and there were no feedback from income to trust. If, however, individuals optimally select their current trust-e.g. because there is some learning and learning depends on income shocks - then OLS estimates are inconsistent as in

\footnotetext{
${ }^{1}$ All the details about the properties of $\eta_{i}$ and $\epsilon_{i}$ are provided in the text.

${ }^{2}$ Note that the estimates could be possibly inefficient as the error term is heteroskedastic (Hildreth and Houck, 1968).
} 
standard selection models (Garen, 1984). To obtain consistent estimates of the parameters in (3) we follow Garen's (1984) selection correction model.

The methodology is a two equation system, where the main equation is the income equation given in equation (3) together with a trust selection equation. The two equation system is given below:

$$
\begin{aligned}
& y_{i c}=\kappa+\beta_{1} \tau_{i c}-\beta_{2} \tau_{i c}^{2}+\beta_{3} x_{c} \tau_{i c}+v_{i} \\
& \tau_{i c}=\gamma \pi_{c}+(1-\gamma) \tau_{p i c}+\xi_{i}
\end{aligned}
$$

We model the trust selection equation as a linear combination of three elements:

- the true trustworthiness of the country pool, $\pi_{c}$, which is in turn given by $m+b x_{c}$ (see above)

- the individual prior, $\tau_{p i c}$ and

- a specific error component $\xi_{i}$ containing the unobserved heterogeneity terms.

The individual prior is our exclusion restriction (see sections 3.2.2 and 4.1.2 in the paper): the initial prior affects the level of trust of the individual but it does not directly enter the income equation.

This specification yields a triangular system of equations with random parameters. If the errors terms $\xi_{i}$ were uncorrelated with $v_{i}$, the system could be estimated consistently with 2SLS using as an instrument $\tau_{p i c}$ (Kelejian, 1974). If instead the error $v_{i}$ and $\xi_{i}$ were correlated (for example as a result of some selection mechanism like the one described in footnote 31), the 2SLS will not be consistent. Garen's (1984) methodology precisely allows us to produce consistent estimates.

The methodology works in two steps:

i) in the first, it uses the trust selection equation to obtain a consistent estimate of $\xi_{i}$, say $\widehat{\xi}_{i}$.

ii) in the second step, this consistent estimate is used to replace the error term $v_{i}$ in with a function of $\widehat{\xi}_{i}$

Using the expression of $v_{i}$ it is possible to obtain $E\left(v_{i} \mid \xi_{i}\right)$ :

$$
\begin{aligned}
& E\left(v_{i} \mid \xi_{i}\right)=\left[\frac{\operatorname{cov}\left(\varsigma_{i}, \xi_{i}\right)}{\operatorname{var}\left(\xi_{i}\right)}-\frac{a \times \operatorname{cov}\left(\eta_{i}^{2}, \xi_{i}\right)}{\operatorname{var}\left(\xi_{i}\right)} \frac{a \times \operatorname{cov}\left(\varepsilon_{i} \eta_{i}^{2}, \xi_{i}\right)}{\operatorname{var}\left(\xi_{i}\right)}\right] \xi_{i}-2 a\left[\frac{\operatorname{cov}\left(\eta_{i}, \xi_{i}\right)}{\operatorname{var}\left(\xi_{i}\right)}+\frac{\operatorname{cov}\left(\varepsilon_{i} \eta_{i}, \xi_{i}\right)}{\operatorname{var}\left(\xi_{i}\right)}\right] \xi_{i}\left(\pi_{c}-\tau_{i c}\right)- \\
& \frac{\operatorname{cov}\left(\eta_{i}, \xi_{i}\right)}{\operatorname{var}\left(\xi_{i}\right)} \xi_{i}\left(\pi_{c}-\tau_{i c}\right)^{2}
\end{aligned}
$$

This implies:

$$
v_{i}=\beta_{4} \xi_{i}+\beta_{5} \xi_{i}\left(\pi_{c}-\tau_{i c}\right)+\beta_{6} \xi_{i}\left(\pi_{c}-\tau_{i c}\right)^{2}+\psi_{i}
$$

where

$$
\begin{aligned}
& \beta_{4}=\left[\frac{\operatorname{cov}\left(\varsigma_{i}, \xi_{i}\right)}{\operatorname{var}\left(\xi_{i}\right)}-\frac{a \times \operatorname{cov}\left(\eta_{i}^{2}, \xi_{i}\right)}{\operatorname{var}\left(\xi_{i}\right)} \frac{a \times \operatorname{cov}\left(\varepsilon_{i} \eta_{i}^{2}, \xi_{i}\right)}{\operatorname{var}\left(\xi_{i}\right)}\right] \\
& \beta_{5}=-2 a\left[\frac{\operatorname{cov}\left(\eta_{i}, \xi_{i}\right)}{\operatorname{var}\left(\xi_{i}\right)}+\frac{\operatorname{cov}\left(\varepsilon_{i} \eta_{i}, \xi_{i}\right)}{\operatorname{var}\left(\xi_{i}\right)}\right] \\
& \beta_{6}=-\frac{\operatorname{cov}\left(\eta_{i}, \xi_{i}\right)}{\operatorname{var}\left(\xi_{i}\right)}
\end{aligned}
$$

Using the consistent estimate of $\xi_{i}, \widehat{\xi}_{i}, v_{i}$ can be expressed as $\beta_{4} \widehat{\xi}_{i}+\beta_{5} \widehat{\xi}_{i}\left(\pi_{c}-\tau_{i}\right)+$ $\beta_{6} \widehat{\xi}_{i}\left(\pi_{c}-\tau_{i}\right)^{2}+\widehat{\psi}_{i}$, where $\widehat{\psi}_{i}$ is a pure error term possibly heteroskedastic. 
Substituting for $v_{i}$ in the income equation in (4), the equation that needs to be estimated becomes:

$$
\begin{aligned}
& y_{i c}=\kappa+\beta_{1} \tau_{i c}-\beta_{2} \tau_{i c}^{2}+\beta_{3} x_{c} \tau_{i c}+\beta_{4} \widehat{\xi}_{i}+\beta_{5} \widehat{\xi}_{i}\left(m+b x_{c}-\tau_{i c}\right)+\beta_{6} \widehat{\xi}_{i}\left(m+b x-\tau_{i c}\right)^{2}+\widehat{\psi}_{i} \\
& =\kappa+\beta_{1} \tau_{i c}-\beta_{2} \tau_{i c}^{2}+\beta_{3} x_{c} \tau_{i c}+\beta_{4} \widehat{\xi}_{i}+\beta_{5} m \widehat{\xi}_{i}+\beta_{5} b x_{c} \widehat{\xi}_{i}-\beta_{5} \tau_{i c} \widehat{\xi}_{i}+\beta_{6} m^{2} \widehat{\xi}_{i}+\beta_{6} b^{2} x_{c}^{2} \widehat{\xi}_{i}+ \\
& \beta_{6} \tau_{i c}^{2} \widehat{\xi}_{i}+\beta_{6} b m x_{c} \widehat{\xi}_{i}-2 \beta_{6} m \tau_{i c} \widehat{\xi}_{i}-2 \beta_{6} b x_{c} \tau_{i c} \widehat{\xi}_{i}+\widehat{\psi}_{i} \\
& =\kappa+\beta_{1} \tau_{i c}-\beta_{2} \tau_{i c}^{2}+\beta_{3} x_{c} \tau_{i c}+\left(\beta_{4}+\beta_{5} m+\beta_{6} m^{2}\right) \widehat{\xi}_{i}+b\left(\beta_{5}+\beta_{6} 2 m\right) x_{c} \widehat{\xi}_{i}-\left(\beta_{5}+\right. \\
& \left.2 \beta_{6} m\right) \tau_{i c} \widehat{\xi}_{i}+\beta_{6} b^{2} x_{c}^{2} \widehat{\xi}_{i}+\beta_{6} \tau_{i c}^{2} \widehat{\xi}_{i}-2 \beta_{6} b x_{c} \tau_{i c} \widehat{\xi}_{i}+\widehat{\psi}_{i} \\
& =\kappa+\beta_{1} \tau_{i c}-\beta_{2} \tau_{i c}^{2}+\beta_{3} x_{c} \tau_{i c}+\beta_{4}^{\prime} \widehat{\xi}_{i}+b \beta_{5}^{\prime} x_{c} \widehat{\xi}_{i}-\beta_{5}^{\prime} \tau_{i c} \widehat{\xi}_{i}+\beta_{6} b^{2} x_{c}^{2} \widehat{\xi}_{i}+\beta_{6} \tau_{i c}^{2} \widehat{\xi}_{i}-2 \beta_{6} b x_{c} \tau_{i c} \widehat{\xi}_{i}+\widehat{\psi}_{i} \\
& \text { where } \beta_{4}^{\prime}=\beta_{4}+m \beta_{5}+m^{2} \beta_{6} ; \beta_{5}^{\prime}=\beta_{5}+2 m \beta_{6} .
\end{aligned}
$$

